University of Alberta

\title{
PRECEPTORSHIP AND CRITICAL THINKING IN NURSING EDUCATION
}

By

Florence Myrick

(c)

A Thesis submitted to the Faculty of Graduate Studies and Research in partial fulfilment of the requirements for the degree of Doctor of Philosophy

Faculty of Nursing University of Alberta

Edmonton, Alberta, Canada

Fall 1998 
Acquisitions and Bibliographic Services

395 Wellington Street Ottawa ON K1A ON4 Canada
Bibliothèque nationale du Canada

Acquisitions et services bibliographiques

395, rue Wellington

Ottawa ON K1A ON4

Canada
The author has granted a nonexclusive licence allowing the National Library of Canada to reproduce, loan, distribute or sell copies of this thesis in microform, paper or electronic formats.

The author retains ownership of the copyright in this thesis. Neither the thesis nor substantial extracts from it may be printed or otherwise reproduced without the author's permission.
L'auteur a accordé une licence non exclusive permettant à la Bibliothèque nationale du Canada de reproduire, prêter, distribuer ou vendre des copies de cette thèse sous la forme de microfiche/film, de reproduction sur papier ou sur format électronique.

L'auteur conserve la propriété du droit d'auteur qui protège cette thèse. $\mathrm{Ni}$ la thèse ni des extraits substantiels de celle-ci ne doivent être imprimés ou autrement reproduits sans son autorisation. 


\begin{abstract}
A major goal of baccalaureate nursing education is the development and promotion of the critical thinking ability of nursing students. Nurse educators are confronted daily with the very real challenge of preparing graduates who must be adept at coping with the growing body of nursing knowledge, the rapid advances in science and technology, and the economic constraints that continue to foster massive health care changes (Jacobs, Ott, Sullivan, Ulrich \& Short, 1997; Laschinger \& MacMaster,
\end{abstract} 1992). In a practice profession such as nursing, acquisition of knowledge is embodied by its application in the practice setting (Malek, 1986). The onus is thus on nurse educators to explore teaching strategies that promote effective teaching/learning and foster critical thinking. While preceptorship is one strategy that is being used increasingly by nursing faculty, little is known about how preceptors teach and even less is known about the process of thinking that occurs in that relationship.

The purpose of this study was to examine the process used in preceptorship to develop and promote the critical thinking ability of basic baccalaureate nursing students. Using the grounded theory method, this study was conducted in a large tertiary care hospital. Participants were fourth year basic baccalaureate nursing students and their staff nurse preceptors. Data collection was comprised of semistructured interviews and observations of the preceptors and the preceptees as they worked together in the practice setting. Secondary data sources included documents deemed appropriate to the study. In accordance with the grounded theory method, constant comparison was used to analyse the qualitative data while theoretical sampling 
guided data selection. The researcher simultaneously collected, coded and analysed the data throughout the study.

The findings of this study indicate that the process occurring in preceptorship to develop and promote the critical thinking ability of basic baccalaureate students is a process of enabling comprised of two major components that include the climate and bringing about. Enabling was discovered to be an interpersonal or interactive process in which the preceptors provide the preceptees with the opportunity or the means by which to develop and promote their critical thinking ability in the practice setting. 


\section{ACKNOWLEDGEMENTS}

I would like to take this opportunity to acknowledge the many people without whom I could not have completed this dissertation. I would like to acknowledge the Doctoral Fellowship from the Social Sciences and Humanities Research Council of Canada (SSHRC), the Andrew Stewart Memorial Graduate Prize, and the W. H. Johns Graduate Fellowship from the University of Alberta, all of which have enabled me to focus full time on my studies and research.

I wish to thank my dissertation committee members: Rene Day, Myer Horowitz and Linda Ogilvie for their support and for stretching my thinking. My appreciation to Marion Allen for acting as Chair of this committee and also for having been so encouraging over these past four years. I was also pleased to have Anita Molzahn, University of Victoria, join the committee as the external examiner. To my advisor Olive Yonge I owe a debt of gratitude. A superb educator, role model and colleague, she has afforded me the freedom to be creative yet has never failed to challenge my thinking. I shall remember always our many walks that were charged with intellectual energy, enthusiasm and enlightenment. It was truly an honour to work with her in this endeavour.

I wish also to extend my appreciation to the baccalaureate nursing students and their staff nurse preceptors who so generously gave of their time in participating in this study. It was a privilege to share in their experiences. I thank them for keeping me grounded in the realities of nursing practice. I also want to acknowledge the Nursing Philosophy Working Group (NPWG). My participation in this group has allowed me to expand my thinking in directions I never thought possible. 
I would like to acknowledge my colleagues in the doctoral program. Their support has been unsurpassed. A special thank you to Joanne, Mahvash, Marilyn, Kathy and Kaysi. To Jeanne, Shirl and Margie, I extend my appreciation for their incredible kindness, generosity and friendship. To Margaret and Pat whose long distance telephone conversations were invaluable.

Finally, I wish to acknowledge two people in particular. To the best critical thinker I know, Heather, and to my mother who continues to be an unwavering source of inspiration and strength. Finally, I must mention Toby and Brittany who have provided me with their unconditional love. 


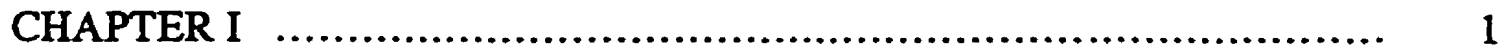

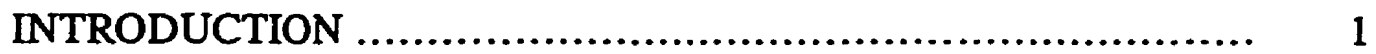

Problem Statement ..................................................... 2

Significance of the Study .............................................. 3

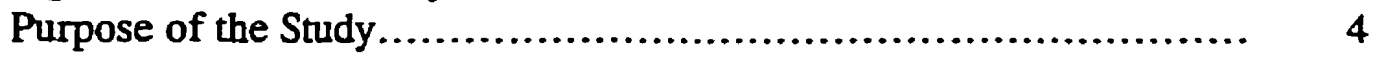

CHAPTER II ............................................................ 5

PRESENT STATE OF KNOWLEDGE............................. 5

Preceptorship...................................................... 5

Quantitative Studies......................................... 6

Qualitative Studies............................................ 10

Critical Thinking.......................................................... 16

Quantitative Studies........................................ 18

Qualitative Studies............................................ 23

Assumptions....................................................... 29

Research Questions............................................... 29

CHAPTER III.............................................................. 30

METHOD ....................................................... 30

Research Design.................................................... 30

Procedures/Data Collection........................................... $\quad 35$

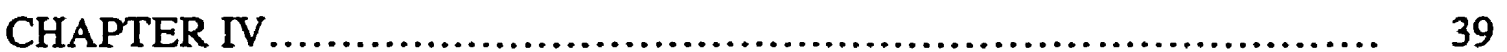

DATA ANALYSIS ............................................. 39

Open coding................................................. 39

Theoretical coding.......................................... 41

Selective coding.............................................. 41

Memoing................................................... 42

Mechanisms to Ensure Rigour....................................... 44

Credibility ................................................. 44

Fittingness.................................................. 46

Auditability ................................................. 47

Confirmability ............................................ 47

Ethical Considerations............................................ 47 


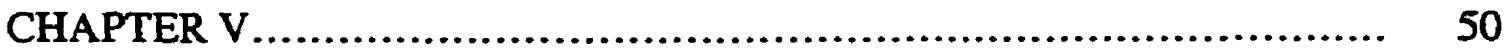

FINDINGS \& DISCUSSION .................................... 50

The Enabling Process.................................................. 51

The Climate............................................... 58

The Preceptor......................................... 58

Valuing............................................. 59

Working with........................................ 62

Supporting.......................................... 67

The Staff.................................................... 72

Accepting ......................................... 72

Bringing About................................................... 76

Incidental................................................ 77

Role Models......................................... 77

Facilitates........................................ 83

Guides............................................... 91

Prioritizes............................................ 94

Purposive................................................... 97

Questions knowledge base............................ 97

Questions decision-making............................ 100

Questions actions..................................... 101

CHAPTER VI.......................................................... 108

SUMMARY, CONCLUSIONS, CAUTIONS, IMPLICATIONS

AND RECOMMENDATIONS ............................................ 108

Summary \& Conclusions..................................................... 108

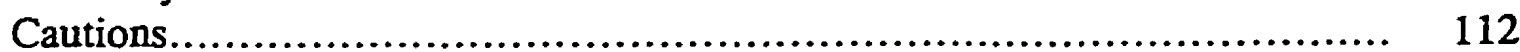

Implications............................................................... 113

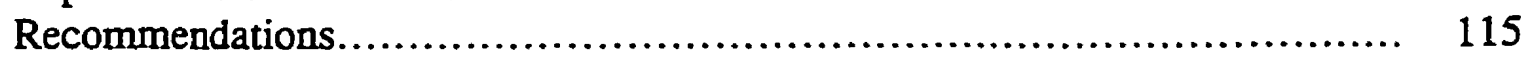

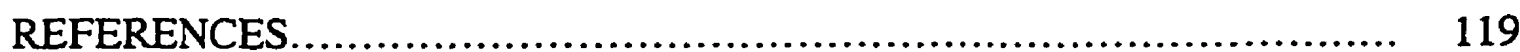


Appendix 1: Interview Guide - Preceptor............................... 134

Appendix 2: Interview Guide - Preceptee................................ 135

Appendix 3: Observational Guide...................................... 136

Appendix 4: Demographic Data - Preceptor.......................... 137

Appendix 5: Demographic Data - Preceptee............................... 138

Appendix 6: Letter of Permission...................................... 139

Appendix 7: Consent Form - Preceptor.............................. 140

Appendix 8: Consent Form - Preceptee.............................. 142

\section{TABLES}

Table 1.1 Synopsis - Quantitative Research Studies

Preceptorship (1981-1986)............................... $\quad 144$

Table 1.2 Synopsis - Quantitative Research Studies

Preceptorship (1987-1990)................................. 145

Table 1.3 Synopsis - Quantitative Research Studies

Preceptorship (1991-1993).................................. 146

Table 1.4 Synopsis - Quantitative Research Studies

Preceptorship (1993-1998).................................. 147

Table 2.1 Synopsis - Quantitative Research Studies

Critical Thinking in Nursing (1981-1987).................... 148

Table 2.2 Synopsis - Quantitative Research Studies

Critical Thinking in Nursing (1987-1992).................... 149

Table 2.3 Synopsis - Quantitative Research Studies

Critical Thinking in Nursing (1993-1996)..................... 150

Table 2.4 Synopsis - Quantitative Research Studies

Critical Thinking in Nursing (1996-1998) 


\section{FIGURES}

Figure 1 Preceptorship \& Critical Thinking

The Process - Enabling................................... 152

Figure 2 Preceptorship \& Critical Thinking

The Process - The Climate.................................. 153

Figure 3 Preceptorship \& Critical Thinking

The Process - Bringing About - Incidental.................... 154

Figure 4 Preceptorship \& Critical Thinking

The Process - Bringing about - Purposive...................... 155

Figure 5 Schematic Representation of Emergent

Framework............................................. 156 


\section{CHAPTER I}

\section{INTRODUCTION}

Today the greatest challenge confronting nurse educators is the preparation of clinically competent practitioners who are sound critical thinkers. Professionals who will not only survive but thrive in the future will be those who possess the intellectual and emotional capacity for effectively and critically assessing and dealing with complex changing situations. Moreover, critical thinking is a requisite for successful adjustment to the ongoing professional demands of this decade and beyond (Paul, 1993). The fostering of critical thinking thus becomes a foremost educational imperative within the learning environment. In higher education that learning environment encompasses the practice setting, a setting in which preceptorship is acquiring increasing momentum as the teaching/learning method of choice particularly in the third and fourth years of undergraduate programs.

One of the primary goals of baccalaureate nursing education is the facilitation of the cognitive development of nursing students vis a vis their ability to think critically, overcome diversity, and participate in clinical decision-making (McGovern, 1997). Indeed, nurse educators are faced daily with the very real challenge of preparing graduates who must be adept at dealing with the growing body of nursing knowledge, the rapid advances in science and technology, and the economic constraints that continue to precipitate massive health care changes (Jacobs, Ott, Sullivan, Ulrich \& Short, 1997; Laschinger \& MacMaster, 1992). In a practice profession such as nursing, acquisition of knowledge is embodied by its application in the practice setting 
(Malek, 1986). However, that application is not an instinctive outcome of classroom instruction. On the contrary, "it must be nurtured, organized, and carefully sequenced... classroom and clinical learning must reinforce each other" (Malek, 1986, p. 20). The onus is thus on nurse educators to explore teaching strategies that promote effective clinical teaching/learning and foster critical thinking. While preceptorship is one strategy that is being endorsed and utilized increasingly by nursing faculty throughout Canada, the United States and Great Britain (Bowles, 1995; Marchette, 1985; Myrick \& Barrett, 1992), little is known about how preceptors teach and even less is known about the process of thinking that occurs in that relationship.

\section{Problem Statement}

The notion that critical thinking must be fostered for all learners is indisputable. The more pressing issue is whether such thinking is being fostered in preceptorship. Can nurse educators say with certainty that preceptorship is a strategy that fosters critical thinking or is it merely "a modern version of the apprenticeship, which achieved bureaucratic loyalty at the expense of professional role enactment" (Andersen, 1991, p. 17)? Nurse educators must ensure that students are receiving the kind of education to which they are financially and scholastically entitled. A fundamental responsibility and accountability is to ensure that teaching methods such as preceptorship are viable. This implies that they are plausible, timely, appropriate to the learner and afford graduates the necessary skills with which to embrace the world of practice now and in the new millennium. Critical thinking has come to be recognized by experts to be an indispensable skill for professional survival (Paul, 1993) and is, 
now more than ever, integral to teaching strategies whether in the classroom or practice setting.

Despite the fact that it has fast become the leading teaching strategy of choice in the practice setting (Bowles, 1995; Marchette, 1985; Myrick \& Barrett, 1992), there is no evidence to support the notion that preceptorship in fact provides students with the opportunity to develop their critical thinking ability. While it has been shown to facilitate the transitional socialization of student nurse to graduate nurse (Jairath, Costello, Wallace, \& Ruby, 1991), there still remains inconclusive evidence regarding the effect of preceptorship on the clinical performance of nursing students in the practice setting. Even more striking is the total lack of research regarding the role of preceptorship in promoting critical thinking.

\section{Significance of the Study}

Ultimately students and professionals capable of using their cognitive powers to think critically will be those who have had ample opportunity to challenge and be challenged through relevant questioning and debate in the practice setting (Hunkins, 1989). It is, therefore, incumbent upon nurse educators to ensure that preceptorship is conducive to equipping future nurses with the appropriate know-how necessary for addressing the multiplicity of situations with which they will be confronted (Jones \& Brown, 1993). The ability to think critically is integral to that know-how and is essential for any nurse who is to function appropriately and effectively in a health care system that is evolving with ever-increasing complexity (Miller \& Malcolm, 1990). Intrinsic to that know-how is the process of how student thinking is fostered by those 
entrusted with direct responsibility for clinical teaching.

In light of its widespread usage, it is essential that preceptorship be examined empirically to determine whether it is, in fact, an appropriate teaching method for promoting critical thinking. How do preceptors foster appropriate thinking that is germane to safe and competent clinical decision-making? To date, no studies have been conducted to examine the process that is used in preceptorship to develop and promote the critical thinking ability of basic baccalaureate students. Such a research study would: provide data that could influence the development and implementation of future preceptorship programs; provide innovative strategies to ensure that critical thinking is being fostered in the preceptorship relationship; contribute to the enhancement of the preceptor/preceptee relationship; and ultimately impact on the relationship between nursing practice and nursing education.

\section{Purpose of the Study}

The purpose of this study was to examine the process used in preceptorship to develop and promote the critical thinking ability of basic baccalaureate nursing students. 


\section{CHAPTER II}

\section{PRESENT STATE OF KNOWLEDGE}

\section{Preceptorship}

Preceptorship may be defined as "an individualized teaching/learning method in which each student is assigned to a particular preceptor...so [she] can experience dayto-day practice with a role model and resource person immediately available within the clinical setting" (Chickerella \& Lutz, 1981, p. 107). Unlike the traditional mode of clinical teaching in which nursing students are taught by an instructor with a studentfaculty ratio ranging anywhere from $8: 1$ to $20: 1$, preceptorship pairs the student with staff nurses on a one-to-one basis. This type of arrangement promotes individualized student attention which, in turn, is purported to enhance student learning and facilitate clinical competence (Shamian \& Inhaber, 1985).

While numerous writers in nursing reflect the perception that preceptorship is a relatively contemporary approach to clinical teaching, historically this is not the case (Backenstose, 1983). In fact, the concept of preceptorship originated in the 15th century, "to describe a teacher who was responsible for the transmission of 'precepts' principles governing conduct, actions or procedures - to one or more understudies" (Bowles, 1995, p. 25).

In nursing, preceptorship has been intrinsic to the profession since its very inception. As far back as 1882 , Florence Nightingale expressly defined that the first year's technical and practical preparation for nurses was to occur in the hospital under the direction of those nurses who had been 'trained to train' (Palmer, 1983). Thus, for 
many years, nursing students were taught by practising nurses. Within this context, however, the educational needs of the students were considered to be secondary to the nursing needs of the hospital. For decades, nurse educators grappled with this untenable situation and were ultimately successful in transferring nursing education from the hospital to the educational setting. With this move, finally nursing faculty could claim complete jurisdiction over the didactic and clinical teaching of their students (Myrick, 1988). It was not until the 1960's and the 1970's, however, with the establishment of the nurse practitioner programs in the United States, that the role of preceptorship began to gain increasing prominence (Bowles, 1995). Since that time, in both Canada and the United States, preceptorship has continued to acquire momentum as the alternative method of clinical teaching by nursing faculty (Helmuth \& Guberski, 1980; Myrick \& Barrett, 1992). In fact, in Great Britain "preceptorship is a concept which has been wholeheartedly endorsed" (Bowles, 1995, p. 25).

\section{Quantitative Studies}

In the last two decades considerable research has been carried out examining the preceptorship relationship from a variety of perspectives. The impact of preceptorship on the socialization and role transition of nursing students (Clayton, Broome \& Ellis, 1989; Dobbs, 1988; Estey \& Ferguson, 1985; Spears, 1986; Goldenberg \& Iwasiw, 1993; Itano, Warren \& Ishida, 1987) and neophyte graduate nurses (Knauss, 1980; McGrath \& Koewing, 1978) has been a major theme throughout the literature. Although the research findings are inconclusive, the current prevailing view amongst both educators and practitioners alike is that preceptorship continues to be the preferred 
method by which to facilitate the socialization and role transition of nursing students and newly graduated nurses in the practice setting.

The influence of preceptorship on nursing performance has been the focus of several studies which have yielded diverse conclusions (Huber, 1981; Marchette, 1984; Jairath, Costello, Wallace \& Ruby, 1991; Yonge \& Trojan, 1992; Brasler, 1993). Findings range from preceptorship resulting in no change in graduate nurse performance (Huber, 1981; Marchette, 1984) to significant improvement in diploma prepared nursing student performance (Jairath et al., 1991) to no apparent significant effect on baccalaureate prepared nursing students (Yonge \& Trojan, 1992). In an investigation by Brasler (1993), preceptor skills as well as the emotional support provided by preceptors were found to be significant predictors of new graduate nurse performance.

The question of the impact of preceptorship specifically on the clinical competence of nursing students has prompted considerable interest also. Similar to the research into nursing performance, findings reveal no real consensus regarding the effect of preceptorship on clinical competence. Some investigations indicate no difference in the clinical competence of nursing students who are preceptored (Olson, Gresley \& Heater, 1984; Myrick, 1986), while other results suggest the contrary (Scheetz, 1989). To date inconclusive evidence remains to support the notion that preceptorship does in fact enhance, or indeed make any difference, in the nursing performance or clinical competence of nursing students or newly graduated nurses alike. 
Not infrequently preceptorship has been described as the method of choice for the orientation of staff nurses in the practice setting (Friesen \& Conahan, 1980; Knauss, 1980; Yonge, Krahn, Trojan \& Reid, 1997). Interestingly, while studies investigating this aspect of preceptorship fail to yield empirical evidence to support such a premise, it continues to remain the strategy of choice (Bisek \& Oermann, 1990; Shamian \& Lemieux, 1984).

More recent studies continue to corroborate the ongoing use of preceptorship as the current clinical teaching strategy of choice particularly in the education of nursing students. In a nation wide survey (Myrick \& Barrett, 1992), it was determined that the majority of Canadian baccalaureate schools of nursing currently use preceptorship or are in the process of implementing its use in the practice setting. The focus of a recent study found that preceptors view role modelling and supervising of learners' skills to be key features of the preceptor role (Coates \& Gormley, 1997). Finally, when job satisfaction in preceptorship and its effect on the clinical performance of the preceptee were examined, investigators found that while the preceptee's job satisfaction impacted on their clinical performance, preceptor job satisfaction did not have any impact (Barrett \& Myrick, 1998).

Despite the fact that in half of the studies cited, the 6-Dimensional Scale of Nursing Performance (Schwirian, 1978) (6-D Scale) was employed as the instrument of choice, discrepancies remain apparent. Several factors may account for such inconsistencies and conceivably could have influenced the findings:

1. "The power of a test increases with sample size" (McCall, 1975, p. 194). A 
sample as low as 12 was used in one of these quantitative studies (Myrick, 1986).

With such a low sample, it could be suggested that the lack of any differences between preceptored and non preceptored students may have been a reflection of low statistical power.

2. According to Burns and Grove (1987), the differences inherent in heterogeneous samples can influence the study outcome and prevent detection of a true comparison between subjects. One investigator compared the performance of nursing students to that of graduate nurses (Huber, 1981); another included both registered nurses and nursing assistants (Shamian \& Lemieux, 1984).

3. Several studies were confined to one specific setting thus limiting the generalizability of the findings (Huber, 1981; Olson, Gresley \& Heater, 1984; Myrick, 1986; Pendergast-Holmes, 1994; Shamian \& Lemieux, 1984).

4. In many of the studies, the use of self-evaluations is prevalent. This method is considered by quantitative research experts to be less reliable than direct observation and is posited to result in inaccurate representations of the study situations (Cook \& Campbell, 1979).

5. Lack of consistency in the preceptorship experiences ranged anywhere from three weeks (Myrick, 1986) to four months (Marchette, 1984). In one study alone the subjects were participating in preceptorships which varied from 12 weeks to 15 weeks (Goldenberg \& Iwasiw, 1993).

6. The inconsistent use of the measurement tool where the tool may not have been sensitive to the occurrence of changes over short periods of time could also have 
generated erroneous findings.

7. Finally, unfamiliarity of the study participants with the evaluation instrument may have generated false findings. As a result of these research studies, no real pattern can be discerned in the findings. Please refer to Tables 1.1 to 1.4 on pages 144 to 147 for a summary of the quantitative studies discussed.

\section{Qualitative Studies}

To date, the qualitative studies carried out on preceptorship have been limited. Those which have been completed address the following areas: evaluation of a nurse preceptorship program (Allanach \& Jennings, 1990; Hsieh \& Knowles, 1990); instructor facilitation of the preceptorship relationship in nursing education; student preceptors' view of their clinical experience (Peirce, 1991); examination of the effect of preceptorship on moral reasoning (Andersen, 1991); an action research study into the role of the nurse preceptor in changing long-term mental health care (Armitage, Champney-Smith \& Andrews, 1991); exploration of the perceptions of nurse preceptors regarding the preceptor role (Stevenson, Doorley, Moddeman \& Benson-Landau, 1995; Yonge, Krahn, Trojan \& Reid, 1997); an interpretive analysis of precepting an unsafe student (Rittman \& Osburn, 1995); and an interpretive analysis of common meanings and relational themes in the preceptorship experience (Nehls, Rather \& Guyett, 1997).

In recognizing the increasing popularity of preceptorship as a clinical teaching method, Hsieh and Knowles (1990) conducted a research study designed specifically to examine the development of the preceptorship relationship. They addressed three areas: the specific elements essential to the development of the preceptorship 
relationship; the instructor role in the facilitation of that relationship; and the variables that affect its development. Based on naturalistic observations and direct feedback from 12 preceptors, 12 students, and two instructors in acute care hospitals, seven commonly occurring themes were identified as important components of the developing relationship. These themes included: trust, clearly defined expectations; honest communication; mutual respect and acceptance; encouragement; and the mutual sharing of self and experience. This study contributes significant insight into the preceptorship relationship and provides the impetus for more formal exploration of this subject in greater depth.

According to Allanach and Jennings (1990), in this time of economic retrenchment, it is entirely conceivable that preceptorship programs may be eliminated. On the other hand, it is recognized that preceptorship programs represent an important mechanism by which to recruit and retain nurses, two concerns that currently overshadow the health care system. In conducting a qualitative study to evaluate the transition process of graduates who participated in a preceptorship program, these researchers found that the objective measures in the study did not support the commonly held notion that the transition from student to graduate nurse is an emotionally laden experience. They suggest that the reason for such a finding may be attributed to the effectiveness of the preceptorship program in sustaining a positive effect on the preceptee. It is the conclusion of these investigators that preceptorship programs do indeed constitute a salient and essential intervention for facilitating the integration of the student nurse to professional nurse role. 
One researcher conducted a study to examine the effects of a senior preceptorship course on the moral reasoning of senior nursing students (Andersen, 1991). Enrolment consisted of seven full-time students in an associate degree of nursing (AND) program in the metropolitan New York area. All students were women ranging in ages from 21 to 45 years. The preceptorship course comprised four weeks, with 21 hours per week allocated for clinical experiences. Students were each assigned to a preceptor on a medical, surgical, orthopaedic, neurologic, or geriatric unit in accordance with their clinical preferences. Kohlberg's methods were applied to assess the moral orientation of students, to analyse factors affecting their moral choices, and to follow changes in their levels of moral development. Weekly seminars were conducted, notes maintained by the faculty advisor, and daily logs written by students and submitted weekly to the faculty advisor. The findings of this study indicate that, with the exception of one student, the levels of moral reasoning of students did not change as a result of the preceptorship experience. In light of her findings, the author suggests that while preceptorship may bridge the gap between education and practice, it may be "little more than a modern version of apprenticeship, which achieved bureaucratic loyalty at the expense of professional enactment" (p. 17).

An action research approach was adopted in a study by Armitage, ChampneySmith and Andrews (1991) to investigate the role of the nurse preceptor in changing long-term mental health care to primary nursing. This exploratory study was carried out on the nursing care practised on a 20-bed psychiatric, rehabilitation/continuing-care unit. The study included a quasi experimental and ethnographic evaluation of non- 
equivalent groups in the change to primary nursing with nurse preceptors acting as charge nurses. The standards of care, patient satisfaction and nursing staff perception of the quality of their working life and the unit atmosphere were evaluated before and after implementation of primary nursing. The findings of this study suggested that the implementation of primary nursing led to nurses being more accountable for care, residents being perceived as more self-sufficient and independent, and an improved environment for care and rehabilitation on the unit.

In a qualitative study, Peirce (1991) explored the view of undergraduate preceptored students regarding clinical experience. Students were required to complete an anonymous open-ended questionnaire about their clinical experience. Content analysis was completed on the answers using the whole response to the question as the unit of analysis. The two themes that emerged indicated: a) what students want from their clinical experience; and b) factors that influence that experience. What students desired included: a good experience; a chance to try new skills in a supportive environment; a thorough orientation; an interested preceptor who is a skilled clinician as well as a teacher; to feel part of and be welcomed by staff; and to feel like a nurse. The study revealed that factors such as the school, the hospital and the student were those most likely to influence the clinical experience. Indeed, it was found that preceptored students need as much if not more guidance than the instructed student. The difference was that the hospital, the preceptor and the unit provide more of the direction to the preceptored student. In addition, differences were found between students' perceptions in the first and last preceptored experiences and were summarily 
attributed to differences in professional growth.

A qualitative, exploratory/descriptive survey was undertaken by Stevenson, Doorley, Moddeman and Benson-Landau (1995) to identify the benefits and disadvantages of the preceptor role as perceived by nurse preceptors. As well, information concerning the rewards that preceptors perceive as desirable was obtained. A sample of 30 nurses was selected randomly from individuals identified by nurse managers or unit-based educators as having served as preceptors in a 772-bed hospital during the previous two years. Sixteen individuals participated in the study. Findings indicated that the rewards perceived as desirable by preceptors included: satisfaction from sharing knowledge and expertise; stimulation of personal growth; honour and recognition; and satisfaction from observing the preceptee grow. Other support and rewards desired by preceptors included: financial rewards, formal recognition; greater responsibility in the orientation process; feedback from the preceptee; guidance for the preceptor; and time with the preceptee away from the patient unit. Findings such as these are especially important for the successful continuation of preceptorship programs. It is through such information that faculty can ensure the provision of rewards that are both appropriate and meaningful to preceptors which, in turn, will provide the impetus for their ongoing participation.

The qualitative study by Rittman and Osburn (1995) addresses the issue of precepting a student who is academically and/or clinically marginal. While such a situation can occur not infrequently, there is little documentation in the research literature. Indeed, "little is known about how preceptors teach students and even less is 
know about precepting unsafe students" (p. 217). The purpose of this study was to describe a preceptor's journey through a difficult senior practicum experience. An hermeneutic analysis of the preceptor's journal disclosed two themes crucial to the precepting of an unsafe student: knowing the student and generating prospects for success. Two components of knowing the student included "watchful listening and assessing dangerousness" (Rittman \& Osburn, 1995, p. 217). This study qualitatively delineated not only the dilemma of admitting a clinically unsatisfactory graduate to the profession of nursing, but also the frustration of the preceptor who recommends otherwise. It provided a situational example of the very real problem in which preceptors not uncommonly find themselves, that is providing evaluation on their assigned students only to have them trivialized or summarily disregarded by the nursing faculty.

These qualitative studies provide salient knowledge and further insights into preceptorship. The pursuit of such knowledge is significant for the nursing profession as a whole. In light of its increasing role in clinical teaching, it is important that nurse researchers continue to examine preceptorship closely to determine whether, in fact, it is achieving in practice what it is purported to achieve, which is the provision of safe, competent clinical practitioners who can think critically and thus use judgment effectively in clinical decision-making. This determination can be made primarily through the type of research that has been ongoing and through additional research that will serve to either corroborate or refute the various findings. As a result of such a process preceptorship will advance from its current atheoretical state which, in turn, 
can only serve to strengthen and validate its role in the clinical teaching of baccalaureate nursing students.

\section{Critical Thinking}

For many years it has been acknowledged that one of the primary goals of university education is the promotion of critical thinking (McMillan, 1987). Indeed, the concept of critical thinking can be traced as far back as Plato's Academy, the prototype on which today's universities were originally founded (Meyers, 1986). Historically, Aristotle's Logic and the principles of rhetoric were considered to be fundamental ingredients in the professional education of young gentlemen studying to become clergymen, doctors, lawyers or teachers (Meyers, 1986). Although a specialized discipline, many modern educators still consider logic to be the basic method by which to teach and learn the skills of critical thinking.

In today's educational milieu, the current trend for the teaching and learning of critical thinking is more frequently carried out through the problem-solving method. A major supposition intrinsic to both of these approaches is that critical thinking is best taught in isolation of subject matter (Meyers, 1986). Studies have demonstrated, however, that there is little correlation between understanding the skills of logic and the application of sound critical thinking abilities in other disciplines (McPeck, 1981). Indeed, according to Meyers (1981), the use of the problem-solving approach for teaching critical thinking also reveals a major flaw: the identification of critical thinking with problem-solving is predicated on the notion that critical thinking always begins with a problem and results in a solution, when in fact, "a central element in 
critical thinking is the ability to raise relevant questions and critique solutions without necessarily posing alternatives" (p. 5).

Currently, there is no clear consensus in the literature regarding the definition of critical thinking. In fact, the definitions of critical thinking are as diverse as the experts who define it. Despite this lack of unanimity, however, educators regard critical thinking as an important educational requisite (Powell, 1987). "Critical thinking as an educational ideal is based on the philosophy that critical thinking is essential to true autonomy in our complex society" (Jones \& Brown, 1991). For the purpose of this study, the following definition of critical thinking will be used. "Critical thinking is a nonlinear, recursive process in which a person forms a judgment about what to believe or what to do in a given context" (Facione \& Facione, 1996, p. 131).

Educators in all disciplines play a major role in the fostering of critical thinking. Nursing is no exception. Students will develop the ability to think critically only by being challenged to use that ability. Unfortunately, over time universities have deviated from the process of promoting critical thinking and instead have begun to focus on course content or the provision of information. While critical thinking is discipline specific with the core ingredient being foundational knowledge of the discipline, it cannot be limited to being taught within the parameters of subject specific content (Brookfield, 1987; Meyers, 1986; Paul, 1993; Sedlak, 1997). Indeed, "the focus of nursing education and practice cannot rely exclusively on content" (Glen, 1995, p. 16). Students must be taught how to think, not merely what to think. 


\section{Quantitative Studies}

Of the studies completed on critical thinking in nursing, the majority have been carried out from a quantitative perspective. Correlational studies have been conducted to examine the relationship between critical thinking and various measures of success in nursing education (Bauwens \& Gerhard, 1987; Behrens, 1996; Sullivan, 1987; Tiessen, 1987). Several researchers have attempted to delve into the effects of nursing education on the ability of students to think critically (Brooks \& Shepherd, 1992; Gross, Takazawa \& Rose, 1987; Pepa, Brown \& Alverson, 1997; Wilson, 1996; Vaughan-Wrobel, O'Sullivan \& Smith, 1997). Other investigators have explored the relationship between critical thinking and clinical decision-making (Brooks \& Shepherd, 1990; Shin, 1998), while the link between moral reasoning and critical thinking in nursing students and practising nurses from different types of nursing programs has been examined also (Ketefian, 1981). The perception of critical thinking in nursing education has been explored (Jones \& Brown, 1991) and studies have been conducted specifically on the critical thinking ability of nursing faculty (Hartley \& Aukamp, 1994; Saarmann, Freitas, Rapps \& Riegel, 1992).

Evolutionary changes in society and in the nursing profession have provoked a realignment of the roles and functions of nurses within the health care system and have thus generated public awareness regarding the ethical and moral dimensions of these roles (Ketefian, 1981). This perspective that provided the impetus for one of the earlier studies on critical thinking in nursing in which the relationship between moral reasoning and critical thinking was examined. Results of this study indicated that 
nurses with a professional educational background demonstrated a positive correlation between critical thinking and moral reasoning.

Being relatively new to academy, a worthwhile endeavour for the discipline of nursing has been the determination of how nursing students compare with their other university counterparts in the area of critical thinking. Berger (1984) determined that, in fact, nursing students tended to score significantly higher in critical thinking than did either freshmen or senior liberal arts students. Such findings serve to validate the transferral of nursing education from the hospital to the university setting and indeed champion its "fit" within the academic disciplines.

Examination of the predictors of success in baccalaureate and diploma nursing programs revealed conflicting findings. The quality of academic performance, academic aptitude and academic experience correlated most strongly with the critical thinking of baccalaureate nursing students (Tiessen, 1987). Critical thinking and academic performance also correlated significantly for diploma prepared nursing students (Behrens, 1996). Conversely, other researchers found no change in student ability to think critically between the first and last semesters of a baccalaureate nursing program and subsequently was not a reliable predictor of success (Bauwens \& Gerhard, 1987). Similar findings were revealed in a two year RN to BSN nursing program (Sullivan, 1987).

Over the years, the discernment of differences in the critical thinking ability of diploma, baccalaureate, masters and associate degree students has been a source of considerable interest to nurse educators. Several investigators found that those 
prepared at the baccalaureate and masters level demonstrated significantly higher critical thinking scores when compared to diploma and associate degree prepared students (Gross, Takazawa \& Rose, 1987; Pardue, 1987). Similar findings examining professionalism and critical thinking also revealed that students from baccalaureate and Post-RN completion programs demonstrated higher critical thinking scores than did those in the diploma and associate degree programs (Brooks \& Shepherd, 1992).

However, in contrast to these findings, the critical thinking scores of baccalaureate nursing students were significantly lower than those of graduate diploma students when examined by another researcher (Wilson, 1996). A more recent study comparing the critical thinking ability of nursing students in two different programs found that those in an accelerated program were able to think more critically than those in a traditional program and were able to grasp the concepts related to nursing practice more quickly (Pepa, Brown \& Alverson, 1997). When the critical thinking of baccalaureate nursing students was investigated by Vaughan-Wrobel, O'Sullivan and Smith (1997), it was found that critical thinking scores were higher at entry for older students and students who had completed another education degree. For students who had previous nursing experience, the critical thinking scores were found to be lower. After adapting for age, previous degree, and nursing experience, no significant differences were found in scores from entry to end of junior and senior years.

Because of its significance to nursing as a practice profession, the relationship between critical thinking and clinical decision-making has also been a research focus of many nurse researchers. Investigators have found that while there was a significant 
though weak relationship between critical thinking and clinical decision-making at all levels of nursing education, baccalaureate prepared students scored higher in critical thinking whereas diploma students tended to score higher in clinical decision-making (Brooks \& Shepherd, 1990). A more recent study determined that baccalaureate students scored significantly higher than associate degree students on critical thinking and clinical decision making (Shin, 1998). The findings of this study also corroborated those of Brooks and Shepherd (1990) indicating that the relationship between critical thinking and clinical decision making is weak but significant. Further research will provide additional insight into this area of inquiry.

The role of nursing faculty in fostering students to think critically cannot be overestimated. To date, however, there have been few studies completed in which the critical thinking ability of nursing faculty has been examined and the findings are conflicting. While one investigation determined that nurse educators demonstrated a higher level of critical thinking ability than did nursing students (Hartley \& Aukamp, 1994), other researchers found that the critical thinking of faculty was not significantly higher than that of sophomore nursing students when the influence of age was controlled statistically (Saarmann, Freitas, Rapps \& Riegel, 1992). Further research would augment current findings in this area. Indeed, a leading authority on critical thinking has found that educators themselves tend to be ill-equipped to teach students to think critically (Paul, 1993). "They have not learned the art of disciplined reasoning," primarily because they themselves were not taught to think critically (Paul, 1993, p. vi). 
Research into the critical thinking ability of registered nurses has also revealed interesting results. For example, there was no significant relationship between professional nursing competence and the critical thinking ability of registered nurses (Maynard, 1996). As well, when a Career Advancement Program was examined to determine its impact on the critical thinking ability and clinical judgment of registered nurses, it was found that neither was influenced by patterns of upward mobility.

Although leading experts recognize that the use of appropriate teaching methods is an integral component in fostering students to think critically, little or no research has been carried out in this area, particularly in the practice setting (Brown \& Keeley, 1994; Meyers, 1986; Paul, 1993; Ruggiero, 1990). In one study, two researchers found that during a psychiatric clinical placement, baccalaureate nursing students using computer assisted instruction scored significantly higher in critical thinking than did students receiving traditional teaching instruction. A more recent study investigated the relationship between selected discourse strategies and student critical thinking during post clinical conferences (Rossignol, 1997). Strategies included teacher high-level questions, teacher elaboration of student ideas, teacher probing questions, student participation and student to student participation. The findings of this study suggest that there is a conceptual relationship between less student talk and student-to-student talk and high levels of critical thinking. Further research into this area would be useful for the development of new and innovative teaching strategies that could foster critical thinking in a more effective manner.

Critical thinking skills and the role of prior experience were the focus of a study 
by Bethune and Jackling (1997). This study examined postgraduate nursing students' perceptions of change in their critical thinking ability during the course of postgraduate study. Results indicated that approximately one half of the students perceived an overall positive shift in their abilities. Findings also revealed, however, that a considerable number of the students who participated in this survey perceived a lack of critical thinking skill development.

In nursing education, critical thinking is not a clearly understood concept, nor is it systematically applied. In a United States survey of the deans and directors of baccalaureate and higher-degree schools of nursing accredited by the National League for Nursing (NLN), two researchers examined perceptions of critical thinking as it is presently described in nursing education (Jones \& Brown, 1991). Findings of this study revealed that critical thinking was conceptualized as a variation of the scientific method. It was explained as a rational linear problem-solving activity that reflected the nursing process.

As with the research into preceptorship, no real patterns can be gleaned from the studies discussed. Please refer to Tables 2.1 to 2.4 on pages 148 to 151 for a synopsis of the quantitative studies discussed.

\section{Qualitative Studies}

The qualitative studies regarding critical thinking in nursing, while limited, address a variety of questions that are salient to nursing. These include: examination of the role of critical thinking in the care of patients with acquired immune deficiency syndrome (AIDS) (Lewis \& Eakes, 1992); evaluation of an assessment model designed 
to teach critical thinking skills to associate degree nursing students (Callahan, 1992); exploration into the critical thinking ability of beginning baccalaureate nursing students during the first clinical nursing course (Sedlak, 1997); an examination of the prevailing practice regarding critical thinking in baccalaureate schools of nursing (Videbeck, 1997; and an interpretive phenomenological examination of the experiences of beginning baccalaureate nursing students' developing clinical reasoning and critical thinking (Haffer \& Raingruber, 1998).

In the provision of care, nurses are being bombarded constantly with complex decisions that do not always have easy answers. Nowhere is this more evident than in the care of patients with AIDS. Nurses must be well equipped to examine information objectively from a variety of perspectives. The role of critical thinking in caring for such patients was examined by two researchers (Lewis \& Eakes, 1992). Participants in the study, including 40 female students, 36 basic and four RN students in a senior level course, were required to write a two-page paper addressing the issue of whether nurses should be required to administer care to AIDS patients. Papers were graded on a 10point scale and students had a week to complete them. Results revealed a diversity of responses. A majority (75\%) of the students thought that nurses should be required to administer to AIDS patients. Six students (15\%) indicated that nurses should not have to provide care to patients with AIDS, while the remaining four (10\%) conveyed ambivalent feelings. In this study, students were afforded the opportunity to examine ideas, beliefs and principles in writing position statements and in generating reasons for their positions. Providing students with such an opportunity to apply critical thinking 
skills in addressing relevant health care issues in the classroom setting is an important preparation for their clinical practice. Research into such an area can provide salient information that will facilitate the development and use of theoretically based teaching strategies for critically thinking.

According to Callahan (1992), it is important to have an assessment curriculum model that allows for challenging students to become self-directed, lifelong learners who are safe, competent, confident and up-to-date in their nursing practice. Using the nursing process in nursing situations, Callahan (1992) conducted a study to identify indicators of self-assessments and levels of thinking of associate degree nursing students (ADN). This was achieved by self-assessment tools and a seminar experience. Bloom's Taxonomy of Thinking Skills was used to enable students to identify levels of thinking. Thirty ADN students participated during a 10 credit course which included a five week clinical rotation. To assist students in monitoring their progress, assessment criteria and levels of thinking were included throughout the course outline and evaluation tools. During the first and last weeks of the semester, students were provided with the same nursing situation in which they had the opportunity to write a brief care plan based on prioritized need. The students then completed 10 objective test questions based on the situation. A seminar experience was provided at the end of each of the five units of the course and allowed students to relate theory to practice as well as to validate their assessments with peers and instructors. The findings of this study indicated that peer-sharing ranked highest in class evaluations. Students were able to express and individualize care plans more quickly and with greater ease. 
Worthy of note is the fact that students who participated in this study also reported that thinking decreased their stress, a finding that warrants further investigation.

The critical thinking of beginning baccalaureate nursing students during the first clinical nursing course was the focus of one research study (Sedlak, 1997). The case study approach was used to describe the students' critical thinking from their own perspectives. Sources of data for describing students' critical thinking included reflective journal writing, interviews, and the researcher's nonparticipatory lab observations. Paul's (1993) dimensions of reasoning were used as a framework to describe students' critical thinking. The data analysis resulted in four major themes: development of the professional self-perspective; development of a perfectionist perspective; development of a caring perspective; and development of a self-directed learning perspective. The descriptive nature of this study determined that beginning students do think critically. It was also found that a supportive environment is instrumental in facilitating students' ability to think critically and to grow as reflective practitioners. These findings are significant for curriculum design and development vis a vis planning appropriate strategies for introducing the process of critical thinking and to ensure an environment suitable for such a process.

The fourth qualitative study describes prevailing practices regarding the definition and evaluation of critical thinking (Videbeck, 1997). The study was conducted in the United States. Accredited four year baccalaureate nursing programs scheduled for accreditation site visits in the 1992 to 1993 and the 1993 to 1994 academic years were invited to participate by providing a copy of the self-study report 
pages relevant to the NLN Required Outcome Criterion of critical thinking. Of the 124 programs in the population, 44 used the newly approved accreditation criteria and provided the requested materials. Analysis revealed that, while 43 programs included both cognitive and affective abilities in their definition of critical thinking, some of these programs used measures that addressed only the cognitive nature. Most of the definitions provided by programs were global in scope with only one providing an operational definition of critical thinking. A number of programs included program/curriculum or course objectives to operationalize critical thinking, while in some cases critical thinking was only inferred from the objectives that included problem-solving, decision-making or use of the nursing process. Use of the nursing process, problem-solving, and decision-making were identified more frequently than clinical judgments when describing activities in nursing practice that required critical thinking, and thus provided the rationale for their selection as evaluation activities. The designation of written clinical assignments as evaluation measures for critical thinking was made more frequently than the observation of actual clinical performance. This study revealed that critical thinking as an outcome in nursing education is being evaluated using a variety of methods and processes. This practice is a result of the individual differences among programs, different conceptions of critical thinking and its illustration in nursing practice. This study provides the impetus for further research and subsequently could provide direction for the teaching and evaluation of critical thinking as well as provide a framework for research.

Finally, an interpretive phenomenological approach was utilized to derive a 
beginning understanding of baccalaureate nursing students' experiences in developing clinical reasoning and critical thinking (Haffer \& Raingruber, 1998). The fifteen students who participated in this study were enrolled in an elective two-unit course which focused on clinical reasoning. Narrative approaches were used to reveal how students experienced their developing critical thinking. Class videotapes and reflective logs, in which students described their reasoning and responses to others' reasoning, provided the data for this study. Findings revealed that confidence emerged as a significant aspect of the students' development of clinical reasoning and critical thinking.

It is the responsibility of nurse educators to ensure that nursing students develop the critical thinking ability required to cope with the accelerated changes occurring in the health care system. Research into the way nurses process information will provide a body of knowledge that is specific to the nursing profession. Research in the area of critical thinking would focus on ensuring that nurses not only know what to think, but more importantly know how to think (Allen, 1992).

In reviewing the current state of knowledge regarding preceptorship and critical thinking, clearly it is evident that no research has been conducted to ascertain any link between the two. Because of its widespread usage as a clinical teaching strategy and the fact that baccalaureate prepared nursing students are expected to be prepared as critical thinkers, it is of the utmost importance that preceptorship be examined to determine if, in fact, it is fostering critical thinking and is not merely "a modern version of apprenticeship" (Andersen, 1991, p. 17). Hence, the impetus for this study. 


\section{Assumptions}

1. A primary goal of university education is the development and promotion of critical thinking.

2. Teaching strategies utilized in baccalaureate education are designed to foster critical thinking.

3. Baccalaureate nursing education fosters clinically competent nurses who have the ability to think critically.

4. As the primary source of tutelage in the practice setting, preceptorship plays a major role in fostering the clinical competence of basic baccalaureate nursing students.

5. Preceptorship fosters the development and use of critical thinking in the practice setting, otherwise it is superfluous to baccalaureate nursing education.

\section{Research Questions}

In preceptorship, what is the process used to develop and promote the use of the critical thinking ability of basic baccalaureate nursing students?

1. How do preceptors perceive critical thinking and the process that is entailed therein?

2. How do preceptees perceive critical thinking and the process that is entailed therein?

3. How are preceptees fostered to think critically while being preceptored in the practice setting? 


\section{CHAPTER III}

\section{METHOD}

\section{Research Design}

Because of the lack of research in the area of preceptorship and critical thinking, a grounded theory approach was considered to be the most appropriate method for this study. This method is especially useful for acquiring a new perspective in a familiar situation or as is the case in this study, for identifying, describing and illustrating relationships between previously unexplored variables (Stern, 1980; Wuest \& Stern, 1990).

The intellectual origins of grounded theory are rooted in symbolic interactionism and can be traced back to the Chicago School of Sociology (Bowers, 1989). The Chicago School, as it became known, refers to the social psychology of symbolic interactionism and related research methods which were developed at the University of Chicago between 1920 and 1950. The Iowa School, a second branch of symbolic interactionism, also traces its beginnings to the University of Chicago during the same time but differs from the Chicago School in its extensive utilization of the work of George Herbert Mead (Bowers, 1989; Kuhn, 1964).

Symbolic interactionism is a down-to-earth approach to the scientific study of human group life and human conduct. Its empirical world is the natural world of such group life and conduct. It lodges its problems in this natural world, conducts its studies in it, and derives its interpretations from such naturalistic studies...Its methodological stance, accordingly, is that of direct examination of 
the empirical world (Plummer, 1996, p. 224).

Symbolic interactionism is founded on three fundamental principles: a) individuals act toward things on the basis of the meanings that those things have for them; b) the meaning of such things are derived from or arise out of the social interaction that one has with other individuals; and c) these meanings are treated or modified through an interpretive process used by the person in dealing with the things they encounter (Blumer, 1969). It is these principles of symbolic interactionism that originally guided Glaser and Strauss' interpretation of what society is, how it works and what aspects of it require examination if particular situations are to be understood (Baker, Wuest \& Stern, 1992).

Symbolic interactionism guides grounded theory in that the researcher must understand behaviour as the participants understand it, learn about their world, learn their interpretation of self in the interaction and share their meanings (Chenitz \& Swanson, 1986). "Behaviour is then studied from the symbolic and interactional levels. It must be observed in context because meanings are derived from social interaction" (Baker, Wuest \& Stern, 1992, p. 1357). In this study, the grounded theory method permitted the researcher to study the process that is used to develop and promote the use of critical thinking by basic baccalaureate nursing students within the context of their preceptorship experience in the practice setting. Grounded theory thus afforded the researcher the opportunity to deal directly with what is actually going on in the preceptorship relationship with regard to the fostering of critical thinking, rather than what ought to be going on. In other words, the grounded theory method "tells it 
like it is" (Glaser, 1978, p. 14).

According to Glaser (1992), "the grounded theory approach is a general methodology of analysis linked with data collection that uses a systematically applied set of methods to generate an inductive theory about a substantive area" (p. 16). Grounded theory is a general method of comparative analysis of qualitative data that requires overlapping, sequential formulation, testing, redesigning and reintegrating of propositions until a theory is generated (Glaser \& Strauss, 1967). The object of this method is to generate theory from empirical data rather than to validate existing theory through theory testing (Glaser \& Strauss, 1967; Knafl \& Howard, 1984; Sarter, 1989). The theory is systematically and inductively discovered through the ongoing collection and analysis of the data which in turn results in its being integrated or grounded in the data (Glaser, 1992). The purpose is not to force but to discover a core variable and the subsequent theory that accounts for that core variable. Because forcing would serve to thwart and defeat the whole notion of discovery, which lies at the very essence of the grounded theory method, it is crucial that the theory be allowed to emerge. The process of data collection is thus controlled by the emerging theory (Glaser, 1996).

The purpose of this study was to generate a theory from the data that would be relevant to preceptors, teachers and learners. As a result of a series of interviews and observations, the researcher was able to explore relevant factors via the collection of qualitative data in the practice setting. Through constant comparison, the data were examined and analysed simultaneously. The generation of several hypotheses was the result. Throughout this process the researcher consulted the literature for existing 
theory relevant to the emerging hypotheses (Stern, 1985). These hypotheses were then further supportive of the emerging conceptual framework which generated a theory that remained grounded in the data (Stern, 1980). In using this approach, the aim was to discover the process that is used in the preceptorship relationship to develop and promote the use of the critical thinking ability of basic baccalaureate nursing students.

Fundamental to the grounded theory method is theoretical sampling (Glaser, 1978). This is "the process of data collection for generating theory whereby the analyst jointly collects, codes and analyses [his] data and decides what data to collect next and where to find them, in order to develop [his] theory as it emerges" (Glaser, 1978, p. 36). Theoretical sampling controls the process of data collection in accordance with the emerging theory (Glaser, 1968). Codes were gleaned from the raw data throughout the entire process, from the beginning of the data collection through the constant comparative analysis. These codes were used then to guide additional data collection. From these data, the codes were developed theoretically with their properties and coded relationships with other categories until each category was duly saturated (Glaser, 1968; Glaser, 1978). Theoretical sampling on a code was completed only when it was saturated and integrated into the emerging theory (Glaser, 1978). Saturation occurred when no new data were discovered from which the researcher could develop properties of the categories. In using theoretical sampling it was not possible to determine in advance precisely what to look for and where it would lead. Only as the researcher "discovers codes and tries to saturate them by looking for comparison groups, does both what codes and their properties and where to collect data 
on them emerge. It is never clear cut for what and to where discovery will lead" (Glaser, 1978, p.37).

Participants were chosen from fourth year basic baccalaureate nursing students (preceptees) and their staff nurse preceptors. Participation outside of the substantive area was not deemed appropriate since the aim of this study was to generate a substantive theory explaining the phenomena observed among basic baccalaureate nursing students and their preceptors and not to develop a formal theory of clinical teaching (Partridge, 1983). Six preceptees and six preceptors participated in the study. The preceptees ranged in age from 24 to 29 years of age. All were female. Two had previously completed two years of university in the Faculty of Science while one had previously completed one year in that same Faculty. The preceptors ranged in age from 29 to 54 years. All were female. All were diploma prepared with two having completed a Post-RN baccalaureate degree in nursing. Experience as a preceptor ranged from one year to ten years. The nursing experience of the preceptors ranged from seven years to 30 years. One of the student's preceptors did not participate in the study while the sixth preceptor was not currently preceptoring a student although she is an experienced preceptor with the program. By virtue of not being too large in number, twelve participants allowed for the deep analysis that is the hallmark of qualitative inquiry (Sandelowski, 1995), and thus resulted in a new and richly textured understanding of the process that is used in preceptorship to develop and promote the use of the critical thinking of basic baccalaureate nursing students. Participants were required to meet three criteria: a) speak and understand English; 
b) be/have been involved in a structured clinical preceptorship; and c) sign a consent form agreeing to participate in the study.

The study was conducted in a tertiary care institution which comprised the units to which the nursing students were designated for their fourth year elective and clinical practicum courses. These courses were offered consecutively over a period of fourteen weeks. During this time, in accordance with their clinical preference, students were each assigned to a preceptor in one of the following areas: the emergency department, the child health centre, neurosurgery, cardio-thoracic surgery or the general surgery and liver transplant unit.

\section{Procedures/Data Collection}

The researcher carried out the data collection during taped interviews with the participants. Prior to these taped interviews, demographic data were obtained from all participants, including age, marital status, and other university education. For the preceptors data on nursing education, post-graduate and continuing education, years of nursing experience, description of work experience and experience in the preceptor role were collected too (Refer to Appendices 4 and 5). Owing to her qualifications including years of experience as an acute care and critical care nurse, nurse educator, and consultant for the development and implementation of preceptorship programs, the researcher was considered to be well qualified to conduct the interviews and did so herself.

Initially it was not possible to determine the specific number of interviews that would be conducted. However, once the categories became saturated and no new 
information was being obtained, the interviews were terminated. In all there were a total of 32 interviews. During the interactions, an interview guide (Appendices 1 and 2) was used and contained open-ended questions which helped to facilitate the participants' freedom of response and in turn permitted the researcher's clarification of information (Strauss \& Corbin, 1990). The guide was a beginning one only and was revised as the data emerged. Rigid adherence to the guide would have thwarted inherent data possibilities, restricted the amount and type of the data collected, and would have also inhibited the researcher from acquiring the density and variation of concepts required for developing a grounded theory (Strauss \& Corbin, 1990). Subsequent interviews were guided by the emerging categories which further developed and validated the theory. Interviews, each lasting anywhere from 15 minutes to 90 minutes, were conducted with individual participants to achieve verification of information.

Secondary data sources included direct observations in the practice setting together with access to daily journals that were chronicled by the individual preceptees. As well, the nurses' notes that were recorded by the preceptees were examined. At a mutually convenient time, the researcher observed both the preceptor and preceptee interactions while they planned and carried out their nursing care. Each preceptor/preceptee pair, for a total of five, was observed while working together in the practice setting. Four observations were made during the day shift and one observation was made during the night shift. The observations were scheduled at the convenience of the preceptors and preceptees. The researcher adopted the role of 
participant observer in that she was present in the practice setting but did not participate or interact with other people to any great extent. According to Spradley (1980), she was engaging in passive participation. Acquiring a designated location, the researcher conducted the observations as unobtrusively as a "fly on the wall" (Field \& Morse, 1985, p. 77). Such a role allowed the researcher to "penetrate farther beneath the surface of public behaviour and superficial expression" (Pearsall, 1965). As with the interview, an observational guide (Appendix 3) was used that served to permit the researcher clarification of information. This guide was a beginning one only and was revised as the data emerged. Observations were carried out until sufficient data were processed which, in conjunction with the interviews, ensured saturation of the data. On average the observations lasted approximately four hours.

Data collection was also augmented by the recording of field notes (Field \& Morse, 1985). To prevent the potentiality of misinterpretation and memory loss, the notes were entered directly into a tape recorder immediately following the interview. These notes served to reflect the researcher's description of the physical setting, any fortuitous events that occurred, and the nonverbal communication of the participants, all of which could not have been detected by the actual tape recording itself. In addition, a journal reflecting the personal component of the field work was chronicled by the researcher. It included the researcher's reactions to participants, responses and reactions discerned from others, and a "record of experiences, ideas, fears, mistakes, confusions, breakthroughs, and problems that arise during field work" (Spradley, 1979, p. 76). Prior to conducting further interviews, the researcher reviewed the field notes 
and the journal, and made notations about questions that needed to be asked. For the sake of accuracy, data were confirmed by participants to determine if the researcher's findings adequately reflected their perspectives. 


\section{CHAPTER IV}

\section{DATA ANALYSIS}

\section{Open Coding}

Analysis of the data began almost immediately as the data collection was undertaken. The first level of analysis, referred to as open coding, was begun. This immediate analysis guided the researcher on which direction to take the study by utilizing theoretical sampling before selecting and focusing on a specific problem (Glaser, 1978). Each piece of the data was carefully scrutinized and compared with other data in every way possible (Glaser, 1978). The result of this process was the inductive generation of substantive categories and their characteristics from indicators such as the actual events, definitions, and meanings derived from the data (Mullen, 1975). Because these indicators tend to be multidimensional, each was coded into as many categories as possible. Categories are the coded data which clustered together. Once created, they were compared with other categories to determine how they connected or clustered (Stern, 1980). These connections are termed "linkages" (Schatzman \& Strauss, 1973). These substantive codes "conceptualize the empirical substance of the area of research" and are different from the theoretical codes which "conceptualize how the substantive codes may relate to each other as hypotheses to be integrated into the theory" (Glaser, 1978, p. 55). Substantive categories or codes are classified in two ways (Glaser, 1978): 1) those which are derived directly from the participants' own words or language, referred to as in vivo words, for example, "approachable", "independent" and "know how"; and 2) those implied codes such as 
"learning" or "expertise" or codes derived directly from the data in this study, for example, "facilitate", "role model" or "prioritize". These codes were created by the researcher from her disciplinary perspective or acquired from existing work (Mullen. 1975).

The process of open coding was facilitated by a number of guiding questions (Glaser, 1992). First, exactly what do these data indicate? Although permitting complete emergence, this question served as a constant reminder to the researcher that what she might have originally started out to study might not be what would emerge. The researcher was surprised at the process used in preceptorship to enable nursing students to use their critical thinking ability in the implementation of care. For example, when the core variable finally emerged and was examined, it revealed a multifaceted process, referred to by the researcher as "enabling." Second, of which category is this incident indicative? As the theory became more and more conceptualized, this question became easier to answer. The constant asking of this question served to keep the researcher from becoming lost in the re-experiencing of the data by forcing her to try and generate codes that related to other codes. Third, what is/are the basic social psychological problem(s) faced by the participants, and what is the basic social psychological process or social structural process that processes the problem to make life workable in the preceptor-preceptee relationship? These questions enabled the researcher to keep the substantive directions in focus as the core variable was being generated (Glaser, 1978). 


\section{Theoretical Coding}

The second level of analysis involved theoretical coding, a process in which the ordering of the data and the interrelation of the substantive codes occurred. It was through the theoretical coding that the dimensions of the categories were established. Examples of theoretical codes include causes, contexts, conditions, contingencies, consequences, and covariances. As the theory began to emerge and take form, the researcher found that she was being guided by a theoretical pattern that had emerged. It was at this time that the researcher began to delineate the number of categories that she was considering. Indeed, it began to become evident that the codes that were emerging were not discrete categories, but rather were the properties, dimensions, contingencies, conditions and contexts of fewer higher level concepts such as "purposive" and "incidental". As more and more codes emerged and memos were written, it became apparent that no new categories were emerging, so saturation of the categories was considered to have occurred. Moreover, saturation was seen to have taken place only when the major recurring themes had emerged and when one more incident would not have helped to explain the emergent theory (Wilson, 1974).

\section{Selective Coding}

The next level of analysis referred to as selective coding is an integral phase in the discovery of the core variable. This phase is often referred to as a process of reduction because it is designed specifically to allow for the search for the core variable (Stern, 1980). It is through this process that the researcher restricted her coding to only those categories that related to the core variable, which in turn became the guide 
to further data collection and theoretical sampling. The researcher explored for conditions and consequences that related specifically to the core process, thus the analysis became guided by the core variable (Glaser, 1978). It was the selective coding that significantly delimited the work from open coding. Memos became more focused while at the same time reflecting gaps for theoretical sampling. As an example, in this study the categories of "role models," "facilitates," "guides," and "prioritizes", which at first were considered separately, were now found to be sub categories or properties of the higher order category of "incidental." Thus it was thus through the process of reduction and comparison that the core variable for this study emerged. Indeed, it was the core variable "enabling" that seemed to explain the process used in preceptorship to develop and promote the critical thinking ability of basic baccalaureate nursing students. Once discovered, the data were re-examined to ascertain the appropriateness of the core variable.

\section{Memoing}

A vital step in the analytical process also is the writing of memos. According to Glaser (1978), "memos are the theorizing write-up of ideas about codes and their relationships as they strike the analyst while coding" (p. 83). There are various significant aspects about the emerging theory that are achieved through this analytical phase (Glaser, 1978). It is through memoing that the data are raised to a conceptualization level. Memoing serves to develop the properties of each category, which begins to define it operationally. As well, hypotheses about linkages between categories and/or their properties are delineated with these linkages, which are then 
integrated with clusters of other categories that in turn helps to generate the theory. Finally, memoing begins to establish the emerging theory with other theories that have, or do not have, potential relevance.

The researcher commenced writing memos when the coding of the data was first begun. This writing served as a means for the collecting and storing of analytical ideas as they occurred to the researcher and thus were written throughout the entire study. As with the open coding, during the memo writing the researcher was guided by a number of questions which, while allowing for true emergence of the categories and their properties, helped to keep the researcher from becoming lost in the reexperiencing of the data (Glaser, 1978). These questions were as follows: What relationship did one code have to another? Were they separate codes or was one code a property or a phase in another? Was one event the cause or the consequent of another and what were the conditions that influenced the codes? This process facilitated the delineation of the code and category boundaries and the empirical criteria on which these were based. It also helped to outline conditions under which the codes and categories emerged, while delimiting their theoretical linkages and significance to the data and the major theoretical patterns in that data (Glaser, 1978). Memos were thus used to document code and category development and revision. It was in this manner that the researcher was able to describe the theoretical properties of each code and/or category which in turn eventually resulted in saturation and the emergence of the core variable and the subsequent theory.

When categories emerged from the data collected in this study, existing theories 
were scrutinized for their relevance to the grounded categories and concepts and, if determined to be appropriate, an effort was made to synthesize or elaborate upon them (Partridge, 1983). In theory development, there is no one method or general starting point. The process is seldom easy and it is frequently guided by experience and intuition. Indeed, the theory may be developed inductively or deductively or both (Partridge, 1983). In this study an effort was made at the development of a substantive theory using inductive methods. Please refer to Figure 5 on page 156 for a schematic representation of the emergent framework.

\section{Mechanisms to Ensure Rigour}

There are four specific criteria against which rigour in qualitative research can be measured (Guba \& Lincoln, 1989), which include credibility, fittingness, auditability and confirmability. Throughout the course of this study, specific mechanisms were instituted to ensure that these criteria were achieved, thus enhancing the rigour of this investigation.

The concept of credibility, and not internal validity as in quantitative research, was used as the criterion against which to evaluate truth value or establish the 'truth' of the findings of this study. First, the researcher established contact at the research site to facilitate an understanding of the context, developed rapport with the participants and established the trust that is required for disclosure by the participants (prolonged engagement). Second, persistent observation, as previously described under data analysis, allowed the researcher to develop depth to the scope afforded by prolonged engagement. Third, the researcher shared her findings, conclusions and analyses with 
a colleague who had no vested interest in the study, which afforded her the opportunity to identify implicit information that she might have possessed but otherwise failed to recognize. Fourth, working hypotheses were constantly revised, developed and ratified until the process accounted for all known cases. Data were scrutinized not only for congruity but also for differences or variations, a process referred to as negative case analysis, which indicated that there was something different from the other cases. This forced the researcher to determine what that difference was. In the case of one preceptorship relationship, it became evident that the enabling of critical thinking was not occurring. Indeed, the preceptor in question expressed some confusion when sharing her perspective on the notion of critical thinking stating, that "it's basically acute care, functioning in acute care." When this was explored further with her, it was evident that she could not be any more explicit. When her preceptee was asked to indicate some things that the preceptor did to help her to think critically, she stated, "I can't." In subsequent observations of this preceptor and preceptee in the practice setting, it became obvious that there was little communication between the two. This observation was further corroborated by additional interviews in which the preceptor's perspective of the experience proved to be much different than that of the preceptee.

Fifth, prior to collection of the data, the researcher documented what she expected to discover and stored it. The impetus which motivated the researcher to embark on this study was twofold: a) the uneasiness that preceptorship may be limited to promoting the socialization of nursing students to the idiosyncrasies of the staff and the units to which they are assigned; and b) that preceptorship may be a modern day 
version of the apprenticeship model, the purpose of which is the development and promotion of psychomotor skills frequently to the exclusion of critical thinking. Throughout the study, the researcher continued to document her impressions. If she discovered only what was originally anticipated, then the credibility of the findings would be suspect. The findings did not reflect the researcher's original expectations, a mechanism called progressive subjectivity. Finally, the researcher validated her findings with the individuals who participated in the study, a mechanism known as member checks, which is the single most important technique for establishing credibility (Guba \& Lincoln, 1989).

The second criterion of fittingness refers to the fact that the findings "can 'fit' into contexts outside the study situation" (Kirk \& Miller, 1986, p. 32) and be viewed as meaningful to individuals not involved in the study. Indeed, when the researcher presented her findings to colleagues she was met with such comments as "I can see that" or "we're finding something similar" or "that's so relevant," or, as one colleague stated, "right on." There are three major threats to this criterion that include "going native', elite bias and the holistic fallacy. In order to guard against these threats, the researcher checked to ensure for representativeness of the data, coded categories and illustrations used to reduce and present the data; verified that the explanations and descriptions of the data reflected typical and atypical elements of the data; purposely attempted to refute conclusions derived from the data; and obtained confirmation of the findings from the participants themselves. 
Auditability is "the ability of another researcher to follow the thinking, decisions and methods used by the original researcher. The second researcher would arrive at similar results but not contradictory conclusions" (Yonge \& Stewin, 1988, p.

64). Throughout the course of the investigation, the researcher developed a comprehensive audit trail that included contextual documentation or field notes that were recorded by the researcher in the field; methodological documentation that entailed recording of all methodological decisions that were made during the course of the study; and analytical documentation that involved the recording of the researcher's thought processes regarding the sorting, coding, categorizing, and comparing of the data. Finally, the researcher meticulously recorded her personal response to the entire research process through the use of field notes, diaries, memos, letters, and mechanical recordings. Lastly, the criterion of confirmability was achieved when credibility, fittingness, and auditability were established.

\section{Ethical Considerations}

Prior to actual commencement of the study, a letter of permission was obtained from the Dean of the Faculty of Nursing (Appendix 6) and Ethical Approval was received from the appropriate Ethics Review Committees. The researcher then provided each participant with a verbal explanation of the interview procedure and purpose of the study. Participants were: a) requested to sign a written consent form prior to being interviewed and audiotaped (Appendices 7 and 8); b) apprised of their right to refuse to answer any question without fear of reprisal; and c) advised that they were free to withdraw from the study at any time. 
The interviews were conducted in a private area mutually agreed upon by the participants and the researcher. The taped interviews were scheduled at times that were convenient to the participants and did not interfere with their work-related responsibilities. As well, observations were carried out in the practice setting. Assuming the role of participant-observer at a mutually agreed upon time, the researcher observed the preceptor and the precepteee as they planned and carried out their nursing care. Preceptee journals and recording of nurses' notes were also observed during this time.

To ensure confidentiality, the names of the participants were removed from the tape recordings, written transcripts, and field notes, and replaced with randomly assigned code numbers. The tape recordings, transcriptions, and notes were retained in a locked cabinet. Following completion of the study, the code sheet containing the participants' demographic information was destroyed. The tape recordings will be retained for later use subject to appropriate ethical review. Specific references or descriptions regarding participants have been excluded from the final report of the study and accordingly will be excluded from any subsequent publications and/or presentations.

Owing to the fact that the researcher was conducting observations in the practice setting where direct patient care was carried out by the preceptor and the preceptees, she was cognizant of the possibility for the potential of witnessing unethical behaviour. Should this have occurred, as a registered nurse, the researcher would have been obligated to adhere to the CNA Code of Ethics and address such an occurrence 
appropriately and with the appropriate individual(s). In the event that the researcher observed that the preceptors were not fulfilling their role, as a nurse educator she would also have had an ethical obligation to address such an occurrence appropriately and with the appropriate individual(s). 


\section{CHAPTER V}

\section{FINDINGS AND DISCUSSION}

This study proved to be a most exciting research endeavour. While the purpose was to examine the process used in preceptorship to develop and promote the critical thinking ability of basic baccalaureate nursing students, by its very nature this study also afforded the researcher a firsthand glimpse into the "real world of preceptorship" as it exists in modern day nursing practice. It permitted the researcher the opportunity to interact with and observe fourth year basic baccalaureate nursing students as they evolved in their nursing practice, to share in their feelings of excitement and anxiety as they embraced the acute care setting, to listen to their concerns and frustrations as they grappled with day-to-day nursing issues, and to witness their jubilation over their individual accomplishments and all the while they maintained an air of unflappable optimism. In interviewing these students, the researcher found herself on more than one occasion thinking, "the future of this profession is in good hands."

It also afforded the researcher the opportunity to share in the experience of those nurses who so generously give of their time and expertise toward the development of these bright and eager students. It was impressive to witness firsthand how these nurses juggle their preceptor role with their role of staff nurse and/or charge nurse, while at the same time accommodating the learning needs of the nursing students who require much of their time and attention. On more than one occasion, the researcher found herself thinking that these nurses are the "unsung heroes" of the nursing profession, for despite their heavy workloads and complex pressures, they still 
continue to remain committed to sharing their time, expertise, and the wisdom of their experience with these neophyte nurses. More significantly, they do so in a spirit of true magnanimity.

The focus of this chapter will be the enabling process, which was discovered in this study to be instrumental in the development and promotion of the critical thinking ability of fourth year basic baccalaureate nursing students while being preceptored in the practice setting. Two key variables were found to be subsumed in that enabling process: a) the climate that is conducive to critical thinking; and b) the bringing about of critical thinking. These variables in turn comprise several subvariables. For example, the climate involves the preceptor and the staff, each of which in turn also comprise additional components while bringing about encompasses the categories of purposive and incidental, both of which also constitute subvariables. A schematic model of the enabling process is presented in Figure 1 on page 152. This model depicts the core concepts which explain how critical thinking is developed and promoted in the preceptorship experience. The findings of this research study reflect the preceptorial views of two groups that include preceptees and preceptors.

\section{The Enabling Process}

In this study, the enabling process can be seen as an interpersonal or interactive process in which the preceptors provide the preceptees with the opportunity or the means by which to develop their ability to think critically in the practice setting. Inherently, as with any interactive process, it can be fraught with many complexities, not the least of which is the fact that the preceptorship relationship not infrequently 
occurs between two complete strangers. As one student stated when commencing her preceptorship experience:

You don't know what you can say and what you can't say at this point. You don't know what's expected of you really. You have no clue what's going on. You're going in blind and it's a stressful experience and to not know the person is stressful...I didn't know her and she didn't know how to take me and you spend so much time walking around on egg shells.

The preceptor's perspective is equally insightful:

I wasn't sure what the student could and could not do...It takes a couple of weeks to assess the student individually where they're at, their skill level, their knowledge level, their strengths and where they need improvement.

It is within the context of a work environment that is challenging at best and daunting at worst that these complete strangers must strive to accommodate one another within a professional and personal capacity. They must work together on a one-to-one basis for extended periods of time in what may be considered to be one of the most demanding set of circumstances that can exist in the workplace setting. Life and death situations must be dealt with on a daily basis. Should the relationship prove to be successful, it becomes beneficial to those involved. If, on the other hand, it should prove less than successful, not only can it be frustrating, but it can be particularly disheartening for the student. In fact, a poor clinical experience can result in student disillusionment about nursing and an inability to integrate and learn (Peirce, 1991). In recounting a previous preceptorship experience, one preceptee reflected, "I hated it and 
I don't think it had anything to do with anything else but the fact that the preceptor didn't want to be a preceptor. It was hugely disappointing." Another preceptee reflecting on the anticipatory anxiety that occurred amongst her and her classmates prior to this preceptorship experience stated, "our biggest fear was getting a grumpy preceptor like somebody who was forced into doing it, who didn't want to do it, and just basically having to struggle through with this miserable person." According to Berguson (1983), one of the most important qualities to look for when selecting preceptors is that they be willing participants, for the precepting of a student requires a genuine commitment of time and energy above and beyond the normal workload. As reflected by one of the preceptors in discussing her role, "it's not something you should be dumped with. It's something that you should aspire to...I think that precepting should be something that you've chosen to do because of your skill level and because of your ability to teach." If the preceptor is reluctant to make this commitment, the quality of the preceptor preceptee relationship is doomed to failure. Conversely, if the preceptor is truly committed to the role, the clinical experience becomes both valuable to the preceptee and rewarding to the preceptor. Indeed, according to Parsons, MacLean, Butcher \& Shamian (1985), the preceptor can reach the student at a level that is unavailable to faculty or instructor. In the words of one of the preceptees:

She's not only my preceptor but she's a friend. She doesn't try and push me into any situations. If I say that I'm not comfortable with that, we usually discuss it...I feel that I can just sit down and talk to her like a friend. Like if I 
had a bad day and I need somebody to talk to.

While there are many aspects to the role of preceptorship in clinical teaching, such as professional socialization of the nursing student, impact on student performance, and promotion of clinical competency, the focus of this study was to determine the process used in preceptorship to develop and promote critical thinking. To discover that process, the researcher deemed it appropriate to ascertain the perspective of the preceptees and the preceptors themselves with regard to the term "critical thinking." It was found that the interpretation of this term varied from preceptor to preceptor and from preceptee to preceptee. This finding seemed to parallel the variation in the perspectives of the experts in the field of critical thinking in that there are as many definitions of critical thinking as there are experts.

One preceptee stated that she viewed critical thinking "as a way of problemsolving." A second preceptee said it involved the "thinking of many possibilities and narrowing it down to the best possibility and the best alternative." A third described it as "putting everything together from different disciplines into one and using it appropriately for the right reasons." Another's perspective was that:

It is being able to think of something in logical steps and having a kind of process of working something out...You take all the information you have and put it together, go through systematically what's important and what isn't, your priorities, and you come to a conclusion.

One of the preceptors described critical thinking as "not a linear process." She went on to say, "I tend to look at the whole picture and try and grasp what is most important 
right at this point in time and how much of the rest has to be dealt with." The most experienced preceptor called critical thinking, "the ability to, in 30 seconds to a minute, understand and read situations, to recognize extremely ill patients and have a wide knowledge base so that you know what's important in the situation. Moreover, it reflects "the thought process underlying decisions and judgments made about clients under the nurse's care" (Oermann, 1997, p. 25), a perspective which is not incongruent with the definition espoused in this study: "Critical thinking is a nonlinear, recursive process in which a person forms a judgment about what to believe or what to do in a given context" (Facione \& Facione, 1996, p. 131). While the definitions and perspectives of critical thinking may be varied, one supposition continues to prevail, which is that critical thinking equips nursing students to reason and to make sound judgments about patient situations (Oermann, 1997). In the practice setting, critical thinking permits students to analyze relevant nursing interventions, examine the consequences of various decisions, consider a myriad of perspectives to nursing care, and evaluate the care that is provided (Oermann, 1997). As one of the preceptees indicated, "you're thinking ahead. You're thinking well what does this person have, what do they need, what can I do as a nurse in order to speed along the process." Critical thinking is not developed through one clinical experience, but rather it is a skill that develops over time and with experience (Oermann, 1997). One preceptor said, "it is an acquired ability and I think you have to have a lot of experience." Another stated, "One of your major roles as a nurse is problem solving and decision making. You learn it as you go along and it becomes second nature." 
According to one of the preceptees, "critical thinking is the application of knowledge, knowing when to question, not just the knowledge. It's knowing why you have the knowledge and what to do with it." Not unlike this perspective, Siegel (1980) purports critical thinking to be relevant not only to the "knowledge how" that includes nursing content entailing both the training of skills and specific abilities, but also the "knowledge that" or propositional information that permits students to learn the methodological criteria or the theory that underlies their judgment. Moreover, critical thinking gives students the ability to reflect on situations and not simply to make decisions blindly, but to understand their relevance and to be able to justify and provide rationales that they deem appropriate for such decisions (Siegel, 1980). "A critical thinker is one who recognizes the importance, and convicting force, of reasons. When assessing claims, evaluating procedures, or making judgments, the critical thinker seeks reasons on which to base his or her assessment, evaluation, or judgment" (Siegel, 1980 , p. 8).

"Critical thinking skills develop best in an atmosphere of dialogue, interchange, and problem solving" (Meyers, 1980, p. xii). The teacher, or in this case the preceptor, who seeks to encourage students in the development of their critical thinking ability always recognizes the student's right to question and seek reasons, and consequently recognizes a responsibility to provide reasons when requested (Siegel, 1980). "The natural inclination to learn must be nurtured" (Meyers, 1986, p. 41), and if that learning is to be nurtured it must be done so in a flexible, supportive environment. Ultimately students who develop their critical thinking ability in the 
practice setting are those who not only possess a sound knowledge base and an understanding of their patients' problems, but also are encouraged to question their nursing care and interventions and to seek answers to their questions (Oermann, 1997). They are the students who are encouraged to consider multiple viewpoints to their patients' care and to explore ideas and problems from different perspectives (Oermann, 1997). Ultimately students who develop critical thinking ability in their practice are those students who have the freedom to be inquisitive, and to seek knowledge even when the use of that knowledge is not readily obvious.

The enabling process, discovered in the preceptorship experience to be responsible for the use of critical thinking, indicates two components found in this instance to be fundamental to the process: a) the climate; and b) the bringing about of critical thinking. The first component, the climate may be described as the context in which the preceptorship relationship takes place. The major variables are the preceptor and the staff. The preceptor, in turn, encompasses the valuing, the working with and the supporting that is reflected specifically by the preceptor for the preceptee throughout the preceptorship experience. The staff refers to the other health care professionals with whom the preceptee must work in the practice setting, in particular other nurses, and encompasses the variable categorized as accepting, or the ability of the staff to make the preceptee feel like a part of the team and not a mere student or outsider. The second major component in the enabling process is referred to as bringing about and reflects the preceptors' fostering of the preceptees' ability to think critically as they carry out their nursing care. This component occurs in either one of 
two ways: a) incidental; and/or b) purposive. Each of the variables and their subvariables will be discussed now in detail.

\section{The Climate}

\section{The Preceptor}

According to Reilly and Oermann (1992), while the learning climate is required to be provocative, stimulating and disciplined, it should also be a "humanistic one which is authentic, supportive, and caring" (p. 45). Sensitivity and caring about the individual preceptee does not imply preclusion of an acceptable level of performance or clinical competence, but rather implies that the preceptor is committed to helping the preceptee achieve desired goals and objectives in the practice setting (Reilly \& Oermann, 1992). It also implies that the preceptees' perspective is encouraged and supported as a preparatory measure for success in their future professional practice.

Over the years, much has been documented about the importance of the environment or the climate as it impacts both positively and negatively on the learner (Brookfield, 1986, 1987; Flynn, 1997; Friere, 1990; Knowles, 1988; Mezirow, 1990). Most experts concur that the climate which is the most effective in the enhancement of learning, or critical thinking, is the one that reflects support, is devoid of threat, fosters openness, inquiry and trust, and avoids competitive performance judgments (Manley, 1997). If the preceptees are constantly in fear of making an error, they become limited in their ability to think critically and to develop experientially (Reilly \& Oermann, 1992). As one preceptor reflected:

I think they [preceptees] do worse if they feel intimidated and they're not 
allowed to make mistakes. If they're really uptight with you and you're coming down hard on them they're not going to learn. All they're worried about is making mistakes and they're just going to learn how to survive. I have learned that fear is not a good motivator for anybody.

In the preceptorship experience, the climate is in no small way influenced significantly by the preceptor, the reality of which did not elude the participants in this study. In discussing their preceptorship relationship, the preceptees were quick to highlight the magnitude of the role that their preceptors play in the "making or breaking" of their clinical experience. They did not hesitate to provide descriptions of those factors that they deem to be fundamental to a successful experience, one that ultimately would contribute to the development and promotion of their critical thinking ability in the practice setting. Similarly, the preceptors provided their perspective with regard to what they consider to constitute a successful learning experience, and in doing so also revealed the characteristics which they deem to be significant to that experience. Within this context then, the variables of valuing, working with, and supporting emerged from the data, all of which were discovered in this study to be important behaviours manifested by the preceptors in their interactions with their preceptees and thus germane to the enabling process.

Valuing. Brookfield (1987) indicates that when individuals are being encouraged to think critically, it is essential that they be valued for their own selves. Indeed, valuing is a characteristic that is shared by preceptors who are effective in enabling the preceptees to think critically, a characteristic that is in turn reflected in 
their approachability, openness and a respect for the preceptees' perspective. Inherent is the preceptors' recognition of the fact that the preceptees wish to be acknowledged and valued as colleagues, neophyte to the setting, but "nonetheless important and equal human beings with ideas and opinions of their own" (Manley, 1997, p. 24). Valuing means respecting the preceptee as a person and demonstrating positive regard toward that preceptee, a perspective that is reflected by one preceptee in the statement, "she's treated me like a colleague and not a student." Another described it this way:

It's not only that she [preceptor] cares about me as a student, that I'm just there as a student but also as a human being...My opinion matters, not just, oh you don't know what you're doing, you're just a student. Never. She makes me feel very equal, like my opinion is important. She'll always ask me, "so what do you think about this patient? Do you think you should do this?" And so I give her my feedback and then she'll either agree with me or say "well I don't agree with you because this is actually more important."

Valuing is reflected by the preceptors who demonstrate confidence in the preceptees' capabilities and acknowledge that they bring their own individual experiences and qualities to the preceptee role. It is through their words and actions that the preceptors reflect respect for the individuality of the preceptees which in turn enables the preceptees to think critically (Brookfield, 1987). If the preceptees do not feel valued, it is conceivable that their ability to think critically can be impaired. Preceptees need to feel comfortable asking questions. They need to know that the preceptors will be the-e if they need them (Manley, 1997). The worst thing that preceptors can do is "to 
suggest, by a verbal response or some kind of body language (smirk, sigh, quizzically raised eyebrow)" (Brookfield, 1987, p. 72) that the preceptees' comments or questions or other forms of contribution is somehow substandard. Such behaviour can easily threaten the preceptees' self-concept, heighten their sense of vulnerability, and instantaneously render them voiceless, the antithesis to an individual's ability to think critically in any situation, and most especially when in the case of the neophyte learner whose sense of self is still so fragile. In the words of one preceptee, "you spend so much time walking around on egg shells that you're not thinking up to your capacity." The preceptors who assist the preceptees to meet their objectives without seeking to control, to dominate or to otherwise restrict their ability to achieve those objectives are the preceptors who enable the preceptees to think critically. One preceptor indicated: She's so close to graduating and being on my level, so to speak, without the years of experience. She will wear the same name tag I do...And so I don't want to make her feel that she's just a student. I respect her abilities. One preceptee stated, "the preceptor has to be a sensitive and very caring person to be a good preceptor, to bring about learning in people." Another preceptee said of her preceptor, "never has she said you're doing it wrong. It's always maybe this will make it easier, do you want to try this and then either it works or it doesn't, I use it or I don't." Yet another stated, "the communication is very good between us. If there's a concern or something, she's very approachable, ready to listen...She makes it easy for me to ask questions. I don't feel like I'm intruding." It is the climate in which the preceptees feel valued that they become enabled to think critically. It is in such a 
climate that the preceptees will have the freedom to evolve in their critical thinking ability. In the words of one of the preceptors, “they're [preceptees] like a flower, they just open up, it's just beautiful." Valuing ultimately fosters a sense of well being and self worth. As one preceptee stated, "the happier I am, the more I want to learn." Another recounted:

I've never felt that I've had a stupid question with her [preceptor]. The feedback she gives me and her attitude toward me is just great, so I guess that's why I feel so comfortable bringing up any kind of question with her and approaching her with that. My mind is more together. In other situations I've had problems. Even with instructors when they're supervising me I just tense up and my anxiety just overwhelms me and it's very difficult for me to really think.

In responding to her preceptee during the carrying out of a specific procedure, a preceptor demonstrates her valuing of the preceptee's perspective, "There's at least four or five different ways we could be doing the suctioning, so this is the way I feel comfortable with but if you want to try the way you know, we can do it that way." According to Brookfield (1987), "there is an uneasy tightrope to be walked in developing critical thinking in others" (p. 73). For the preceptors, it is a balancing act between valuing the integrity and the individuality of the preceptees while at the same time ensuring that they are sufficiently challenged in their practice experience.

Working with. Generally speaking, the role of the preceptor is to "bridge the gap between the reality of the workplace and the idealism of an academic environment 
without compromising professional ideals" (O'Mara, 1997, p. 57). Above all else, open and honest communication contribute to the creation of a positive preceptorship relationship. Intrinsic to that communication is the preceptor's ability for working with or collaborating with, as opposed to dictating to, the preceptee throughout the practical experience. Such an approach circumvents the development of a hierarchical relationship and ensures one that is egalitarian. Indeed, working with reflects a reciprocal relationship between the preceptor and the preceptee, one in which there is active collaboration between the preceptor and the preceptee in working together to accomplish the goals and objectives of the learning experience, one in which both perspectives are regarded as equally worthwhile and valid. Indeed, the major advantage of the preceptorship experience is the one-to-one relationship in which the preceptor and the preceptee work together to assess what learning is required, and based on that assessment and reflection, can design experiences to achieve that learning. In describing working with her preceptor, one preceptee stated, "we sit together and we talk about who I am going to nurse and who she's going to nurse and we go through what needs to be done and if I have any questions." A second preceptee recounted, "it's kind of more like a colleague approach. We discuss how we're going to divide the day up and then when I need her help I come and see her." A third recalled, "we [preceptor and preceptee] meet together to discuss what needs to be worked on during the day. We give each other a significant amount of feedback. I let her know what I need and she lets me know what she expects of me." One preceptor reflected, "I let her judge her own patient assignments." Another stated: 
We have found often on night shifts it's a good time to sit down and look at her [preceptee] objectives and what she is accomplishing and what does she still hope to accomplish. I'll ask her are there any specific areas that she might have a problem with or how does she want to work it, what does she feel comfortable with.

Authentic collaboration occurs after the preceptors have spent considerable time earning the preceptees' trust and by acting democratically and respectfully toward them (Brookfield, 1995). Coming to trust another person is the most fragile of human endeavours. It requires knowing individuals over a period of time and experiencing their honesty mirrored in their actions that reflect their consistency and dependability (Morrow, 1984). In a trusting relationship with their preceptors, the preceptees are more inclined to discover and to seek out new experiences, to question their own decision-making and actions, and ultimately to think critically about their nursing care situations. The preceptors who communicate confidence in the preceptees' ability to achieve in clinical practice, who take the students seriously and who treat them as adults, are the preceptors who demonstrate that they can be trusted. The preceptors who do not impose or force their viewpoint are the preceptors who demonstrate the ability to work with the preceptees in a truly collegial manner. Such behaviour forms the basis of true collaboration or working with the preceptees. As suggested by Heidegger (1968), "if the relation between the teacher and the taught is genuine...there is never a place in it for the authority of the know-it-all" (p. 15). In describing ber approach with her preceptee, one preceptor recounted: 
Depending on how many patients are on the floor, we'll take four or five patients and I'll say how many do you want to take care of, any particular one. If it's just a regular day, then she will say, "well I think I can handle them all or how about I take these?". I don't just want to assign her to four or five patients because time management is very difficult at this stage. It only comes with experience. And she does very thorough assessments, much more thorough than she will be able to do, unfortunately, when she's got half a dozen patients. So I know this takes time, so I usually pick up the slack. I don't want to rain on her parade and make her feel like 'oh gee, I don't think you can handle four patients.' I let her make the call so if she thinks she can care for them all, I just help out with whatever she needs and we just go about our business doing whatever has to be done for these patients.

It is thus in working with the preceptees that the preceptors enable them to become responsible and accountable for their own decisions, to think critically about those decisions, and to achieve an acceptable comfort level in reaching those decisions. It is through such a process that the preceptees gain the experience required for evolving as practising nurses. They become enabled to think on their feet and deal appropriately with the day-to-day clinical situations that require sound clinical decisionmaking grounded in critical thinking.

Integral to clinical practice is the evaluation process which entails the acquisition of information by the preceptors for making judgments about the preceptees' performance. The climate in which the clinical evaluation takes place is a 
critical determinant of the manner in which the preceptees perceive the process (Reilly \& Oermann, 1992). A supportive climate which reflects mutual trust and respect between preceptors and preceptees is fundamental for evaluation to be viewed as a means for growth and to be valued by the preceptees (Reilly \& Oermann, 1992). In the context of working with one another, the feedback from the preceptors is viewed as a means of helping the preceptees to learn, to discover new experiences, to further develop their skills and their critical thinking ability, and is not considered to be a punitive process addressing the negative aspects of their performance as an end in itself (Reilly \& Oermann, 1992).

When the preceptors are working with them, the preceptees come to see themselves as participants and not merely as students who need to be directed. They come to accept that they have answers and/or are capable of discovering them, and that they do not need to wait for the preceptors to tell them what to do and how to think (Hedin \& Donovan, 1989). In the words of one of the preceptees, "there's a lot of collaboration [between us]. She doesn't assign me what to do. We work together to figure out what we want to accomplish and how we want to do that. She doesn't say, 'Do this, do that'." Another recounted:

I needed to know that the knowledge was in my head...I've never had any negative feedback from her. I've had suggestions for improvement but never anything that's negative so it's always made me feel like I can know what I'm doing.

Just as trust on the part of the preceptees is important, so too is trust on the part 
of the preceptors. It is essential in the working with one another. The preceptees gain the preceptors' trust by demonstrating initiative in ensuring that the learning objectives are clearly conveyed and met, by taking responsibility for communicating effectively with the preceptors, and by being accountable for their professional behaviour. As stated by one preceptor, "I expect the student to have things thought through before she comes to me." Subsequently preceptor trust translates into confidence in the preceptee's ability.

In working with preceptees, the ability of preceptors to empathize was also discovered to be an important asset. Empathy implies that preceptors can view a situation from their preceptees' perspective (Reilly \& Oermann, 1992). It is the ability of the preceptor to see the experience through the eyes of the preceptee. In the words of one preceptee when describing her preceptor, "someone who's open-minded; someone who can empathize. I think she knows what it's like to be a student...I find her really open-minded and she's trusting... and I feel that she really supports me too when I make decisions." In projecting empathy toward the preceptees, the preceptors indicate that they are listening with full attention to their concerns and that they really understand what it is that the preceptees wish to have understood. In giving their full attention, the preceptors signify that the preceptees are important and worth their time, which is all the more meaningful because "there is no way that giving time and attention can be faked" (Gazda, Childers, \& Walters, 1982).

Supporting. A practice setting replete with learning experiences yet devoid of support can be discouraging for the preceptees and can result in the loss of many 
opportunities for growth (Reilly \& Oermann, 1992). The preceptors play a major role in influencing the nature of the practice setting and the degree to which the preceptees are supported in their learning experience and are enabled to think critically. As one preceptee reflected, "I think it makes it even easier cause all the staff like her [preceptor], so I mean they like her and I'm kind of an extension of her so that's what I find. Like everybody's been super nice. As indicated by another, "it's hard to determine if the support from the staff comes from liking my preceptor and it rubs off on me, or maybe I've just become part of the team, or maybe a bit of both."

On occasions when the preceptors are unavailable, it is not uncommon for the preceptees to be assigned to another staff nurse during which times preceptor support continues to be most crucial to the preceptees' experience. As one preceptee described, "I just feel more secure when I know that she [preceptor] is available to me at all times." As another stated, "we work closely together, but when I'm buddied with another nurse she [preceptor] is always there. I never feel abandoned. We make sure we take our breaks together and discuss the day." One preceptor described her approach to providing support and watching out or advocating for her preceptee when she is assigned as charge nurse or is on the desk, and thus not working directly with the preceptee, this way:

I lead her toward the nurses who've also been preceptors who I know are good preceptors, who think like I do, care with the same style, so that when there are days when I have to go on the desk I have her partner with one of those nurses. In describing an instance when, because of attending her son's graduation, she was 
unable to work the same schedule as her preceptee and subsequently had arranged for her to work with another staff nurse, a preceptor recounted, "I picked who I thought she would do well with. And actually when I got home at about one o'clock in the morning I phoned up to speak to her to see how it was going." The impact of preceptor support on the preceptees cannot be overestimated. In this study it was discovered that the support demonstrated by the preceptors has a significant impact on the preceptees' ability to think critically and to perform competently, and in essence provides a safety net in a setting that can be described at times as overwhelming for the neophyte nurse. The preceptors are aware of the subtle group dynamics occurring in the practice setting which influence the preceptorship experience, and can modify the environment accordingly until the preceptees reach an acceptable comfort level, a factor essential to the development and promotion of critical thinking (Farnkopt, 1982). It is the preceptor who can raise the awareness level of those staff members who are insensitive to the dynamics involved and facilitate staff consciousness by presenting a positive role model of cordiality, acceptance and hospitality to the preceptee (Farnkopt, 1982). As one preceptee so aptly summarized, "she's [preceptor] so good, she's made me part of the team rather than an outsider."

The supporting preceptors are those who, rather than encouraging dependence and reliance on preceptor approval, foster independence with learning and self-reliance. As one preceptor indicated, "I feel quite good about stepping back." According to Reilly \& Oermann (1992), in the practice setting "students need freedom to explore, question and dissent because without this, critical thinking is inhibited" (p. 118). One 
preceptee stated, "being allowed to be flexible has allowed me to develop not only my skills but the way I think things out. A second recalled, "I think my problem-solving ability has increased quite a bit. Like I'm able to think through things. I'm not as panicked." A third said, "it's nice to be left alone to do your stuff and know if you ever need help there's somebody there." And yet another indicated:

She's [preceptor] really been good at giving me my independence yet keep support there, you know not leaving me. Like she'll check up on me and say well how are you doing, is there too much going on, making sure I'm not too flustered or whatever.

Supporting preceptors are those who accept differences among students in their approaches to solving clinical problems. As reflected by one of the preceptors:

My approach the first day is to make them feel comfortable so that they are not afraid, that I will accept them and they won't be afraid to ask me questions. If they can't come to you, then you've missed the whole communication process and you can't draw knowledge out of them if they're frightened. With each student you approach you find the strength of the student at the time they arrive and you change your approach individually,

Another preceptee indicated:

I feel comfortable enough to go to her and ask her questions, or say I don't know that, can you explain it to me. Part of it is that she isn't going to think any less of me, that I'm not a good student or that I'm not intelligent. She's never made me feel that way, so it's made me feel more comfortable in going to 
her and in turn helped the learning process like helped me to want to learn and want to achieve. She allows me the freedom I want but she's there when I need her.

While the preceptors who are supporting of the preceptees are those who promote independent learning, they also continue to hold the preceptees accountable for their actions and for meeting commitments to their nursing care. The preceptees assume responsibility for providing quality care and for completing the patient assignments for which they are held accountable (Reilly \& Oermann, 1992). Prior to the preceptorship experience, students are held accountable through preclinical preparation time, which gives them the time and the opportunity to acquire the necessary knowledge and skills for safe, competent practice (Omara, 1997). Being preceptored may be the first time during which the preceptees cannot prepare for their patient assignments in advance. In the words of one preceptee:

In previous years we always came in the night before and did our research and knew everything about the patient, where they were from, who their mother was, who their father was, what they do for a living, what religion they were, everything. Now we go in blind like everyone else, so it's back to playing real world. I don't know everything about them....And I like to know cause it gives you that certain comfort zone like you know something about this certain person. You have a lot more responsibility because you don't have time to learn all this stuff.

In the preceptorship experience then, the preparation is defined differently. While the 
preceptees bring their knowledge to practice setting, they are now required to process patient information quickly, and to use sound judgment based on that information to make immediate or on the spot clinical decisions. For the preceptees, the challenge can be a daunting one unless they are working with preceptors who are supportive, in which case they are provided with a "healthy measure of support in all stages of their attempt to become critical thinkers" (Brookfield, 1987, p. 74). In the process of enabling the preceptees in their critical thinking, it is as important for the preceptors to know when to provide them with unconditional support as it is to know when to challenge them. Ultimately, it is the simultaneous challenging of the preceptees' mode of thinking while providing structure and support for their ideas that enables them to think critically (Brookfield, 1987).

\section{The Staff}

Accepting. The staff in the practice setting, and whether they accept the preceptee as being a part of the team, was discovered to have a significant effect on the preceptees' experience and on their ability to think critically. While it was ascertained that the preceptor is the primary influence on the preceptee experience, others in the setting, from the nurse unit manager to the staff nurse, from the physician to the physiotherapist, from the housekeeper to the ward clerk, all impact on the learning climate in the practice setting and subsequently either enhance or impede the preceptees' experience, thus affecting their ability to be able to think critically (Barnum, 1997). Indeed, one factor deemed essential for the ultimate success of students in meeting their learning goals and objectives in the practice setting is the staff 
attitude (Farnkopf, 1983). Not infrequently, a new face on a nursing unit is cause for alarm on the part of the members of the nursing and ancillary staffs. New faces usually imply new or different ideas which may mean change. Not only can this be disconcerting, but it can be also threatening to the established staff (Farnkopf, 1983). Sometimes the preceptees may be very outspoken about their perception of the new clinical setting and, while their comments may be intended to be helpful, they can be interpreted by the staff to be critical or intrusive. If the staff become defensive, it can spell disaster for the preceptees. Fortunately, the majority of nurses enjoy the opportunity to work with student nurses (Farnkopf, 1983). As discovered in this study, they derive a great deal of satisfaction in having the opportunity to teach someone who is enthusiastic in learning about the practice setting and the individuals who are responsible for making it operate effectively. As one preceptor stated, "the staff love having students." Another indicated, "I'm there for her but so are my other fellow nurses." One preceptee recounted:

It's so different from past clinical experiences. I feel more like staff than a student coming on, and I don't feel like a burden...it's like the way everyone approaches me. Like I feel I'm part of the staff. They treat me as an equal. Another remarked, "the team work is just phenomenal. Everybody helps each other." A third stated:

In the past I've had one nurse one day and another nurse another day. And a lot of them weren't interested. They didn't teach me anything. They liked the fact that I helped them make beds or I helped them to do this but they weren't 
interested in me. So I did a lot of reading and stuff on my own. I was basically on my own.

Yet another reported, "I think the staff on the unit are a major help cause they're always giving me feedback that I'm doing a good job."

According to Manley (1997), "the environment that is most effective in enhancing learning has available learning resources" (p. 33). A large component of those resources include the staff with whom the preceptees must work, staff who also possess expertise which can contribute to the preceptees' experience. A major factor in that experience is how the staff and the preceptor interact with one another. Indeed, the preceptors' relationship with their fellow nurses and the other health care professionals was discovered in this study to impact directly upon the preceptees. As one preceptee recalled:

I think I lucked out. My preceptor is a good nurse. She's liked by the staff and they know she's competent...I guess cause the staff respect her it actually amazingly rubs off on me. Because she's treated me like a colleague, it seems like the people she's friends with treat me like a colleague too. Another described her preceptor this way:

She gets along with everybody. Like I'll be walking down wherever with her and everyone says hi to her. Everybody likes her and that's because she just does her job and she loves her job and that really reflects on her personality and how she comes across. I think as a nursing student you need that. 
Staff accceptance, and ultimately their support, cannot be overestimated. That the staff are accepting of the preceptees is a significant factor in enabling the preceptees to think critically. Indeed, it is in the practice setting that the preceptees begin to operationalize the theories that have been in the forefront of their classsroom experiences. Although they may have been taught new and alternative ways of interpreting and analyzing nursing situations in the familiarity of the classroom and the laboratory setting, it is in the unfamiliarity and perhaps overwhelming milieu of the practice setting, or real world of nursing, that they must acquire the ability to apply that thinking to the patient situations. It is in the practice setting that they must adjust to and accommodate the idiosyncrasies of the staff. If the staff are not accepting, it can become an insurmountable challenge.

In summary, the impact of the climate on the ability of preceptees to think critically in the practice setting was discovered to be fundamental to the enabling process. In the words of one of the preceptees, "without it the rest doesn't happen." Indeed, much of the success in enabling the preceptees to think critically rests with the tone that is set by the preceptors and the staff. Preceptees must be led gently into the active role of discussing, dialoguing, and problem solving (Meyers, 1986). They watch very carefully to see how respectfully preceptors and staff field comment and quickly pick up nonverbal cues that indicate how open, approachable and supportive the preceptors and the staff are to their questions and contributions as well as how valued they are as colleagues. In the words of Nouwen (1966):

The hospitable teacher has to reveal to the students that they have something to 
offer...The teacher has first of all to reveal, to take away the veil covering many students' intellectual life, and help them see that their own life experiences, their own insights and convictions, their own intuitions and formulations are worth serious attention. It is so easy to impress students with books they have not read, with terms that they have not heard, with situations with which they are unfamiliar. It is much more difficult to be a receiver who can help the students to distinguish carefully between the wheat and weeds in their own lives to show the beauty of the gifts they carry with them (p. 61).

Figure 2 on page 156 provides a conceptual depiction of the core concept categorized as the climate and the subvariables entailed therein.

\section{Bringing About}

The second major component of the enabling process involves the bringing about of critical thinking. This component may be described as that facet of the enabling process in which the preceptor encourages the preceptee to pose questions, to examine problems, to consider various perspectives, and to pursue alternative ways of thinking about patient situations for the purpose of making clinical judgments (Reilly \& Oermann, 1992). This process occurs in either one of two ways. It is: a) incidental, in which the preceptor role models, facilitates, guides, and prioritizes with the preceptees as they carry out their nursing care, and thus indirectly sparks the preceptees' critical thinking ability; and/or b) purposive, in which the preceptor acts as a catalyst in motivating the preceptees to think critically. In this instance, the preceptor directly questions the preceptees' knowledge base, decision-making and actions. Please 
refer to Figure 3 on page 154 for a conceptual depiction of Bringing About. Incidental

The term incidental describes that which occurs serendipitously or "by the way" (The Oxford Dictionary of Current English, 1992, p. 445) which, in this case, accurately reflects one part of the process that occurs in preceptorship to bring about the critical thinking ability of basic baccalaureate nursing students in the practice setting. Indeed, it was discovered that when the preceptor role models facilitates, guides, and prioritizes, it is not necessarily done so with the express purpose of stimulating the critical thinking ability of the preceptee. Critical thinking is being sparked fortuitously. In other words, the preceptors do not set out specifically to stimulate the preceptees to think critically, but rather it ensues inadvertently as a result of their behaviours.

Role models. Traditionally, role modelling has been an accepted method for the teaching of professional attitudes and behaviours, and for decades in nursing it has been recognized as one of the most powerful ways by which learning occurs in the practice setting (Betz, 1985; Bidwell \& Brasier, 1989; Davies, 1993; Howie, 1988; Infante, Forbes, Houldin \& Naylor, 1989). In the case of the preceptorship experience, the preceptor serves as a powerful role model for the preceptee. Indeed, it is the preceptor who plays the major role in the success or failure of the preceptee's experience. "Observing role models to help us imagine, define, and practice the kinds of behaviours we would like to exhibit in our own lives is one of the most common means by which we learn" (Brookfield, 1987, p. 85). Role modelling is a process in which an 
individual identifies with and assumes the values and behaviours of another person which ultimately results in behaviour modification that is usually permanent (Bidwell \& Brasler, 1989). The role model is "an individual who possesses certain skills and displays techniques that the individual lacks and from whom, by observation and comparison with his own performance, the individual can learn" (Kemper 1968, p. 33). Preceptorship is the vehicle that provides the preceptee with the opportunity to translate theoretical knowledge into the learning of a variety of intellectual and psychomotor skills required for providing patient centered quality nursing care (Schweer, 1972). In a recent study, it was revealed that preceptors view one of their primary functions to be role modelling (Coates \& Gormley, 1997). Through observation, the preceptees learn as much from their preceptors' behaviour as they do from their verbal symbolization (Howie, 1988). As the preceptors go about the everyday business of carrying out their nursing care, the preceptees absorb much of what the preceptors say or do, which they emulate in the subsequent clinical situations with which they are confronted. Indeed, the preceptees seek to assimilate the preceptors' role modelling into their own clinical practice (Betz, 1985).

By modelling critical thinking, Meyers (1986) observes, teachers, and in this case preceptors, "can do much to encourage this frame of mind in their students" (p. 47). In fact, individuals who are perceived to be good role models of critical thinking by those who have experienced their influence, appear to display specific characteristics. A cluster of distinctive attributes of effective role modelling has emerged in descriptions within adult development (Levinson, 1978), psychotherapy 
(Rogers, 1980), adult education (Merriam, 1984; Daloz, 1986), and the business world (Roche, 1979). Traits such as clarity, consistency, openness, communicativeness, specificity, and accessibility have been found to be characteristic of those who role model critical thinking effectively (Brookfield, 1987). In this study, several of these traits became manifestly apparent. For example, the preceptors who acted in ways that were perceived clearly by the preceptees displayed clarity. As one preceptee recounted, "when I do get a chance by watching her I pick up on things. My thinking would be triggered". Or as another stated, "I think I've got some knowledge now myself just from watching what she does and you can see how certain things are solved."

Consistency is an important ingredient for any successful human interaction. It has particular significance for the preceptorship relationship, for it is within this context that an expert and a neophyte continuously interact. It is within this context that the preceptors and the preceptees must use sound critical thinking upon which to make clinical judgments about patient situations that are not only complex but often life-threatening. Not infrequently the preceptees experience feelings of vulnerability in these situations. Indeed, they enter the practice setting as neophytes with little understanding of the contextual meaning of many situations (Benner, 1984). Subsequently they come to rely heavily on the preceptors' ability to display consistent behaviour and responses. Consistency in the preceptors' behaviour fosters stability, confidence and security in the preceptees. The preceptees know what to expect, get clear and consistent messages regarding their progress, and are able to learn more 
freely and quickly (Manley, 1997). In circumstances when there is variation in behaviour or responses, it is crucial that the preceptors provide reasonable explanations to help the preceptees sort through the complex nature of the situation. As one preceptee described:

If there's some new thing either she'll walk me through it or she'll do it the first time or I'll watch something that she's doing without her meaning or even really thinking it's a learning experience and then I'll watch it and I find myself carrying over her techniques or you know then I know how to do it.

Of considerable significance to preceptees is their preceptors' openness or perceived ability to be honest and respectful of the integrity of those with whom they interact and a willingness to be accountable for their actions (Brookfield, 1987). This quality is referred to as "realness" (Rogers, 1980, p. 271) or the ability of the preceptor to "reveal himself as human, not god" (Daloz, 1986, p. 220). According to Beidler (1986), "being a model of intellectual and personal honesty will save you from the expectation that you need to know everything and will save students from shirking the responsibility of their own learning" (p. 78). The preceptors who display such openness are, in the minds of the preceptees, perceived as having authenticity and integrity (Brookfiled, 1987). In describing her preceptor, one student stated:

It's not like she's an authority over me and it's not like I get that from her or she uses that, not at all. She treats me very equal to her, wanting to know my opinion about things. Not just, 'okay this is what you do that's it'. It's 'so what did you think? Was that good for you? Do you need more? Do you need 
less?' It's always getting my input on things.

Another trait indicated as important in the role modelling of critical thinking is that of specificity (Brookfield, 1987). The preceptors who display individual behaviour that permits interpretative imitation by the preceptees possess what would be described as specificity (Brookfield, 1987). Such behaviour is easy for the preceptees to understand and to emulate. For example, one preceptee described her preceptor as, "very level headed; she's very calm, cool and collected and I think some of that's rubbing off on me." In the words of a preceptor, "she's [preceptee] watched us do this on the ward so she became at ease with that." Another preceptee recounted:

I see her as being very confident, and she's a woman. She really knows her stuff and she gets it across to doctors and I see them respecting her and listening to her...I also see how she gets along with the other nurses and she gets along really well with them. They respect what she says and will come and ask her for advice.

When the preceptors' behaviour is explicit and easily discernible, it poses no interpretative difficulty for the preceptees' assimilation into their own individual practice.

According to Brookfield (1987), "good modellers are seen as accessible by observers. They do not threaten or intimidate potential imitators" (p. 88). This trait is reflected in the words of one preceptor when describing her approach to enabling the preceptee to think critically:

They've a ton of information that comes in and it's like teaching them to put it 
in a funnel and let the stuff come through a little bit at a time so they can deal with it. I try to diffuse situations so that they're not totally overwhelmed.

A preceptee recounted:

I think the main thing that helped me think critically was that she would go over the steps, her own steps in her mind, how she would think and how she would handle the problems, so it was more role modelling. I got an idea how she thought about things and their cause...It's interesting to find what possibilities are important to her and how she narrows them down to the best alternative. In nursing, specific attributes associated with effective role modelling by the clinical teacher have been identified also. One trait that may be appended to those already delineated involves the preceptors' attitude concerning the role itself. This characteristic has been discussed in the literature (Morgan \& Knox, 1987) and emerged quite readily in this study. Throughout much of this study, it was apparent that a major quality perceived to be intrinsic to a successful preceptorship is the preceptors' attitude about the preceptor role itself. As one preceptee indicated, “I feel she [preceptor] really enjoys it [preceptoring]. It's not just something she does." Another described her preceptor as, "somebody who's been there and who likes doing it [preceptoring] and who wants to do it, not just has to do it to put it on their resume, but who likes doing it." Yet another preceptee recounted:

Going through nursing you have your ups and downs where you really love it or think why am I doing this. Okay I'm almost there, that's why I'm finishing but why am I doing this? And it's good to go out there and see people like [my 
preceptor] who really bring that out. And you're like this is the reason I went in and this is why I want to do this. You know they help enforce that which is a positive thing.

As role models, preceptors maintain a powerful influence over their preceptees. In their quest for professional identity, preceptees progress from imitating the preceptors' behaviour to assimilating that behaviour to fit new situations. It is during this adaptation process that they require a supporter and a reinforcer of behaviour (Howie, 1988). As role models, the preceptors can do much to enhance or detract from the preceptees' clinical experience. They can make or break the experience, a fact which has extreme implications for the entire profession. Indeed, failure to adequately introduce nursing students to the reality of nursing has been attributed in no small way to the large numbers of nurses who choose to leave the profession (Limon, Spencer, \& Waters, 1981; Peirce, 1991).

Facilitates. The concept of facilitation in teaching originates from the work of Rogers (1983), whose humanistic approach stresses the need for student-centered learning (Burrows, 1997). Unlike the more traditional pedagogical method, such an approach emphasizes freedom for individual development which in turn enables students to become more versatile and self-directed (Burrows, 1997; Rogers, 1983). "Facilitators do not direct; they assist adults to attain a state of self-actualization or to become fully functioning persons" (Brookfield, 1986, p. 123). The preceptors possess knowledge, skills, and attitudes which form an intrinsic part of themselves as individuals, and which are derived out of their own personal experiences in their 
practice area (Burnard, 1992). It is within this context that the preceptors facilitate the preceptees to discover what they need to achieve and need to know in their clinical practice, and to become enabled to think critically when carrying out their nursing care. One preceptee recounted:

She [preceptor] cues me on things that I don't know or she'll give me little points, and if I can't answer she'll wait for me to put it together, and if I can't she'll give me a little something else. She gives me little bits and pieces and allows me to put it together.

Clinical practice places the preceptees in a very vulnerable position. Their "learning occurs as a public event, in front of others - the teacher, clients, peers, agency staff and sometimes even individuals from other disciplines" (Reilly \& Oermann, 1992, p. 148). The preceptors who facilitate are those who accept that they are managers of learning. Always sensitive to the preceptees' learning situation, they readily establish a means of informal consultation, promptly address the needs, interests and abilities of the preceptees, and demonstrate ongoing support in what is often a threatening and always complex environment (Burnard, 1992).

The term facilitate means "to make easy" (Concise Oxford Dictionary, 1982) and was discovered in this study to play a significant role in enabling preceptees to think critically. Preceptors who facilitate are those who, by drawing upon their own expertise and experience, assist their preceptees to achieve their individual goals and learning objectives in the practice setting (Beckett \& Wall, 1985). A resource person who paves the way for preceptees' learning, preceptors who do so ultimately enable 
them to think critically when confronted with various clinical situations. "Simply remembering that a successful educational experience is one in which people are helped to learn is one of the most profound truths of education for critical thinking" (Brookfield, 1987, p. 236).

According to Burnard (1992), "the most important issue in facilitating learning is structure" (p. iii). Indeed, while the process of facilitation may be focused on the preceptees and their needs and wants, it is important that a simple structure is used to ensure that the learning occurs. "Learning is and must be maintained as the primary goal $^{n}$ in the preceptorship experience (O'Mara, 1997, p.48). Fundamental to that structure is identifying learning needs, establishing goals, identifying available learning resources, planning and carrying out facilitation, and assessing and evaluating the learning experience (Burnard, 1992).

Integral to the preceptorship experience is the identification of preceptees' learning needs and the establishment of individual goals. While preceptees arrive in the practice setting with predetermined learning objectives that are a requisite for course completion, how these objectives are to be achieved is discussed by preceptors and preceptees on a day-to-day basis. Not all preceptees will have similar learning requirements, thus it is unreasonable to expect them to complete the same learning activities (Reilly \& Oermann, 1992). Indeed, selection of experiences in the practice setting depends primarily on preceptees' level of knowledge and skills and individual learning needs. Collaborating with preceptees in the selection of appropriate experiences provides for individual styles of preferences, interests and learning, and 
allows for the identification of any incongruity between the learning objectives and the preceptees' capability (de Tornyay \& Thompson, 1982; Reilly \& Oermann, 1992). One preceptee related:

The shift starts off and usually we meet in the coffee room and we discuss anything that we need to work on for that day. Like, okay I want to do a catheter or I want to do a certain skill or I want experience in a certain area then I tell her that and she lets me know where she's at for that day. The approach of one preceptor is reflected as follows:

For the first two or three weeks I try to be with them constantly because I want them to pick up on my expectations, what I think the role should be. I want to observe how they function and just what level they are. What I do the first day is I explain the goal, what I expect them to leave with and then they tell me what they expect, what they wish.

Another preceptee said, "She has a copy of my objectives so we discuss those and if certain things come up that she knows are one of my objectives she'll make sure we get in there to achieve it."

Preceptors as facilitators allow experiential learning around which objectives can be identified within a unique interpersonal relationship and in which meaningful learning germane to the preceptees' individual goals may occur (Beckett \& Wall, 1985). Through interaction with their preceptees, preceptors thus facilitate the setting of goals that are well within the grasp of their preceptees and not infrequently may be a case of agreeing on what is possible rather than on what is ideal (Burnard, 1992). Such 
was the experience of one preceptor, "she also wants to look after a liver transplant patient but I think we'll wait til the end of her rotation when she's a bit more organized." Facilitating is an ongoing process and its success depends upon "crossfertilization and exchange of ideas, knowledge and experience" (Beckett \& Wall, 1985, p. 260). The relationship of preceptors who facilitate their preceptees is essential for harmony between the objectives of the agency and the learning needs of their preceptees. Not only is the amount and variety of clinical experience that preceptees are exposed to in the preceptorship assignment a major consideration, but the learning resources that are available for that process are also of significance in facilitating the preceptees in the practice setting. "The environment that is most effective in enhancing learning has available learning resources" (Manley, 1997). While others in the setting also have expertise to contribute, preceptors become the primary people resource for their preceptees. Frequently, preceptees themselves, however, are quite adept at identifying people resources and in seeking out those individuals from whom they feel they can learn or in avoiding those who do not provide a positive experience. One preceptee recounted:

There's only been one or two situations where I felt that the person didn't really appreciate me being around. So basically when my preceptor buddies me up with them I just tell her no I don't want to be with that person. And she's very open to that.

Preceptors facilitate their preceptees' learning by availing them of extant expertise in the practice setting. Indeed, this was demonstrated by one preceptor who 
commented, "we've arranged for her [preceptee] to go with the ostomy nurse for a day and also a follow-through with a patient." Arranging for preceptees to attend rounds, case conferences or meetings that relate to their current activity, provides them with exposure to a broader perspective and different ways of thinking and dealing with similar clinical situations. Such exposure is essential, not only for broadening their clinical experience, but for advancing their development as critical thinkers and ultimately as professional nurses. One preceptor stated, "I took her for a meeting with those from three other surgical floors." Preceptors who facilitate display creativity in seeking relevant opportunities from other practice areas, especially when they are not directly available to their preceptees in the setting to which they have been assigned. For example, in order to maximize her preceptee's experience and facilitate her learning, one preceptor considered the feasiblity of other options:

What she hasn't had a chance to do yet, and she may not before she graduates, is to put in or start an I.V. And I keep waiting for something to come up. And if nothing comes up in the next couple of weeks, we're going to go over to the PAC [Pre-admission Clinic] because they do them there all the time. In describing her experience, one preceptee stated, "the preceptor facilitates my learning. She brings me in books and sits down at the end of the day to go over things."

Aside from people resources, many practice settings also have libraries, audiovisual aids and learning centers. Preceptors who facilitate are those who are knowledgeable about such learning resources and who ensure that their preceptees are 
informed of their availability so that they might readily augment their clinical learning experiences in the practice setting (Manley, 1992).

Preceptors who facilitate also help their preceptees to plan how they will learn the new knowledge or skill identified as part of a learning need and support them as they work toward their goal (Burnard, 1992). As one preceptee described, "she [preceptor] always goes about trying to find ways to allow me to meet my objectives." Another stated, "she [preceptor] doesn't try to push me into anything but at the same time she does seek learning experiences for me."

Preceptors who facilitate are those who encourage their preceptees to think things through and to develop new ideas for themselves. For example, one preceptee stated, "she [preceptor] just really lets me go at my own pace. That's really helped my critical thinking." Another stated, "she gives me cues until I get it, but normally she allows me to think about it myself." One preceptee described it this way, "sometimes my methods are a little bit different than her methods and she never says you shouldn't do that cause my way is better. Like we talk about different ways of doing things." Another preceptee reflected:

If she [preceptor] was always watching over me, then I'd get nervous. I wouldn't rely on my own ability or my own thought processes. I go to her and tell her this is what's wrong. This is what I've done. Have I left anything out. So I'm doing the critical thinking part and I'm getting her to verify if I'm on the right track.

Another recalled, "she's given me more responsibility slowly but surely and believe it 
or not that does develop your critical thinking because you are responsible for more."

One important aspect of facilitating the preceptees' experience is the assessment and evaluation of the learning. "However the learning takes place, the important last stage in the process is to consider how successful it has been" (Burnard, 1992, p. vii). Preceptors who facilitate mutually assess and evaluate the achievement of the goals and objectives of the experience with their preceptees. Such preceptors encourage their preceptees to make their own assessment. As related by one preceptor, "when she's done a skill, I try to get her to evaluate how things went and give her feedback on it." Or, as another stated, "I watch her skills and we discuss afterwards how she felt about it and how the procedure went." One preceptee recounted:

My preceptor, she's just incredible. She let's me know how I'm doing and I always ask her for feedback, like how am I doing? How do you think I'm doing? She always gives me feedback...and my opinion matters too.

Such an approach serves to instill confidence in preceptees and in turn eliminates the fear of reprisal or the fear of being made to feel "small" or inferior in any way because the preceptors do not agree with them (Burnard, 1992). Such an approach, will render preceptees more likely to alert their preceptors to the fact that they do not understand something, or to suggest the use of a different approach which may be easier for them to comprehend (Burnard, 1992). Even if preceptees have not achieved all that they have set out to achieve, it is important that they be left with a feeling that they have gained something positive from the experience, discovered more about themselves, and identified new learning needs which they had not been aware of previously. Perhaps 
they will emerge with a clearer understanding of themselves as learners and with a much better idea of how they would approach the same learning need the next time (Burnard, 1992).

Guides. According to the Concise Oxford Dictionary (1982), the term guide refers to a person who "shows the way" or one who "advises" (p. 389). Preceptors who guide their preceptee's practice do so by providing meaningful learning experiences, teaching and validating psychomotor competencies, fostering the development of clinical judgment, and giving immediate feedback on performance as necessary (Bizek \& Oermann, 1990).

One of the most important factors in ensuring the success of preceptees' experience is the provision of appropriate learning experiences. Preceptors review individual goals and learning objectives and select appropriate patient assignments in collaboration with their preceptees. One preceptor reported this way, "we chose him [patient] because one of her objectives was to care for a patient who required chest care. He needed ventolin, physiotherapy and the use of an incentive spirometer so he was a good patient for that objective."

In the preceptorship experience, preceptors are those who guide their preceptees in gaining the knowledge and skills that they require for carrying out safe and competent patient care, and for assuming the role and responsibilities of the nurse in the practice setting (Bisek \& Oermann, 1990). One preceptee stated, "Whenever I have a problem or I don't know the answer for something I go see her [preceptor] and talk to her and then she tells me how she'd figure it out." Another recalled, "before 
we start the day she [preceptor] goes through the patient assignment with me and tells me special things that I should keep in mind, and asks me if there's any questions that I have." A preceptor reflected:

I try to fit the learning process in with patients so that I try and get them [preceptee] to understand the condition by viewing the patient, seeing the patient, and then understanding what went on with that patient and why things are done. And I try to tell them the practical way of doing things.

Preceptors who guide serve not only as their preceptees' bridge to social integration, but also to their involvement in unit routines (Friesen \& Conahan, 1980). For example, preceptors are instrumental in pointing out opportunities for their preceptees to carry out a skill and not infrequently coach them through new and unfamiliar procedures. One preceptee related:

Usually when it comes to a new skill she [preceptor] either shows me first or she tells me briefly what to do and I go ahead and do it. And then the more complicated things, like changing an IV tubing, she actually shows me first and the next one I do on my own.

A preceptor explained:

I gauge her experience day by day and see how she's doing. I ask are you doing okay, do you have any questions or if there's some new thing that she's come up against I'll go over it with her.

Through the guidance of their preceptors, preceptees also learn to problemsolve in real rather than educationally designed situations (Goldenberg, 1988). One 
preceptee indicated, "she [preceptor] explains why she thinks the way she does and why she does things." Or as a preceptor stated, "I'll say I wouldn't do that and this is why I wouldn't do that." Another preceptee reflected:

She [preceptor] shows me how she problem solves. Like when she explains things she'll explain why she does it and the reasons for it. And when I'm trying to problem solve I run it by her and to see if I'm doing the right thing. Another preceptor recounted:

I've always shared my type of critical thinking with the student and said this may work for you. And sometimes I just have to say to them just hang on to my coat tails we'll get through this and we'll discuss it later.

A major strength in the preceptorship experience is the individualized guidance that students can receive in formulating and revising their learning objectives and goals (O'Mara, 1992). This one-to-one relationship between the preceptor and the preceptee provides for close supervision and immediate feedback on performance, and contributes to the development of the preceptees' self-confidence and competence in performing clinical skills and in enabling them to think critically (Reilly \& Oermann, 1992). One preceptee summarized the relationship as follows, "I guess you'd call her [preceptor] a safety net almost because if you need help or you need a question answered you have someone right there." As one preceptor stated, "they [preceptee] do grow and they do need that resource [preceptor]. They just couldn't survive. It's essential they have somebody with them." Most preceptees regard their preceptors not as constant evaluators, much as clinical instructors are perceived, but rather as experienced peers, 
neutral individuals to whom they can turn to for guidance in answering questions, validating decisions and discussing ideas (Goldenberg, 1988). One preceptee indicated, "if I have a question and there's something I don't understand, why they did something, we'll talk about that." One preceptor described, "she [preceptee] comes to me if she has a question or she has a problem with her patient." Learning experiences are tailored to meet preceptees' individual learning needs and the one-to-one relationship provides for close supervision and immediate performance feedback (Bizek \& Oermann, 1990). Preceptees are thus enabled to develop their own role under the expert guidance of their preceptors.

Prioritizes. Organizational ability and priority setting are fundamental skills integral to all professionals and especially to all clinical practitioners such as nurses (Morrow, 1984). It is through such skills that the professional nurse circumvents inefficient and possibly dangerous approaches to problem-solving and clincial decisionmaking (Alfaro-LeFevre, 1995). Interestingly, one of the most common problems initially confronted by preceptors is their preceptees' inability to organize and complete their work in a timely fashion. As one preceptor commented, "it's not with the skills that she [preceptee] needs help. It's more with the organizing of everything so that she gets things done and doesn't forget the medications or the charting."

A major factor in preceptees' ability to organize their work is prioritization. Preceptees frequently have difficulty in defining what is important or what should be done first and why. In particular, at the beginning of their practice experience, preceptees must learn to decide which activities require action and which do not, or 
what is normal and what is abnormal (Morrow, 1984). As one preceptee explained, "my preceptor helps me to prioritize things. She says you have to think about what you're doing first." One of the preceptors stated, "I try to give a good example to get her to think about things that have to be done first and things that can wait." Periodic checks throughout the shift by preceptors help their preceptees stay on track. For example, one preceptor indicated, "throughout the day I check on her meds and check on the procedures that need to be done so they aren't missed." Or, as another stated, "I look at her little crib notes to see if she's doing what I'd be doing for that patient."

Preceptors who prioritize with their preceptees spend time with them at the beginning of the shift reviewing what is essential to do at the moment, what must be completed on schedule, what must be accomplished during the shift, and what would be nice to do but not essential to do (Morrow, 1982). This process assists preceptees to sort through the countless activities that must be completed and establishes a sense of order (Morrow, 1984; Predd, 1982). One preceptee said, "before we start the day she [preceptor] goes through the patient assignment with me and tells me special things that I should keep in mind and asks me if there are any questions." Another indicated, "we sit down in the morning and I write out my daily plan and she [preceptor] has a look at it and says yes that's great or oh remember this." One preceptor recounted:

The biggest thing is to prioritize, to know what things are important and what aren't. You sort of teach her [preceptee] to start with the ABC's. Tick off your pertinent things, get back to the nice fine things in about fifteen minutes down the road. That's very difficult because you have to teach them to stay focused. 
Okay, you can let go of some things but you have to complete your work, so while you're letting go you have to learn when not to let go. It's really fine tuned and it's reaily difficuit.

A useful technique used by preceptors who prioritize with their preceptees are those who take a few minutes at the end of the shift to review how things went, to discuss how their preceptees feel about the day, and to consider where their preceptees might want to go next or to change an approach (Morrow, 1982). One preceptee recalled:

We sit down and chart together and that's usually when we discuss what's going on. Or if there's something I'm concerned or curious about a patient, I'll catch her in the med room and we can go to the conference room and talk about it. Another recounted, "she [preceptor] just goes over my charting to make sure that it's complete. She'll read my charting and she'll say okay well did you do this, right well you have to chart that." One other precepteee stated, "I look at what she writes and she looks at what I write and then she goes over it if I need to remember to do something else."

By approaching preceptees with sensitivity and in a helping rather than a corrective manner, preceptors help them to examine the thinking behind their prioritization and in turn enhance their improvement (Morrow, 1982). If priorities appear misplaced, preceptors must determine their preceptees' perspective and rationale and give gentle rather than harsh feedback. Such an approach encourages preceptees to become both confident and competent in developing a plan that achieves safe and 
effective nursing care. One preceptee reflected, "I think I've accomplished my organizational goal because of my preceptor. She allows me to express myself." Figure 3 on page 154 depicts the subvariable categorized as incidental.

\section{Purposive}

Unlike incidental bringing about, purposive is intentional or deliberate. Preceptors question their preceptees' knowledge base, decision-making and actions, and in doing so directly bring about or trigger their critical thinking.

According to Hunkins (1974), "the question is central to learning" (p. 1). Since the Greek philosopher Socrates used a method of questioning to derive a definition, the question has been an integral component of the teaching-learning process and has come to be recognized as a powerful device in promoting thinking (Hunkins, 1989).

Questioning is fundamental to student learning. It not only enables students to elevate their level of thinking, but in the process it also enables them to deal intelligently with their world (Hunkins, 1974). The most widely renowned exemplar of teacher questioning is the dialogue of Socrates in "The Meno," in which he elicits the Pythagorean Theorem from an untutored slave boy (Scholdra \& Quiring, 1973). The implication of this dialogue is that the perceptive teacher who uses skilful questioning techniques can promote high levels of thinking in their students (Scholdra \& Quiring, 1973).

Questions can be utilized to direct the thinking process, provoke interest, stimulate and challenge the student, influence the social and emotional milieu of the teaching/learning environment, promote discussion, and evaluate learning (House, 
Chassie \& Spohn, 1990). The practice setting is an environment rich in opportunity for enabling critical thinking through the use of questions. Indeed, the preceptors are in a prime position to challenge the way their preceptees think, encourage them to justify or clarify their assertions, promote the generation of original ideas, explanations, or solutions to patient problems, provide mental and emotional tools to help resolve dilemmas, and provide a more personal environment with the one-to-one relationship (Conger \& Mezza, 1996).

While the act of questioning is significant, the level of question asked is also essential for the enabling of critical thinking. For example, it is essential that questioning include, not only low level or factual questions, but that clarifying and higher level questions be used also (Oermann, 1997). Factual level or low-level questions require that the preceptee recall specific information and facts. Higher level questions, on the other hand, cannot be answered by memory alone. They require evaluation or judgment of the clinical situation, and may require comparisons across patients or clinical situations (de Tornyay \& Thompson, 1987; Oermann, 1997). An understanding of the different level of questions can enable preceptors to better structure them from low to high, using factual questions to ascertain their preceptees' knowledge base and from there progress toward questions that require explanations, descriptions, evaluations and judgments about patient situations (Oermann, 1997).

Although there are numerous classification systems with regard to questions, nurse educators are most familiar with Bloom's Taxonomy of Educational Objectives (Bloom, 1956). This taxonomy delineates cognitive function in six areas: knowledge, 
comprehension, application, analysis, synthesis and evaluation. Categories are hierarchical because each level subsumes the use of the thinking processes of all lower levels. Moreover, the various levels of the taxonomy serve as building blocks (Hunkins, 1972). Because the top four categories require higher-order thinking skills, the hierarchy is usually divided into high (application, analysis, synthesis, and evaluation) and low (knowledge, and comprehension) cognitive levels (Wink, 1993).

Questions can also be classified as convergent or divergent (Wink, 1993). Convergent questions require low-level thinking. Responses are predictable and typically specific, succinct, and factual (House, Chassie \& Spohn, 1993). Convergent questions require the learner to answer yes or no, compare, contrast, define, specify, name or indicate relationships (House, Chassie \& Spohn, 1993). Divergent questions, on the other hand, are more thought provoking than convergent questions and necessitate a higher level of thinking. Answers to divergent questions are unpredictable and require the learner to "defend, hypothesize, infer, judge, justify choice, predict, reconstruct, and value" (House, Chassie \& Spohn, 1993, p. 196). As with Bloom's taxonomy, the difference between convergent and divergent questioning also addresses the category of questions according to a hierarchy of levels. For example the more complex the question, the higher the thinking level required. The context and the framing of the question signifies the level of thought processing required for appropriate student response (House, Chaissie \& Spohn, 1993).

Questions can also be derived from the perspective of a three tier hierarchy, each level requiring incrementally higher levels and complexity in thinking (House, 
Chassie \& Spohn, 1993). The three levels of questioning are described by Bowling (1979) as knowledge questioning, application questioning and problem-solving questioning. Knowledge questioning, the first level, requires memory or recall and is designed to obtain specific information or concrete responses that have right or wrong answers. Application questioning is the second level and requires students to use the information recalled at the knowledge level within a specific context. Problem-solving questioning is the third level of questioning and is designed to promote thinking at the highest mental capacity. All three levels of questioning can be appropriate with all students regardless of the learning setting (House, Chassie \& Spohn, 1993).

In the preceptorship experience, skilful questioning has many positive implications. For example, preceptees questioned by their preceptors must demonstrate what they know regarding their knowledge base, discuss their individual perspectives, and reflect on critical issues or personal values that they may not have examined previously. When questioned, they also must apply theoretical knowledge to patient situations and provide the rationale underlying their comprehension of circumstances inherent in the particular situations (Wink, 1993). As well, questioning provides the opportunity for preceptees to correct any misconceptions demonstrated by the question itself or by their own response to the question (Wink, 1993).

The ability to ask stimulating, challenging questions is perhaps the most important skill that a clinical nursing instructor or preceptor can display (Craig \& Page, 1981). At best, effective questioning can trigger preceptees to think critically and thus enhance their problem-solving and clinical decision-making abilities by 
stimulating the highest level of thought processing (House, Chassie, \& Spohn, 1990). When we think critically, we judge the correctness of statements and the soundness of the reasoning that leads to conclusions. Critical thinking assists preceptees to interpret complex ideas, assess and analyse information that is provided about individual patient situations, and distinguish between that which is reasonable and that which is unreasonable. Indeed, preceptees' problem-solving and clinical decision-making hinge directly on their ability to think critically (Ruggiero, 1990).

Theoretical knowledge is the medium that renders practice more efficient and more effective (Meleis, 1991). Being able to practice by scientific principles through a sound knowledge base permits preceptees the opportunity to be able to accurately determine the consequences of their nursing care and the potential range of patient responses. Theoretical knowledge provides them with a perspective with which to consider patient situations, and a way to organize, analyse, and interpret the information that they encounter (Raudonis, 1997). A theoretical knowledge base permits the preceptees to plan and implement care purposefully and proactively. When they practice purposefully and systematically, they are more efficient, have better control over the outcomes of their actions, and are better able to communicate to others (Raudonis, 1997). A sound knowledge base serves to guide the preceptees' clinical decision-making and their actions and ultimately ensures a foundation for safe and competent nursing care. Once they understand why a particular situation occurs, it becomes possible to identify what effect a specific action will have on the situation or conversely what actions will prevent the situation from arising in the first place (Dale, 
1994). Moreover, an understanding of the theory underlying a given situation results in preceptees being able to make informed decisions that result in purposeful actions.

Clinical decision-making and the ability to make a clinical judgment requires relevant knowledge for application to the clinical situation, skill in data collection, and knowledge of appropriate strategies for effective problem solving with patients (Reilly \& Oermann, 1992). Clinical decision making requires the ability to think critically. When preceptors question their preceptees, they directly bring about their critical thinking. For example, when confronted with questions concerning patient situations, if preceptees are to make effective clinical decisions, they must be able to recall relevant knowledge and in turn translate and interpret that knowledge in light of particular situations (Wink, 1993). Clinical decision-making requires an adequate knowledge base for analysing patient situations, generating possible alternatives, and making judgments as to which are the best alternatives to select (Reilly \& Oermann, 1992). The following excerpt reflects a preceptor questioning a preceptee's knowledge base regarding a particular patient situation:

If we have a cardiac patient, okay, what are the three main arteries, what is the problem, what can you anticipate? I want you to come back tomorrow and tell me what medications will work for this or not. If we have a trauma, okay, what are your $A B C$ 's? Tell me about the airway, the lungs, what do you see? So she tells me and I see how far her knowledge has come and then I try and expand on it or we research it together.

One preceptor stated, "I go through the Kardex with her and we talk about the 
diagnosis and I ask her what that entails and try to determine her knowledge of the situation." Questions that are well framed, timed and formulated not only stimulate critical thinking, but also enhance the breadth and depth of the answers and help preceptees to draw on and apply acquired knowledge in new and unique situations for the purpose of problem solving and making clinical decisions. Questions also trigger preceptees' ability to critically evaluate their own knowledge base, level of comprehension, ability to apply theoretical principles, accuracy of their assessments, and analysis of the data (Wink, 1993).

In the quest for effective clinical decision-making, preceptors' use of questioning assists their preceptees to ignore unnecessary and irrelevant information and to focus on cues that elucidate significant patterns in the overall situation (Wink, 1993). One preceptee recounted:

She [preceptor] cues me and things that I don't know she'll give me little points and if I can't answer she'll wait for me to put it together and if I can't she'll give me a little something else. She gives me little bits and pieces and allows me to put it together.

One preceptor, referring to a particular patient situation, described how she questioned her preceptee:

Okay, when is it [patient's condition] acutely urgent? And she [preceptee] stopped and thought. Okay, now you're assuming you see a man arriving with back pain and you see that he's got renal colic. Well, we walked through the process, for example when it's urgent it could be an aneurysm. You can't 
assume. You've seen this man, you've seen five patients with renal colic. You take his vital signs, his blood pressure is low. If he's got pain it usually increases. Stop and think about it. Don't assume that this patient has renal colic. He's grey, he's sweaty and he's got a low blood pressure. Change your opinion. Now tell me what else could we be working with here? When preceptors assist their preceptees to identify which cues lead them to draw a conclusion, the preceptees become more aware of their own thinking processes. This awareness in turn affords the preceptees the opportunity to be able to examine their approach to patient situations and thus become enabled and confident to make the necessary changes that are in the best interests of the patient. Preceptees thus become enabled to make clinical judgments based on effective decision-making and sound critical thinking. "To listen and question at just the right place and degree delimits the truly brilliant instructor from the average...Clearly, the questions a teacher asks can make the difference between an antiquated wasteland and an exciting learning

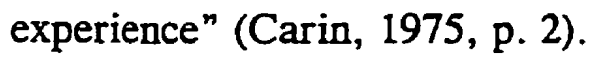

Preceptees must continually make decisions regarding nursing diagnoses and the course of action to be taken for their nursing care (Reilly \& Oermann, 1992). As preceptees interpret situations, they simultaneously analyse the data available to them for the purpose of developing nursing diagnoses and plans for action. By questioning their clinical decision-making, preceptors assist their preceptees to decide on the data that need to be collected about the patient, to make appropriate interpretations of the data, and to identify the necessary nursing actions that need to be taken in the situation 
(Reilly \& Oermann, 1992). One preceptor described it thus:

I've been doing that [questioning] with her [preceptee] all along. That's how I determine whether she knows the diagnosis and what that entails and what kind of nursing care that she's going to do for that type of patient. You have to have some idea of the diagnosis before you can determine what kind of nursing care they need. What does this mean? What do I have to do for this patient? When preceptors question their preceptees' decision-making, they assist them in eliciting aspects of the situation that are significant in identifying the problem, whether patient or setting oriented (Reilly \& Oermann, 1992). Because of their limited practical knowledge and relative inexperience in the practice setting, preceptees require this kind of assistance in identifying and delimiting patient problems. As one preceptor explained:

I will point out certain things like now look at A, B and C and tell me what you find or tell me what you think. And I like her [preceptee] to think things out. Like, why do you think we're looking at this? And she's pretty right on her answers. And if she's not, then by the time I've explained why, she can understand the rationale.

One preceptee reflected:

If I get a patient, I go do the history and I'll come back to her [preceptor] and she goes, 'okay well what do you think you know is going on with that person? What do you think you need to do?' And then I'll mention the things and she goes 'okay what's your first priority with that person?' With her asking me 
well what do you think, what do you think is priority, it gets me thinking not just sitting there. And you learn by thinking and problem-solving it on your own.

In affording preceptees the opportunity with which to discuss their clinical decisionmaking, preceptors again provide a means for them to assess the thought processes that they use to arrive at their decisions and to improve their understanding of the alternatives that they might have considered (Reilly \& Oermann, 1992). As one preceptor recounted:

I try to debrief any critical situations that occur and have them [preceptee] think through what they would have done had they been in charge of the situation. I always ask them what's the worst possible thing that could have happened in the situation because they're always terrified that they've done something wrong.

One preceptee stated:

We talk about the things you can do and it's not a this is what you do, these are the steps, but it's an interaction. It's a what would you do and why would you do it? It's almost like a puzzle. You fit it all together and you can have a holistic picture of what's going on. And that happens when she [preceptor] and I are interacting.

Ultimately, preceptees' knowledge base and decision-making are directed toward actions designed to provide competent nursing care. Creative problem-solving, sound decision-making, adeptness in coping with the unanticipated, and mastery of daily routine, are fundamental components of that nursing care (May, 1980). These 
factors contribute daily to the challenges which confront preceptees in ensuring actions that provide safe and efficient patient care. Inherently, preceptees' actions demand not only skill in performance, but also the ability to be able to continuously evaluate their own actions as they occur (Reilly \& Oermann, 1992). It requires critiquing their actions within the context of the goals they wish to achieve. As one preceptor indicated:

Every hour or so I'm saying have you done this, have you done that? Where are you with the care? That way I can determine her [preceptee] prioritizing. If something happens, I'll say to her so what would you do, or what do you want to do about that?

Another stated, "I try to step back and ask her to tell me about your [preceptee] patient. What should you be doing for the day. And if she's wrong well I'll just say well why would you do that?" Careful questioning and the one-to-one discussion with preceptees about their patient care are important factors in the enabling critical thinking (Oermann, 1997). Preceptors question their preceptees about their actions and the rationale underlying each action, alternatives contemplated, and different perspectives to ponder about their care. By questioning the preceptees' actions, preceptors not only spark intellectual curiosity, but promote recognition of inconsistencies in nursing care, and foster awareness of irregularities and differences between patient situations (Barnum, 1997). Preceptees thus become enabled to deal confidently and competently with the day-to-day complexities of nursing care. Figure 4 on page 155 depicts the subvariable categorized as purposive. 


\section{CHAPTER V}

\section{SUMMARY, CONCLUSIONS, CAUTIONS, IMPLICATIONS AND RECOMMENDATIONS}

\section{Summary \& Conclusions}

This study examined the process used in preceptorship to develop and promote the critical thinking ability of basic baccalaureate nursing students. The researcher's incentive for embarking on this study was motivated by a twofold concern: a) because preceptorship may be limited to promoting the socialization of nursing students to the idiosyncrasies of their assigned units, it may not be providing an appropriate medium for the development and promotion of critical thinking; and b) preceptorship may in fact be a modern day version of apprenticeship the modus operandi of which is the development and promotion of psychomotor skills frequently to the exclusion of critical thinking. As the data emerged, however, it was discovered that there is a process occurring in preceptorship to develop and promote the critical thinking ability of basic baccalaureate nursing students. The process is a multifaceted one labelled enabling.

The enabling process in preceptorship was determined to be an interpersonal or interactive process in which preceptors provide their preceptees with the opportunity or the means by which to develop and promote their critical thinking ability in the practice setting. This process was discovered to comprise two major components:

a) the climate; and b) bringing about. The climate may be described as the context in 
which the preceptorship experience takes place and is influenced by two factors, namely the preceptor and the staff. In discussing their preceptorship experiences, preceptees stressed the magnitude of the role that their preceptors play in the "making or breaking" of their clinical experience. They readily provided descriptions of those factors that they deem to be essential to a successful relationship that ultimately contribute to the development and promotion of their critical thinking ability in the practice setting. Similarly, preceptors provided their perspective regarding what they consider to constitute a successful learning experience and in doing so also revealed the characteristics which they deem to be important to that experience. Within this context then valuing, working with, and supporting emerged from the data as important behaviours manifested by the preceptors in their interactions with their preceptees and germane to the enabling process.

The staff in the practice setting and whether they accept preceptees as being a part of the team, was discovered also to have a significant effect on preceptees' experience and ability to think critically. While it was ascertained that preceptors are the primary influence on their preceptees' experience, others in the setting, from the nurse unit manager to the staff nurse, from the physician to the physiotherapist, from the housekeeper to the ward clerk, all impact on the overall climate in the practice setting and subsequently either enhance or impede preceptees' experience and affect their ability to be able to think critically.

The second major component of the enabling process is bringing about. This component may be described as that facet of the enabling process in which preceptors 
encourage their preceptees to pose questions, to examine problems, to consider various perspectives, and to pursue alternative ways of thinking about patient situations for the purpose of making clinical judgments (Reilly \& Oermann, 1992). This process occurs in one of two ways. It is: a) incidental; and/or b) purposive.

The term incidental describes that which occurs serendipitously or "by the way" (The Oxford Dictionary of Current English, 1992, p. 445), which in this case accurately reflects one part of the process that is occurring in preceptorship to bring about critical thinking. It was found that when the preceptors role model, facilitate, guide, and prioritize, they are not doing so with the express purpose of stimulating the critical thinking ability of their preceptees. Rather, critical thinking is being triggered fortuitously as a result of these behaviours.

Unlike incidental bringing about, purposive bringing about is intentional or deliberate. It was discovered that when the preceptors question their preceptees' knowledge base, decision-making and actions, they directly bring about or trigger their preceptees to think critically and thus enhance their problem-solving by stimulating their thought processing (House, Chassie, \& Spohn, 1990). Preceptees are thus assisted to interpret complex ideas, assess and analyse information about individual patient situations, distinguish between that which is reasonable and unreasonable and to become enabled to make a sound clinical judgment. The incidental and purposive bringing about were not found to be mutually exclusive in that preceptors bring about critical thinking by doing so incidentally and purposively or doing so incidentally or purposively. 
As the data emerged in this study, several interesting discoveries of particular significance to the process surfaced and are again worth highlighting. For example, a major factor in the development and promotion of critical thinking was found to be the climate. As so aptly stated by one of the preceptees when viewing the emergent conceptual framework, "without this [the climate], none of this [bringing about] can happen." A second discovery pertains to the bringing about component of the enabling process, which was found to be skewed more toward the incidental rather than the purposive realm of the process. In other words, it was found that preceptors are more likely to indirectly enable preceptees to think critically when they role model facilitate, guide and prioritize than they are to directly enable critical thinking through the use of questions about their knowledge base, decision-making and actions. This discovery is especially relevant to the future planning and implementation of preceptorship experiences for basic baccalaureate nursing students. It is also particularly salient for the role that nursing faculty assume in that experience to ensure the development and promotion of critical thinking.

A third interesting discovery was the fact that while preceptors ask higher level questions requiring evaluation or judgment of clinical situations, they tend to lean toward the use of lower level questions that require recall of specific information and facts on the part of the preceptee. Such a discovery has major implications for nursing education and ultimately for nursing practice. Although it is recognized that questioning is fundamental to student learning and the enabling of critical thinking, research studies indicate that teachers do not ask powerful or higher level questions 
(Hunkins, 1974). Nursing education has been found to be no exception to such a finding (Craig \& Page, 1981; Scholdra \& Quiring, 1973). Despite the fact that it is acknowledged by students and faculty alike that questioning is highly desirable for developing and promoting critical thinking, there is substantiated evidence that nursing instructors actually lack this particular skill (Craig \& Page, 1981). In this study, it was discovered that while preceptors do question their preceptees regarding their knowledge base, decision-making and actions, they tend to use lower level questions more frequently than they use higher level questions.

\section{Cautions}

At best, all research studies are beset with a variety of cautions, the most obvious being that of time, skill, money and creativity. Such constraints notwithstanding, this particular study was also predisposed to the potential disadvantages imposed by personal bias, analytical creativity and interview technique (Patridge, 1983).

The length of time during which this study was conducted may be perceived to be a limitation. Data were collected for a total of fourteen weeks. During this time the nursing students taking part in this study were assigned to a preceptorship experience in the practice setting. The preceptorship was the major component of two consecutive courses in the nursing program that comprised the nursing elective and the final clinical practicum. It is conceivable that the depth and richness of the data may have been unduly influenced by this limited time frame. The researcher's analytical creativity also may have posed a limitation to the depth and richness of the emergent conceptual 
framework (Glaser, 1978; Patridge, 1983).

Throughout the research process, personal bias is always a potential overriding factor from the identification of the problem to the finalization of the study. In grounded theory, protection against bias is afforded by the process of delaying hypotheses generation until data collection is well established (Patridge, 1983), an approach to data collection referred to as "theoretical sensitivity" (Glaser, 1978). Theoretical sensitivity is fostered by entering "the setting with as few predetermined ideas as possible...especially logically deducted prior hypotheses" (Glaser, 1978, p. 3). Personal bias, however, is not relinquished by merely espousing an open-minded inductive approach. It is essential that the researcher be cautious throughout the entire research process in order to circumvent unfounded notions from unnecessarily biasing the emerging theory (Patridge, 1983).

Finally, reliance on the interview as the primary data source potentially may have posed serious constraints and bias. It is recognized that interviewees may provide information that they perceive the interviewer wishes to hear (Field \& Morse, 1985; Patridge, 1987). In light of this possibility, the researcher took considerable care to ensure that the interviews were conducted in a neutral manner so that any personal biases, anticipated responses, or any other semblance of influence were not disclosed.

\section{Implications}

In light of the findings of this study, there are several major implications that have come to light:

1. Intrinsic to the enabling process is a climate that is conducive to the 
development and promotion of critical thinking. While the preceptor is integral to that climate and of primary significance to the success of the preceptorship experience, so too is staff acceptance of the preceptee fundamental. Although extrinsic to the preceptorship relationship, staff acceptance impacts directly upon the development and promotion of the preceptee's ability to think critically in the practice setting. Extant extrinsic factors such as staff acceptance, therefore, have major implications for the planning and implementation of the preceptorship experience. Such a finding connotes that setting selection should not be limited to appropriateness of available experiences, but rather it should also encompass a mechanism to determine staff receptivity to student placements.

2. Preceptor behaviours such as role modelling, facilitating, guiding and prioritizing serve indirectly to trigger the critical thinking ability of basic baccalaureate nursing students in the practice setting. To a lesser extent, preceptees' critical thinking ability is sparked directly when their preceptors question their knowledge base, decision-making, and actions. From this discovery then, it can be assumed that critical thinking is being developed and promoted in the preceptorship experience, albeit primarily by chance or serendiptiously as a result of preceptor behaviours. This finding connotes significant questions for nursing faculty. If it is assumed that baccalaureate nursing education is promoting critical thinking, then is it sufficient to leave it to chance in the preceptorship experience or is it more appropriate that it be enabled directly? In case of the latter, then are there mechanisms that can be instituted to provide ongoing support for preceptors in their endeavour to directly enable the 
critical thinking ability of nursing students while under their tutelage? How can nursing faculty contribute to this support?

3. In this study, preceptors tended to ask lower level questions more frequently than higher level questions. In light of the fact that higher level thinking is a desired outcome of the basic baccalaureate nursing program, and considering the tendency toward lower level questioning in the preceptorship experience, are preceptors who ask lower level questions justified in expecting preceptees to develop higher level thinking such as those involved in the processes of analysing, synthesizing and evaluating (Scholdra \& Quiring, 1973)? What is the significance of this factor on student evaluation and program objectives/outcomes? How active a role should faculty assume in this regard? Do faculty have a role to play and how best can it be operationlized?

\section{Recommendations}

Based on the findings in this study, the following recommendations are proposed:

1. Serious consideration must be given to the development of routine assessment or appraisal of the individual nursing units to which students are assigned. Such an assessment would include, but would not be limited to, the determination of relevant clinical experiences available for achievement of student and/or course objectives. It would also entail careful consideration and/or scrutiny concerning staff receptivity to student placements. As well, continuous monitoring of the experience by faculty through regular meetings with preceptors, students and staff in the practice setting is suggested. Such an arrangement not only would provide knowledge of the 
preceptorship relationship, but would also afford the faculty a firsthand impression of staff and student interaction.

2. Faculty should direct attention to careful examination of the dynamics of questioning and actively seek ways to improve questioning techniques. While researching the process used in preceptorship to develop and promote critical thinking, the significance of questioning as a clinical teaching skill emerged. Effective use of questioning can assist preceptees to apply new and acquired knowledge in unique situations. The formation and answering of questions help guide the learning process. Although studies of faculty evaluation in nursing have consistently acknowledged questioning as a desirable instructor behaviour, investigations of actual faculty behaviour have revealed a general lack of questioning skills (Craig \& Page, 1981). In this study, it was discovered that while preceptors question their preceptees about their knowledge base, decision-making and actions, they tend to do so with lower level questions. In the enabling of critical thinking, it is important to ensure that preceptor questions include not only lower but also higher level questions, particularly if preceptees are being expected to develop higher level thinking that involves the processes of analysing, synthesizing and evaluating.

3. Faculty need to assume a more active role in the implementation of the preceptorship experience. The concept of precepting preceptors is a timely one. Because the findings in this study reflect the notion that preceptors are more likely to enable critical thinking incidentally rather than purposively, it would be prudent on the part of faculty to spend some quality time with preceptors themselves. This would 
permit faculty the occasion to provide preceptors with information about the significance of questioning their preceptees, the types and levels of questions that are possible, and the ways in which such questions can be used more efficiently and effectively so that preceptees may develop higher level thinking ability. Owing to their lack of teaching experience, the opportunity for preceptors to spend time in a one-toone relationship with an experienced teacher would provide role modelling, role socialization and would facilitate role transition from staff nurse to nurse preceptor. Working with preceptors in this manner would also foster a closer working relationship between nursing education and nursing practice, thus bridging the perceived gap between the two. Ultimately, such an arrangement could only serve to benefit nursing students and the profession in general.

4. Additional research should be carried out to examine the dynamic of critical thinking in nursing education. Given the expectation that faculty promote the use of critical thinking, then the following questions are posed: a) how do nursing faculty articulate their understanding of critical thinking; b) what strategies can faculty identify that assist them in promoting and using critical thinking in their teaching;

c) how can nursing faculty demonstrate effective leadership in promoting the use of critical thinking particularly with respect to the practice experience; d) what mechanisms are in place to assess the extent to which faculty promote the use of critical thinking with their students; e) are there specific strategies that facilitate faculty in teaching students to think critically (The Center and Foundation for Critical Thinking, 1998)? 
5. Further research needs to be conducted to examine preceptorship, not only in baccalaureate nursing education but also within the context of graduate nursing education and other practice disciplines as well.

In conclusion, theory generation is essential for the development of a much needed theoretical base for clinical teaching in nursing education. This study provides a systematic, legitimate theory that reflects the richness of the preceptorship experience. It has generated a plausible theory that can be used to understand the contextual reality of the preceptorship relationship and how that relationship enables the critical thinking ability of basic baccalaureate nursing students in the practice setting.

The process of enabling that has emerged provides a framework with which to strengthen preceptorship as a teaching/learning experience. As a result of the findings in this study, it has become evident to the researcher that the role of nursing faculty cannot continue to remain on the periphery of clinical teaching, much as it has been over the past decade. The teaching expertise of nursing faculty is indispensable to the success of student learning, not only in the classroom but in the practice setting as well. In assuming a more active role in the implementation of preceptorship, nursing faculty can monitor the development and promotion of the critical thinking ability of nursing students while they are under the tutelage of preceptors. In assuming a more active role, nursing faculty can provide preceptors with the benefit of their expertise to ensure the more frequent use of appropriate strategies that directly enable the critical thinking ability of basic baccalaureate nursing students as they carry out their nursing care. 


\section{REFERENCES}

Abegglen, J., \& O'Neill Conger, C. (1997). Critical thinking in nursing: Classroom tactics that work. Journal of Nursing Education. 36(10), 452-458.

Allen, L. R. (1992). Review of research in nursing education. Volume v. National League for Nursing. New York, NY: National League for Nursing.

Alfaro-LeFevre, R. (1995). Critical thinking in nursing. A practical approach. W. B. Saunders: Philadelphia, PA.

Anderson, S. L. (1991). Does student preceptorship affect moral reasoning? Nurse Educator, 16(3), 14-17.

Armitage, P., Champney-Smith, J., \& Andrews, K. (1991). Primary nursing and the role of the nurse preceptor in changing long-term mental health care: an evaluation. Journal of Advanced Nursing, 16, 413-422.

Backenstose, A. G. (1983). The use of clinical preceptors. In S. Stuart-Siddall and A. Haberlin (Eds.). Preceptorship in nursing education. Rockville, MD: Aspen.

Baker, C., Wuest, J., \& Stern, P. N. (1992). Method slurring: The grounded theory/phenomenology example. Journal of Advanced Nursing 17, 1355-1360.

Barrett, C., \& Myrick, F. (1998). Job satisfaction in preceptorship and its effect on the clinical performance of the preceptee. Journal of Advanced Nursing. 27 , 364-371.

Bauwens, E., \& Gerhard, G. (1987). The use of the Watson-Glaser Critical Thinking Appraisal to predict success in a baccalaureate nursing program. Journal of Nursing Education, 26(7), 278-282.

Bechtel, G. A., Smith, J. N., Printz, V., \& Gronseth, D. (1993). Critical thinking and clinical judgment of professional nurses in a career mobility program. Journal of Nursing Staff Development. 9, 218-222.

Beckett, C., \& Wall, M. (1985). Role of the clinical facilitator. Nurse Educator Today, 5, 259-262.

Behrens, P. J. The Watson-Glaser Critical Thinking Appraisal and academic performance of diploma school students. Journal of Nursing Education, 35(1), 32-36. 
Beidler, P. E. (1981). Distinguished teachers on effective teaching. New directions for teaching and learning (ed.). No. 28. San Francisco: Jossey-Bass.

Benner, P. (1984). From novice to expert. Excellence and power in clinical practice. Don Mills, ON: Addison-Wesley.

Berger, M. (1984). Critical thinking ability and nursing students. Journal of Nursing Education, 23, 306-308.

Bergerson, C. T. (1983). What preceptoring is (pp. 89-95). In S. StuartSiddall and J. M. Haberlin (Eds.). Rockville, MD: Aspen.

Bethune, E., \& Jackling, N. (1997). Critical thinking skills: The role of prior experience. Journal of Advanced Nursing, 26, 1005-1012.

Betz, C. (1985). Students in transition: Imitators of role models. Journal of Nursing Education, 24(7), 301-303.

Bidwell, A. S., \& Brassler, M. L. (1989). Role modelling versus mentoring in nursing education. IMAGE: Journal of Nursing Scholarship. 21(1), 23-25.

Bisek, K., \& Oermann, M. (1990). Study of educational experiences, support, and job satisfaction among critical care nurse preceptors. Heart \& Lung, 19(5), 439444.

Blumer, H. (1969). Symbolic interactionism: Perspectives and method. Englewood Cliffs, NJ: Prentice-Hall.

Bowers, B. J. (1988). Grounded theory. In B. Sarter (Ed). Paths to knowledge. Innovative research methods for nursing (pp. 33-57). New York, NY. NLN.

Bowles, N. (1995). A critical appraisal of preceptorship. Nursing Standard, 2(45), 25-28.

Brasler, E. M. (1993). Predictors of clinical performance of new graduate nurses participating in preceptor orientation programs. Journal of Nursing Education. 24(4), 158-165.

Burnard, P. (1992). Facilitating learning. Part (ii). The process of facilitation. Nursing Times, $88(6)$, i-viii. 
Burrows, D. E. (1997). Facilitation: A concept analysis. Journal of Advanced Nursing. 25, 396-404.

Brookfield, S. D. (1986). The facilitator's role in adult iearning (pp. 123-165). Understanding and facilitating adult learning: A comprehensive analysis of principles and effective practices. San Francisco: Jossey-Bass.

Brookfield, S. D. (1987). Developing critical thinkers. Challenging adults to explore alternative ways of thinking and acting. San Francisco: Jossey-Bass.

Brookfield, S. D. (1995). Becoming a critically reflective teacher. San Francisco: Jossey-Bass.

Brooks, K., \& Shepherd, J. (1990). the relationship between clinical decisionmaking skills in nursing and general critical thinking abilities of senior nursing students in four types of nursing programs. Journal of Nursing Education. 29(9), 391-399.

Brooks, K., \& Shepherd, J. (1992). Professionalism versus general critical thinking abilities of senior nursing students in four types of nursing curricula. Journal of Professional Nursing. 8(2), 87-95.

Brown, N. N., \& Keeley, S. M. (1994). Asking the right questions. A guide to critical thinking (4th ed.). Englewood Cliffs, NJ: Prentice-Hall.

Burns, N., \& Grove, S. K. (1987). The practice of nursing research. Conduct. critique and utilization. Philadelphia, PA: W. B. Saunders.

Cairn, A. A. (1975). Teaching science through discovery (3rd ed.). Columbus OH: Charles E. Mernell.

Callahan, S. M. (1992). Thinking skills - An assessment model for ADN in the 90's. Journal of Nursing Education, 31(2), 85-87.

Chenitz, W. C. (1986). Qualitative research using grounded theory. In W. C. Chenitz and J. M. Swanson (Eds.). From practice to grounded theory (pp. 3-15). Menlo Park, CA: Addison-Wesley.

Chickerella, B. G., \& Lutz, W. J. (1981). Professional nurturance: preceptorship for undergraduate nursing. American Journal of Nursing. 81(1), 107109. 
Clayton, G., Broome, M., \& Ellis, L. (1989). Relationship between a preceptorship experience and role socialization of graduate nurses. Journal of Nursing Education. 28(2), 72-75.

Coates, V. E., \& Gormley, E. (1997). Learning the practice of nursing: Views about preceptorship. Nurse Education Today, 17, 91-98.

Cook, T. D., \& Campbell, d. T. (1979). Quasi-experimental: design and analysis issues for field studies. Chicago: Rand McNally.

Concise Oxford Dictionary (1982) (7th ed.). Oxford University Press.

Conger, M. M., \& Mezza, I. (1996). Fostering critical thinking in nursing students in the clinical setting. Nurse Educator, 21(3), 11-15.

Craig, J. L. \& Page, G. (1981). The questioning skills of nursing instructors. Journal of Nursing Education, 20(5), 18-23.

The Center and Foundation for Critical Thinking (1998). Critical Thinking. Events and Resources Catalog. 2, 1-15.

Dale, A. E. (1994). The theory-theory gap: The challenge for nurse teachers. Journal of Advanced Nursing, 20, 521-524.

Daloz, L. (1986). Effective teaching and mentoring: Realizing the transformational power of adult learning experiences. San Francisco: Jossey-Bass.

Davis, E. (1993). Clinical role modelling: Uncovering hidden knowledge. Journal of Advanced Nursing, 18, 627-636.

de Tornyay, R., \& Thompson, M. A. (1982). Strategies for teaching nursing (2nd ed.). New York, NY: John Wiley \& Sons.

de Tornyay, R., \& Thompson, M. A. (1987). Strategies for teaching nursing (3rd ed.). New York, NY: John Wiley \& Sons.

Dobbs, K. (1988). The senior preceptorship as a method for anticipatory socialization of baccalaureate nursing students. Journal of Nursing Education, 27(4), 167-171.

Donovan, J. (1995). The process of analysis during a grounded theory study of men during their partners' pregnancies. Journal of Advanced Nursing, 21, 708-715. 
Ennis, R. H. (1987). Critical thinking and subject specificity. Clarification and needs research. Educational Researcher, 18(30), 4-10.

Estey, H., \& Ferguson, F. (1985). A process of role transition: Nursing students in a clinical preceptorship. RNABC News, 17(4), 25-27.

Farnkopf, F. T. (1983). Criteria for evaluating a clinical setting for a preceptor (pp. 157-164). In S. Stuart-Siddall and J. M. Haberlin. Preceptorships in nursing education. Rockville, MD: Aspen.

Ferguson, L., M., \& Calder, B. L. (1993). A comparison of preceptor and educator valuing of nursing student clinical performance. Journal of Nursing Education, 32(1), 30-36.

Field, P. A., \& Morse, J. M. (1985). Nursing research. the application of qualitative approaches. Rockville, MD: Aspen.

Flynn, J. P. (1997). The role of the preceptor. A guide for nurse educators (Ed.). New York, NY: Springer.

Friere, P. (1997). Pedagogy of the oppressed (New revised 20th-anniversary ed.). New York, NY: Continuum.

Friesen, L, \& Conahan, B. J. (1980). A clinical preceptor program: Strategy for new graduate orientation. Journal of Nursing Administration, 10(4), 18-23.

Gazda, G. M., Childers, W. C., \& Walters, R. P. (1982). Interpersonal communication. A handbook for health professionals. Rockville, MD: Aspen.

Glaser, B. G., \& Strauss, A. L. (1985). The discovery of grounded theory: Strategies for qualitative research. New York: Aldine de Gruyter.

Glaser, B. G. (1978). Theoretical sensitivity. Advances in the methodology of grounded theory. Mill Valley, CA: Sociology Press.

Glaser, B. G. (1992). Basics of grounded theory analysis. Mill Valley, CA: Sociology Press.

Glen, S. (1995). Developing critical thinking in higher education. Nurse Education Today. 15(3), 170-176.

Goldenberg, D. (1988). Preceptorship: A one-to-one relationship with a triple "p" rating (preceptor, preceptee, patient). Nursing Forum. 23(1), 10-15. 
Goldenberg, D., \& Iwasiw, C. (1993). Professional socialisation of nursing students as an outcome of a senior clinical preceptorship experience. Nurse Education Today, 15, 3-15.

Greipp, M., Shitson, s., Gehring, L., \& McGinley, M. (1989). an innovative approach to orientation: Faculty preceptors. Journal of Nursing Staff Development. 5(6), 269-272.

Gross, Y. T., Takazawa, E. S., \& Rose, C. L. (1987). Critical thinking and nursing education. Journal of Nursing Education, 26(8), 317-323.

Guba, E. G., \& Lincoln, Y. S., (1989). Fourth generation evaluation. Newbury Park, CA: Sage.

Haffer, A. G., \& Raingruber, B. J. (1998). Discovering confidence in clinical reasoning and critical thinking development in baccalaureate nursing students. Journal of Nursing Education, 37(2), 61-70.

Hardy, L. (1990). The path to nursing knowledge - personal reflections. Nurse Education Today, 10(5), 325-332.

Hartley, D., \& Aukamp, V. (1994). Critical thinking ability of nurse educators and nursing students. Journal of Nursing Education, 33(1), 34-35.

Hedin, B. A., \& Donovan, J. (1989). A feminist perspective on nursing education. Nurse Educator, 14(4), 8-13.

Heidegger, M. (1968). What is called thinking? (J. Glenn Gray, trans.). New York, NY: Harper. (Original work published 1954).

Helmuth, M. R., \& Guberski, T. D. (1980). Preparation for preceptor role. Nursing Outlook, 28(1), 36-39.

House, B. M., Chassie, M. B., \& Spohn, B. B. (1990). Questioning: An essential ingredient in effective teaching. Journal of Continuing Education in Nursing 21(5), 196-201.

Howie, J. (1988). The effective clinical teacher: A role model. Australian Journal of Advanced Nursing. 5(2), 23-26. 
Hsieh, N. L., \& Knowles, D. W. (1990). Instructor facilitation of the preceptorship relationship in nursing education. Journal of Nursing Education. 29(6), 262-268.

Huber, M. L. (1981). The effect of preceptorship and internship orientation programs on graduate nurse performance. Unpublished doctoral dissertation. Wayne State University, Detroit.

Hueston, M. (1995). Preceptors' perceptions of the preceptor/student relationship. Unpublished master's thesis. Dalhousie University, Halifax, NS.

Hunkins, F. P. (1974). Questioning strategies and techniques. Boston, MA: Allyn and Bacon.

Hunkins, F. P. (1989). Teaching thinking through effective questioning. Boston, MA: Christopher-Gordon.

Hutchinson, S. (1993). Grounded theory: The method (pp. 180-212). In P. L. Munhall and C. O. Boyd. Nursing research. A qualitative perspective. New York, NY: National League for Nursing Press.

Illanach, B. C., \& Mowinski, B. (1990). Evaluating the effects of a nurse preceptorship programme. Journal of Advanced Nursing, 15, 22-28.

Infante, M., Forbes, E., Houldin, A., \& Nayler, M. (1989). A clinical teaching project: Examination of a clinical teaching model. Journal of Professional Nursing . 5(3), 132-139.

Itano, J., Warren, J., \& Ishida, B. (1987). A comparison of role conceptions and role deprivation of baccalaureate students in nursing participating in a preceptorship or traditional clinical program. Journal of Nursing Education.26(2), 6972.

Jacobs, P. M., Ott, B., Sullivan, B., Ulrich, Y., \& Short, L. (1997). An approach to defining and operationalizing critical thinking. Journal of Nursing Education, 36(1), 19-22.

Jairath, N., Costello, J., Wallace, P., \& Rudy, L. (1991). the effect of preceptorship upon diploma program nursing students' transition to the professional nursing role. Journal of Nursing Education, 30(6), 251-255.

Jones, S. A., \& Brown, L. N. (1991). Critical thinking: Impact on nursing education. Journal of Advanced Nursing, 16, 529-533. 
Jones, S. A., \& Brown, L. N. (1993). Alternative views on defining critical thinking through the nursing process. Holistic Nurse Practitioner. 7(3), 71-76.

Karuhije, H. F. (1986). Educational preparation for clinical teaching: Perceptions of the nurse educator. Journal of Nursing Education. 25(4), 137-143.

Kemper, T. D. (1968). Reference groups, socialisation and achievement. American Social Review, 33, 31-34.

Ketefian, S. (1981). Moral reasoning and moral behaviour among selected groups of practising nurses. Nursing Research. 30(3), 171-176.

Kirk, J., \& Miller, L. A. (1986). Reliability and validity in qualitative research. Newbury Park, CA: Sage.

Kintgen-Andrews, J. (1991). Critical thinking and nursing education: Perplexities and insights. Journal of Nursing Education, 30(4), 152-157.

Kolb, D. A., Wolfe, D., Fry, R., Bushe, G., Gish, G., Griggs, W., Gypen, J., Manring, S., \& Sims, R. (1981). Professional education and career development: A cross-sectional study of adaptive competencies in experiential learning. Life Long Learning Project, Final Report. Cleveland, OH: Case Western Reserve University.

Kolb, D. A. (1984). Experiential learning: Experience as the source of learning and development. Englewood Cliffs, NJ: Prentice Hall.

Knauss, P. (1980). Staff nurse preceptorship: An experiment for graduate nurse orientation. Journal of Continuing Education in Nursing. 11(5), 44-46.

Knowles, M. S. (1988). The modern practice of adult education: From pedagogy to andragogy. Chicago: Follett.

Kyung, R. S. (1998). Critical thinking ability and clinical decision-making skills among senior nursing students in associate and baccalaureate programmes in Korea. Journal of Advanced Nursing, 27, 414-418.

Laschinger, H. K. S., \& McMaster, E. (1992). Effect of pregraduate preceptorship experience on development of adaptive competencies of baccalaureate nursing students. Journal of Nursing Education. 31(6), 258-264. 18-19.

Lewis, K. E. (1986). What it takes to be a preceptor. Canadian Nurse, 82(11), 
Lewis, J. B., \& Eakes, G. G. (1992). The AIDS care dilemma: An exercise in critical thinking. Journal of Nursing Education. 31(3), 146-137.

Maes, J. B. (1983). The challenge of being a preceptor (pp. 103-112). In S. Stuart-Siddell and J. M. Haberlin. Preceptorship in nursing education. Rockville, MD: Aspen.

Malek, C. J. (1986). A model for teaching critical thinking. Nurse Educator. 11(6), 20-23.

Manley, M. J. (1997). Adult learning concepts important to precepting (pp. 1547). In J. P. Flynn (Ed.). The role of the preceptor. A guide for nurse educators and clinicians. New York, NY: Springer.

Marchette, L. (1984). the effect of a nurse internship program on novice nurses' self-perception of clinical performance. Journal of Nursing Administration. 15(5), 6-7.

Martin, G. P. (1983). Using nursing preceptorships as a method of orientation of nursing staff to a hospital setting. Vancouver, BC. University of British Columbia.

May, L. (1980). Clinical preceptors for new nurses. American Journal of Nursing, 9 , 1824-1826.

Maynard, C. A. (1996). Relationship of critical thinking ability to professional nursing competence. Journal of Nursing Education. 35(1), 12-18.

McGovern, M. (1997). Promoting the cognitive development of freshman nursing students. Journal of Nursing Education, 31(1), 29-35.

McGrath, B., \& Koewing, J. (1978). A clinical preceptorship for new graduate nurses. Journal of Nursing Administration, 4(3), 12-18.

McMillan, J. (1987). enhancing college students' critical thinking: A review of studies. Research in Higher Education, 26(1), 3-29.

Meleis, A. (1991). Theoretical nursing development and progress (2nd ed.). Philadelphia, PA: J. B. Lippincott.

Meyers, C. (1986). Teaching students to think critically. San Francisco: Jossey-Bass. 
Mezirow, J. (1990). Fostering critical reflection in adulthood: A quide to transformative and emancipatory learning. San Francisco: Jossey-Bass.

Morgan, J., \& Knox, J. (1987). Characteristics of "best" and "worst" clinical teachers as perceived by university nursing faculty and students. Journal of Advanced Nursing. 12, 331-337.

Miller, M. A., \& Malcolm, N. S. (1990). Critical thinking in the nursing curriculum. Nursing \& Health Care, 11, 67-73.

Morrow, K. L. (1984). Preceptorships in nursing staff development. Rockville, MD: Aspen.

Mullen, P. D. (1975). Cutting back: Life after a heart attack. Unpublished doctoral dissertation. Berkeley, CA: University of California.

Myrick, F. (1986). The effect of preceptorship on the clinical competency of baccalaureate student nurses. Unpublished Masters' Thesis. The University of Western Ontario. London, ON.

Myrick, F. (1988). Preceptorship: A viable alternative clinical teaching strategy? Journal of Advanced Nursing, 13, 588-591.

Myrick, F., \& Awry, J. (1988). The effect of preceptorship on the clinical competency of baccalaureate student nurses: A pilot study. Canadian Journal of Nursing Research, 20(3), 29-43.

Myrick, F., \& Barrett, C. (1992). Preceptor selection criteria in Canadian basic baccalaureate schools of nursing - A survey. Canadian Journal of Nursing Research, 24(3), 53-68.

Nehls, N., Rather, M., \& Guyette, M. (1997). the preceptor model of clinical instruction: The lived experiences of students, preceptors, and faculty-of-record. Journal of Nursing Education, 36(5), 220-227.

Nouwen, H. (1966). Reaching out. New York, NY: Doubleday.

Oermann, M. H. (1994). Reforming nursing education for future practice. Journal of Nursing Education, 33(5), 215-219.

Oermann, M. H. (1997). Evaluating critical thinking in clinical practice. Nurse Educator. 22(5), 25-28. 
Olson, R. K., Gresley, R. S., \& Heater, B. (1984). The effects of an undergraduate clinical internship on the self-concept and role mastery of baccalaureate nursing students. Journal of Nursing Education. 23(3), 105-108.

O'Mara, A. M. (1997). A model preceptor program for student nurses (pp. 4775). In J. P. Flynn (Ed.). The role of the preceptor. A quide for nurse educators and clinicians. New York, NY: Springer.

Ouellet, L. L. (1993). Relationship of a preceptorship experience to the views about nursing as a profession of baccalaureate nursing students. Nurse Education Today, 13, 16-23.

Palmer, I. (1983). From whence we came. In N. L. Chaska (Ed.). The nursing profession: A time to speak. New York, NY: McGraw-Hill.

Pardue, S. F. (1987). Decision-making skills and critical thinking ability among associate degree, diploma, baccalaureate, and master's prepared nurses. Journal of Nursing Education, 26(9), 354-361.

Parsons, R., MacLean, J., Butcher, P., \& Shamian, J. (1985). The staff nurse as peer educator. Canadian Nurse, 19-20.

Patridge, R. (1983). Post-licensure baccalaureate education for registered nurses. Unpublished doctoral dissertation. Berkeley, CA: University of California.

Paul, R. (1993). Critical thinking. What every person needs to survive in a rapidly changing world. Santa Rosa, CA: The Foundation for Critical Thinking.

Pearsall, M. (1965). Participant observation as role and method in behavioural research. Nursing Research, 14(1), 37-42.

Peirce, A. G. (1991). Preceptorial students' view of their clinical experience. Journal of Nursing Education, 30(6), 244-250.

Pepa, C. A., Brown, J. M., \& Alverson, E. M. (1997). A comparison of critical thinking abilities between accelerated and traditional baccalaureate nursing students. Journal of Nursing Education, 36(1), 46-48.

Perciful, E. G., \& Nester, P. A. (1996). The effect of an innovative clinical teaching method on nursing students' knowledge and critical thinking skills. Journal of Nursing Education, 35(1), 23-28. 
Powell, S. (1987). Improving critical thinking. Educational Psychology, 7(3), 169-185.

Predd, C. (1982). How to stay efficient in hectic nursing situations. Nursing Life, 50-51.

Profetto-McGrath, J., \& Myrick, F. (1996). Critical thinking - A concept analysis. Unpublished Manuscript.

Rittman, M. R., \& Osburn, J. (1995). An interpretive analysis of precepting an unsafe student. Journal of Nursing Education, 34(5), 217-221.

Raudonis, B. M. (1997). Theory-based nursing practice. Journal of Advanced Nursing, 26, 138-145.

Reilly, D. E., \& Oermann, M. H. (1992). Clinical teaching in nursing education (2nd ed.). New York, NY: National League for Nursing.

Retsas, A., \& Wilson, J. (1996). The critical thinking abilities of RNs entering university courses. Australian Journal of Advanced Nursing, 13(3), 27-34.

Rittman, M. R., \& Osburn, J. (1995). An interpretive analysis of precepting an unsafe student. Journal of Nursing Education, 34(5), 217-221.

Rogers, C. (1980). A way of being. Boston: Houghton Mifflin.

Rogers, C. (1983). Freedom to learn for the 80's. Columbus: Bell \& Howell.

Rossignol, M. (1998). Relationship between selected discourse strategies and student critical thinking. Journal of Nursing Education, 36(10), 467-475.

Ruggiero, V. R. (1990). Beyond feelings. A guide to critical thinking (3rd ed.). Toronto: Mayfield.

Saarmann, L., Freitas, L., Rapps, J., \& Riegel, B. (1992). The relationship of education to critical thinking ability and values among nurses: Socialization into professional nursing. Journal of Professional Nursing. 8(1), 25-34.

Sandelowski, M. (1995). Focus on qualitative methods. Sample size in qualitative research. Research in Nursing \& Health, 18, 179-183.

Schatzman, L, \& Strauss, A. L. Field research. Englewood Cliffs, NJ: Prentice-Hall. 
Scheetz, L. (1989). Baccalaureate nursing student preceptorship programs and the development of clinical competence. Journal of Nursing Education, 28(1), 29-35.

Scholdra, J. D., \& Quiring, J. D. (1973). The level of questions posed by nurse educators. Journal of Nursing Education, 12(3), 15-20.

Schwirian, P. M. (1978). Evaluating the performance of nurses. A multidimensional approach. Nursing Research. 27(6), 347-351.

Sedlak, C. A. (1997). Critical thinking of beginning baccalaureate nursing students during the first clinical course. Journal of Nursing Education, 36(1), 11-18.

Shamian, J., \& Lemieux, S. (1984). An evaluation of the preceptor model versus the formal teaching model. Journal of Continuing Education in Nursing. 15(3), 86-89.

Shamian, J., \& Lemieux, S. (1985). The concept and practice of preceptorship in contemporary nursing. A review of the literature. International Journal of Nursing Studies, 22(2), 79-88.

Siegel, H. (1980). Critical thinking as an educational ideal. The Educational Forum, XLV(1), 7-23.

Spence Laschinger, H. K., \& MacMaster, E. (1992). Effect of pregraduate preceptorship experience on development of adaptive competencies of baccalaureate nursing students. Journal of Nursing Education, 31(6), 258-264.

Spradley, J. P. (1979). The ethnographic interview. Philadelphia, PA: Holt, Rinehart and Winston, Inc.

Spradley, J. P. (1980). Participant observation. Philadelphia, PA: Harcourt Brace Jovanovich.

Stern, P. N. (1976). Integrative discipline in stepfather families. Unpublished doctoral dissertation. San Francisco, CA: University of California.

Stern, P. N. (1980). Grounded theory methodology: Its uses and processes. IMAGE: The Journal of Nursing Scholarship 12(1), 20-30.

Stern, P. N. (1985). Using grounded theory method in nursing research. In M. Leininger (Ed.). Qualitative research methods in nursing (pp. 149-160). Orlando, FL: Grune and Stratton. 
Stevenson, B., Doorley, J., Moddeman, G., \& Benson-Landau, M. (1995). The preceptor experience. A qualitative study of perceptions of nurse preceptors regarding the preceptor role. Journal of Nursing Staff Development. 11(3), 160-165.

Strauss, A., \& Corbin, J. (1994). Basics of qualitative research: Grounded theory, procedures and techniques. Newbury, CA: Sage.

Sullivan, E. (1987). Critical thinking, creativity, clinical performance, and achievements in RN students. Nurse Educator, 12(2), 12-16.

Tiessen, J. B. (1987). Critical thinking and selected correlates among baccalaureate nursing students. Journal of Professional Nursing. 3(2), 118-123.

Vaughan-Wrobel, B. C., Sullivan, P., \& Smith, L. (1997). Evaluating critical thinking skills of baccalaureate nursing students. Journal of Nursing Education. $\underline{36}(10), 485-488$.

Videbeck, S. L. (1997). Critical thinking: Prevailing practice in baccalaureate schools of nursing. Journal of Nursing Education. 36(1), 5-10.

Wandelt, M., \& Stewart, D. S. (1975). Slater Nursing Competencies Rating Scale. New York, NY: Appleton-Century-Crofts.

Wilson, H. S. (1996). Infra controlling: The social order of freedom in an antipsychiatric community. In B. Glaser (Ed.). Gerund grounded theory: The basic social process dissertation. Mill Valley, CA: Sociology Press.

Windsor, A., (1987). Nursing students' perceptions of clinical experience. Journal of Nursing Education. 26(4), 150-154.

Wuest, J., \& Stern, P. N. (1990). Childhood otitis media: The family's endless quest for relief. Issues in Comprehensive Pediatric Nursing. 13, 25-29.

Yonge, O., \& Stewin, L. (1988). Reliability and validity. Misnomers for qualitative research. Canadian Journal of Nursing Research. 20(2), 61-67.

Yonge, O., \& Trojan, L. (1992). The nursing performance of preceptored and non-preceptored baccalaureate nursing students. Canadian Journal of Nursing Research, 24(4), 61-75.

Yonge, O., Krahn, H., \& Reid, D. (1997). Through the eyes of the preceptor. Canadian Journal of Nursing Administration, Nov.-Dec., 65-85. 
Yonge, O. (1998). Assessing and preparing students for distance preceptorship placements. Journal of Advanced Nursing. 26, 812-816. 


\section{Appendix 1: Interview Guide - Preceptor \\ Examples of Guiding Questions}

These questions were utilized as a guide in the first interview to provide systematic data collection for all participants. Because it was not possible to determine a priori what successive interviews would include, subsequent interviews were used to obtain explanations concerning areas that lacked clarity. They entailed further direct questioning which provided a more complete description for the theory development.

1. Tell me about your role as preceptor.

2. How would you describe the process that you go through in guiding the preceptees to think about their patient assignments?

3. Is there anything in particular that you do when discussing the planning, implementation and evaluation of patient assignments with the preceptees?

4. Is there any specific way that you carry out discussions with preceptees?

5. What kinds of questions do you ask to assist the preceptee with their patient assignments?

6. What do you think is meant by the term "critical thinking"?

7. Do you think that critical thinking is an important part of your role as a preceptor? If so, how is it important?

8. How do you use critical thinking in your role as preceptor? 


\section{Appendix 2: Interview Guide - Preceptee \\ Examples of Guiding Questions}

These questions were utilized as a guide in the first interview to provide systematic data collection for all participants. Because it was not possible to determine a priori what successive interviews would include, subsequent interviews were used to obtain explanations concerning areas that lacked clarity. They entailed further direct questioning which provided a more complete description for the theory development.

1. Tell me about your role as preceptee.

2. How would you describe the process that you go through when your preceptor is guiding you to think about your patient assignments?

3. Is there anything in particular that your preceptor does when discussing the planning, implementation and evaluation of patient assignments with you?

4. Is there any specific way that your preceptor carries out discussions with you?

5. What kinds of questions does your preceptor ask to assist you with your patient assignments?

6. What do you think is meant by the term "critical thinking"?

7. Do you think that critical thinking is an important part of your role as nursing student? If so, how is it important?

8. How do you use critical thinking in your role as preceptee?

9. Does your preceptor contribute to your ability to think critically? If so, how?

10. Are there other situations in your nursing program where you felt your critical thinking was being developed and promoted? 


\section{Appendix 3: Observational Guide}

1. How do the preceptor and the preceptee interact as they plan, implement and evaluate care?

2. How do the preceptor and the preceptee review the patients' conditions together?

3. What process of discussion takes place, for example, analysis, synthesis, etc.?

4. Does the preceptor allow for any reflection time throughout the shift?

5. Is there any designated period in which the preceptor and the preceptee take time to examine situations, discuss questions and concerns?

6. How is the preceptee challenged cognitively or is the preceptee limited to a functional type of experience?

7. Is the nursing care based on any particular framework, for example, a nursing, medical model? 


\section{Appendix 4: Demographic Data - Preceptor}

1. Code

2. Birth Date

$\overline{\text { Month }} \overline{\text { Year }}$

3. Gender

$$
\overline{\text { Female }} \quad \overline{\text { Male }}
$$

4. Marital Status

$$
\text { Married } \overline{\text { Single }} \overline{\text { Other }}
$$

5. Nursing Education

$\begin{array}{ll}\text { - } & \text { Diploma } \\ \text { Baccalaureate } \\ \text { - } \\ \text { Masters } \\ \text { Other }\end{array}$

Year graduated Year graduated Year graduated Year graduated

6. Post graduate education

7. Continuing education

8. Total years of nursing experience

9. Brief description of work experience and major responsibilities:

10. Total years of experience as preceptor

11. Brief description of the preparation you received for the role of preceptor:

12. Level of students for whom you have been preceptor 
Appendix 5: Demographic Data - Preceptee

1. Code

2. Birth Date

$\overline{\text { Month }} \overline{\text { Year }}$

3. Gender

$\overline{\text { Female }} \quad \overline{\text { Male }}$

4. Marital Status

$\overline{\text { Married }} \overline{\text { Single }} \overline{\text { Other }}$

5. Other university education

6. Unit Assignment 


\section{Appendix 6: Letter of Permission}

To: Dr. M. Wood

Dean

Faculty of Nursing

University of Alberta

Edmonton, Alberta

Dear Dr. Wood:

I am a doctoral student at the Faculty of Nursing, University of Alberta. I will be conducting a research study to examine the process used to foster the critical thinking ability of basic baccalaureate nursing students in the preceptorship relationship.

I am writing to request your permission to access the nursing students completing their senior nursing courses in the basic baccalaureate nursing program. In light of the fact that these courses are heavily dependent on preceptorship for clinical teaching, it would be most suitable for my study.

For your convenience, I am enclosing a brief description of the study. If you have any questions or concerns, please do not hesitate to contact me at 431-2463.

I look forward to hearing from you.

Yours truly,

Florence Myrick $\mathrm{RN} \mathrm{PhD}(\mathrm{c})$

Doctoral Candidate

University of Alberta 


\section{Appendix 7: Consent Form - Preceptor}

Project Title: Preceptorship and Critical Thinking

Investigator: Florence Myrick RN

$\mathrm{PhD}$ Candidate

Faculty of Nursing

University of Alberta

Phone: 431-2463

Supervisor: Olive Yonge RN PhD

Professor

Faculty of Nursing

University of Alberta

Phone: 492-2402

Purpose: I am interested in learning how staff nurse preceptors help nursing students develop their thinking while in the practice setting. The information from this study will assist nurse educators and preceptors in their efforts to improve the quality of clinical teaching for nursing students.

I am asking that you, as a preceptor, take part in this study. If you have any questions or concerns, please do not hesitate to call me at 431-2463. I will be pleased to answer any questions or concerns that you may have. There is no direct benefit to you for taking part in this study nor are there any risks involved. Your participation is completely voluntary. You do not have be a part of this study if you do not wish to be. Should you decide to take part and, at any time during the study, you wish to withdraw, it is entirely within your right to do so. Your wishes will be respected at all times. You may refuse to answer any question or refuse to discuss any topic.

You will be interviewed a number of times. The first interview will take about ninety minutes. The other interviews will take about sixty minutes. You will be interviewed at a time and place that is suitable to you and the researcher. These interviews will be tape recorded and, to protect your identity, will be coded with a number. Only the researcher will know your name.

I would also like to observe you while you work with the student in the practice setting. This will take place on a day and at a time that is suitable to you, the student and the researcher. 
The results of this study may include some of your words but your name will at no time be used. The results may be published in nursing journals and presented at professional conferences. At no time, will you be identified in any way. A summary of the results will be given to you upon request.

All the information will be stored in a locked filing cabinet. The list that links your name with your code number will be kept in a separate locked filing cabinet. The consent forms will be held for one year and the data will be held for seven years after which time they will be destroyed. The data may be used in a future study, but the researcher will have to get approval from the proper review committee.

Consent: I acknowledge that the above research procedures have been fully explained to me. I am satisfied with the answers to my questions. If I have any questions or concerns I know that I can call the researcher at any time. I know that I do not have to take part in this study and that I do so of my own free will. I know that I can withdraw from the study at any time. I understand that there are no benefits or risks to me and I know that the records will be kept confidential at all times.

$\overline{\text { (Signature of Researcher) }} \overline{\text { (Signature of Participant) }}$

(Date)

(Date)

Request for Summary of Results

If you would like to receive your own copy of a summary of the results of this study when it is finished, please fill out this section. If you change your address or telephone number before you hear from me, please call me at 431-2463 and give me your change of address. Thank you.

Name:

Address:

City:

Postal Code: 


\section{Appendix 8: Consent Form - Preceptee}

Project Title: Preceptorship and Critical Thinking

Investigator: Florence Myrick RN

$\mathrm{PhD}$ Candidate

Faculty of Nursing

University of Alberta

Phone: 431-2463

Supervisor: Olive Yonge RN PhD

Professor

Faculty of Nursing

University of Alberta

Phone: 492-2402

Purpose: I am interested in learning how staff nurse preceptors help nursing students develop their thinking while in the practice setting. The information from this study will assist nurse educators and preceptors in their efforts to improve the quality of clinical teaching for nursing students.

I am asking that you, as a student assigned to a preceptor, to take part in this study. If you have any questions or concerns, please do not hesitate to call me at 4312463. I will be pleased to answer any questions or concerns that you may have. There is no direct benefit to you for taking part in this study nor are there any risks involved. Your participation is completely voluntary. You do not have be a part of this study if you do not wish to be. Should you decide to take part and, at any time during the study, you wish to withdraw, it is entirely within your right to do so. Your wishes will be respected at all times. You may refuse to answer any question or refuse to discuss any topic.

You will be interviewed a number of times. The first interview will take about ninety minutes. The other interviews will take about sixty minutes. You will be interviewed at a time and place that is suitable to you and the researcher. These interviews will be tape recorded and, to protect your identity, will be coded with a number. Only the researcher will know your name.

I would also like to observe you while you work with your assigned preceptor in the practice setting. This will take place on a day and at a time that is suitable to you, the preceptor and the researcher. 
The results of this study may include some of your words but your name will at no time be used. The results may be published in nursing journals and presented at professional conferences. At no time, will you be identified in any way. A summary of the results will be given to you upon request.

All the information will be stored in a locked filing cabinet. The list that links your name with your code number will be kept in a separate locked filing cabinet. The consent forms will be held for one year and the data will be held for seven years after which time they will be destroyed. The data may be used in a future study, but the researcher will have to get approval from the proper review committee.

Consent: I acknowledge that the above research procedures have been fully explained to me. I am satisfied with the answers to my questions. If I have any questions or concerns I know that I can call the researcher at any time. I know that I do not have to take part in this study and that I do so of my own free will. I know that I can withdraw from the study at any time. I understand that there are no benefits or risks to me and I know that the records will be kept confidential at all times.

$\overline{\text { (Signature of Researcher) }} \overline{\text { (Signature of Participant) }}$

(Date)

(Date)

Request for Summary of Results

If you would like to receive your own copy of a summary of the results of this study when it is finished, please fill out this section. If you change your address or telephone number before you hear from me, please call me at 431-2463 and give me your change of address. Thank you.

Name:

Address:

City:

Postal Code: 
TABLE 1.1 - SYNOPSIS

QUANTITATIVE RESEARCH STUDIES

PRECEPTORSHIP

(1981-1986)

\begin{tabular}{|c|c|}
\hline $\begin{array}{l}\text { Researcher: } \\
\text { Sample: } \\
\text { Setting: } \\
\text { Variable: } \\
\text { Instrument: } \\
\text { Findings: } \\
\end{array}$ & $\begin{array}{l}\text { Huber, } 1981 \\
\text { Student \& graduate nurses }(\mathrm{N}=36) \\
\text { Hospital-based preceptorship orientation } \\
\text { Performance } \\
\text { 6-D Scale } \\
\text { No significant difference in those preceptored }\end{array}$ \\
\hline $\begin{array}{l}\text { Researcher: } \\
\text { Sample: } \\
\text { Setting: } \\
\text { Variable: } \\
\text { Instrument: } \\
\text { Findings: }\end{array}$ & $\begin{array}{l}\text { Marchette, } 1984 \\
\text { Novice nurses }(\mathrm{N}=26) \\
\text { Four month internship - med-surg unit } \\
\text { Performance } \\
\text { 6-D Scale } \\
\text { No significant difference in those preceptored }\end{array}$ \\
\hline $\begin{array}{l}\text { Researcher: } \\
\text { Sample: } \\
\text { Setting: } \\
\text { Variable: } \\
\text { Instrument: } \\
\text { Findings: }\end{array}$ & $\begin{array}{l}\text { Olson, Gresley \& Heater, } 1984 \\
\text { Student nurses ( } \mathrm{N}=48) \\
\text { Acute care setting } \\
\text { Competence } \\
\text { Tennessee Self-Concept Scale } \\
\text { No significant difference in those preceptored }\end{array}$ \\
\hline $\begin{array}{l}\text { Researcher: } \\
\text { Sample: } \\
\text { Setting: } \\
\text { Variable: } \\
\text { Instrument: } \\
\text { Findings: }\end{array}$ & $\begin{array}{l}\text { Shamian \& Lemieux, } 1984 \\
\text { Registered nurses \& nursing students }(\mathrm{N}=316) \\
\text { Acute care setting } \\
\text { Preceptor model versus formal teaching model } \\
\text { Self-designed Questionnaire } \\
\text { Preceptor model superior in attainment of knowledge, acquisition of } \\
\text { assessment, skills and attendance in educational programs }\end{array}$ \\
\hline $\begin{array}{l}\text { Researcher: } \\
\text { Sample: } \\
\text { Setting: } \\
\text { Variable: } \\
\text { Instrument: } \\
\text { Findings: }\end{array}$ & $\begin{array}{l}\text { Myrick, } 1986 \\
\text { Fourth year basic baccalaureate nursing students }(\mathrm{N}=12) \\
\text { Acute care setting } \\
\text { Competence } \\
\text { 6-D Scale } \\
\text { Slater Nursing Competency Rating Scale } \\
\text { No significant difference in those preceptored }\end{array}$ \\
\hline
\end{tabular}


TABLE 1.2 - SYNOPSIS

QUANTITATIVE RESEARCH STUDIES

PRECEPTORSHIP

(1987-1990)

\begin{tabular}{|c|c|}
\hline $\begin{array}{l}\text { Researcher: } \\
\text { Sample: } \\
\text { Setting: } \\
\text { Variable: } \\
\text { Instrument: } \\
\text { Findings: }\end{array}$ & $\begin{array}{l}\text { Itano, Warren \& Ishida, } 1987 \\
\text { First \& Second year baccalaureate nursing students }(N=103) \\
\text { Acute care setting } \\
\text { Role socialization } \\
\text { Corwin's Nursing Role Conception Scale } \\
\text { Significant difference in those preceptored }\end{array}$ \\
\hline $\begin{array}{l}\text { Researcher: } \\
\text { Sample: } \\
\text { Setting: } \\
\text { Variable: } \\
\text { Instrument: } \\
\text { Findings: }\end{array}$ & $\begin{array}{l}\text { Dobbs, } 1988 \\
\text { Basic baccalaureate nursing students }(\mathrm{N}=103) \\
\text { Variety of clinical settings } \\
\text { Anticipatory socialization } \\
\text { Corwin's Nursing Role Conception Scale } \\
\text { Preceptorship promotes anticipatory socialization }\end{array}$ \\
\hline $\begin{array}{l}\text { Researcher: } \\
\text { Sample: } \\
\text { Setting: } \\
\text { Variable: } \\
\text { Instrument: } \\
\text { Findings: } \\
\end{array}$ & $\begin{array}{l}\text { Clayton, Broome \& Ellis, } 1989 \\
\text { Senior basic baccalaureate nursing students }(\mathrm{N}=33) \\
\text { Variety of clinical settings } \\
\text { Role socialization } \\
\text { 6-D Scale } \\
\text { Significant difference in those preceptored }\end{array}$ \\
\hline $\begin{array}{l}\text { Researcher: } \\
\text { Sample: } \\
\text { Setting: } \\
\text { Variable: } \\
\text { Instrument: } \\
\text { Findings: } \\
\end{array}$ & $\begin{array}{l}\text { Scheetz, } 1989 \\
\text { Senior baccalaureate nursing students } \\
\text { Acute care setting } \\
\text { Competence } \\
\text { (CCRS) PIS SES } \\
\text { CCRS - significant difference } \\
\end{array}$ \\
\hline $\begin{array}{l}\text { Researcher: } \\
\text { Sample: } \\
\text { Setting: } \\
\text { Variable: } \\
\text { Instrument: } \\
\text { Findings: }\end{array}$ & $\begin{array}{l}\text { Bisek \& Oermann, } 1990 \\
\text { Critical care nurse preceptors }(\mathrm{N}=73) \\
\text { ICU - } 10 \text { teaching hospitals } \\
\text { Educational experiences, support and job satisfaction } \\
\text { Three-part Questionnaire } \\
\text { Job satisfaction not related to participation in an educational } \\
\text { program }\end{array}$ \\
\hline
\end{tabular}


TABLE 1.3 - SYNOPSIS

\section{QUANTITATIVE RESEARCH STUDIES PRECEPTORSHIP \\ (1991-1993)}

\begin{tabular}{|c|c|}
\hline $\begin{array}{l}\text { Researcher: } \\
\text { Sample: } \\
\text { Setting: } \\
\text { Variable: } \\
\text { Instrument: } \\
\text { Findings: } \\
\end{array}$ & $\begin{array}{l}\text { Jairath, Costello, Wallace, \& Rudy, } 1991 \\
\text { Diploma nursing students (N=22) } \\
\text { Acute care setting } \\
\text { Performance } \\
\text { 6-D Scale } \\
\text { Significant difference in those preceptored }\end{array}$ \\
\hline $\begin{array}{l}\text { Researcher: } \\
\text { Sample: } \\
\text { Setting: } \\
\text { Variable: } \\
\text { Instrument: } \\
\text { Findings: }\end{array}$ & $\begin{array}{l}\text { Spence-Laschinger \& MacMaster, } 1992 \\
\text { Baccalaureate nursing students (N=5) } \\
\text { Classroom } \\
\text { Student perception of preceptorship experience } \\
\text { Questionnaire } \\
\text { Significant difference of those preceptored }\end{array}$ \\
\hline $\begin{array}{l}\text { Researcher: } \\
\text { Sample: } \\
\text { Setting: } \\
\text { Variable: } \\
\text { Instrument: } \\
\text { Findings: } \\
\end{array}$ & $\begin{array}{l}\text { Yonge \& Trojan, } 1992 \\
\text { Baccalaureate nursing students }(\mathrm{N}=71 \\
\text { Professors }(\mathrm{N}=3) \text { Preceptors }(\mathrm{N}=33) \\
\text { Variety of clinical settings } \\
\text { Performance } \\
\text { 6-D Scale } \\
\text { Preceptored students scored significantly }\end{array}$ \\
\hline $\begin{array}{l}\text { Researcher: } \\
\text { Sample: } \\
\text { Setting: } \\
\text { Variable: } \\
\text { Instrument: } \\
\text { Findings: }\end{array}$ & $\begin{array}{l}\text { Ferguson \& Calder, } 1993 \\
\text { Preceptors }(\mathrm{N}=126) \\
\text { Educators }(\mathrm{N}=19) \\
\text { Acute care setting } \\
\text { Similarities and differences in the valuing of selected clinical } \\
\text { performance and evaluation criteria } \\
\text { Questionnaire } \\
\text { More similarities than differences }\end{array}$ \\
\hline $\begin{array}{l}\text { Researcher: } \\
\text { Sample: } \\
\text { Setting: } \\
\text { Variable: } \\
\text { Instrument: } \\
\text { Findings: }\end{array}$ & $\begin{array}{l}\text { Goldenberg \& Iwasiw, } 1993 \\
\text { Senior community college, baccalaureate and RN-BSCN nursing } \\
\text { students } \\
\text { Variety of clinical settings } \\
\text { Professional socialization } \\
\text { Three-part Questionnaire } \\
\text { Groups similar and more professional in attitude; community } \\
\text { college students report less conflict }\end{array}$ \\
\hline
\end{tabular}


TABLE 1.4 - SYNOPSIS

\section{QUANTITATIVE RESEARCH STUDIES PRECEPTORSHIP (1993-1998)}

\begin{tabular}{|c|c|}
\hline $\begin{array}{l}\text { Researcher: } \\
\text { Sample: } \\
\text { Setting: } \\
\text { Variable: } \\
\text { Instrument: } \\
\text { Findings: }\end{array}$ & $\begin{array}{l}\text { Ouellet, } 1993 \\
\text { Baccalaureate nursing students }(\mathrm{N}=103) \\
\text { Variety of clinical settings } \\
\text { Student perceptions about professional nursing } \\
\text { Valiga concept of Nursing Scale (1982) } \\
\text { No difference following four week preceptorship. Significant } \\
\text { differences after seven week preceptorship }\end{array}$ \\
\hline $\begin{array}{l}\text { Researcher: } \\
\text { Sample: } \\
\text { Setting: } \\
\text { Variable: } \\
\text { Instrument: } \\
\text { Findings: }\end{array}$ & $\begin{array}{l}\text { Yonge, Krahn, Trojan \& Reid, } 1997 \\
\text { Preceptors (N=295) } \\
\text { Province of Alberta } \\
\text { Preceptors } \\
\text { Questionnaire } \\
\text { Orientation to preceptor role adequate. Greatest advantage } \\
\text { was re-examining their knowledge; most common problem is } \\
\text { a student with poor nursing skills }\end{array}$ \\
\hline $\begin{array}{l}\text { Setting: } \\
\text { Variable: } \\
\text { Instrument: } \\
\text { Findings: }\end{array}$ & $\begin{array}{l}\text { Coates \& Gormley, } 1997 \\
\text { Nursing students }(\mathrm{N}=15 \\
\text { Preceptors }(\mathrm{N}=62) \text {; Senior nurse managers }(\mathrm{N}=2) \text {; Nurse } \\
\text { teachers }(\mathrm{N}=8) \\
\text { College of Nursing } \\
\text { Views about preceptorship } \\
\text { Questionnaire \& Interviews } \\
\text { Preceptors act as role models and supervisors to the students. } \\
\text { Knowledge of area and experience greatest preceptor assets }\end{array}$ \\
\hline $\begin{array}{l}\text { Researcher: } \\
\text { Sample: } \\
\text { Setting: } \\
\text { Variable: } \\
\text { Instrument: } \\
\text { Findings: }\end{array}$ & $\begin{array}{l}\text { Barrett \& Myrick, } 1998 \\
\text { Preceptors (N=35) } \\
\text { Preceptees (N-33) } \\
\text { Three university schools of nursing in Atlantic Canada } \\
\text { Job satisfaction } \\
\text { Job Descriptive Index (JDI); 6-D Scale } \\
\text { Preceptors and preceptees differ significantly in job } \\
\text { satisfaction. No relationship found between preceptor job } \\
\text { satisfaction and preceptee clinical performance }\end{array}$ \\
\hline
\end{tabular}


TABLE 2.1 - SYNOPSIS

QUANTITATIVE RESEARCH STUDIES

CRITICAL THINKING (CT) IN NURSING

(1981-1987)

\begin{tabular}{|ll||}
\hline Researcher: & Ketefian, 1981 \\
Sample: & Practising nurses (N-79) \\
Setting: & Variety of clinical settings \\
Variable: & Critical thinking, moral judgment \& level of edu prep \\
Instrument: & WGCTA; REST's Defining Issues Test \\
Findings: & Pos relation re CT \& moral judgment; higher in prof nurses \\
\hline Researcher: & Berger, 1984 \\
Sample: & BSN students \& liberal arts students (N=137) \\
Setting: & Classroom \\
Variable: & Critical thinking and GPA \\
Instrument: & WGCTA \\
Findings: & No sig cor between CT \& GPA. Nsg students higher scores \\
\hline Researcher: & Bauwens \& Gerhard, 1987 \\
Sample: & Baccalaureate nursing students (N=145) \\
Setting: & Classroom \\
Variable: & Early predictors of success \\
Instrument: & WGCTA \\
Findings: & No sig change in total scores first and last program semesters \\
\hline Researcher: & Tiessen, 1987 \\
Sample: & Fourth year BSN students (N=50) \\
Setting: & Classroom \\
Variable: & predictor variables of CT \\
Instrument: & WGCTA \\
Findings: & Pos cor between CT, SAT math scores, college credit hours \\
& in Arts \& Humanities, \& GPA \\
\hline Researcher: & Pardue, 1987 \\
Sample: & Stratified sample of RNs (N=121) \\
Setting: & Two large health care institutions \\
Variable: & CT and clinical decision-making \\
Instrument: & WGCTA \\
Findings: & The CT of BSN \& MSN grad sig higher than diploma \& \\
& assoc degree \\
\hline & \\
\hline
\end{tabular}


TABLE 2.2 - SYNOPSIS

QUANTITATIVE RESEARCH STUDIES

CRITICAL THINKING (CT) IN NURSING

(1987-1992)

\begin{tabular}{|ll|}
\hline \hline Researcher: & Sullivan, 1987 \\
Sample: & RN to BSN program students (N=51) \\
Setting: & Clinical setting/classroom \\
Variable: & CT, Creativity, Performance \\
Instrument: & WGCTA; TTCT; Slater-Stewart Evaluation Nursing Scale \\
Findings: & Pos cor between: entry \& exit CT scores, entry \& exit, GPA \\
& \& creativity. No change in CT scores from entry to exit \\
\hline Researcher: & Brooks \& Shepherd, 1990 \\
Sample: & Diploma, AD, RN \& BSN students (N=200) \\
Setting: & Variety of clinical settings \\
Variable: & CT \& Clinical-decision making (CDM) \\
Instrument: & WGCTA; Gover's Nsg Perf Simulation \\
Findings: & CT higher in BSN. CDM higher in RNs \\
\hline Researcher: & Jones \& Brown, 1991 \\
Sample: & Deans \& Directors of NLN accredited SONs \\
Setting: & Survey \\
Variable: & CT as characterized in nursing education \\
Instrument: & Questionnaire \\
Findings: & CT seen as variation of scientific method \\
\hline Researcher: & Brooks \& Shepherd, 1992 \\
Sample: & Diploma, AD, RN \& BSN students (N=200) \\
Setting: & Variety of clinical settings \\
Variable: & Professionalism \& CT \\
Instrument: & WGCTA; Health Care Prof Attitude Inventory \\
Findings: & Professionalism lowest in dipl students. CT scores higher in \\
& BSN \& Post-RN students \\
\hline Researcher: & Saarmann, Freitas, Rapps \& Riegel, 1992 \\
Sample: & Faculty, nursing students, RNs (N=192) \\
Setting: & Variety of clinical settings \\
Variable: & CT \& professional values \\
Instrument: & WGCTA \\
Findings: & Faculty CT not sig higher than students \\
\hline & \\
\hline
\end{tabular}


TABLE 2.3 - SYNOPSIS

QUANTITATIVE RESEARCH STUDIES

CRITICAL THINKING (CT) IN NURSING

(1993-1996)

\begin{tabular}{|ll|}
\hline Researcher: & Bechtel, Smith, Printz, \& Gronseth, 1993 \\
Sample: & Registered Nurses (N=78) \\
Setting: & 250-bed health care facility \\
Variable: & CT and clinical decision-making \\
Instrument: & WGCTA \\
Findings: & CT \& clinical decision-making not significantly influenced by \\
& patterns of upward mobility \\
\hline Researcher: & Hartley \& Aukamp, 1994 \\
Sample: & Nurse Educators (N=50) \\
Setting: & 10 NLN accredited BSN program \\
Variable: & Critical thinking \\
Instrument: & WGCTA \\
Findings: & Nurse Educators had higher level of CT than nursing students \\
\hline Researcher: & Behrens, 1996 \\
Sample: & Diploma nursing students (N=109) \\
Setting: & Classroom \\
Variable: & Critical thinking \& GPA \\
Instrument: & WGCTA \\
Findings: & Scores on WGCTA correlate significantly with students' GPA \\
\hline Researcher: & Perciful \& Nester, 1996 \\
Sample: & Two BSN graduating classes (N=83) \\
Setting: & Classroom \\
Variable: & Teaching method, CT \& CDM \\
Instrument: & WGCTA \\
Findings: & CT \& CDM higher in those students receiving computer- \\
& assisted instruction \\
\hline Researcher: & Maynard, 1996 \\
Sample: & Cross-sectional sample of nursing grads (N-121) \\
Setting: & Classroom \\
Variable: & CT \& professional nursing competence \\
Instrument: & WGCTA \\
Findings: & CT does not change significantly during the educational \\
& experience \\
\hline & \\
\hline
\end{tabular}


TABLE 2.4 - SYNOPSIS

QUANTITATIVE RESEARCH STUDIES

CRITICAL THINKING (CT) IN NURSING

(1996-1998)

\begin{tabular}{|c|c|}
\hline $\begin{array}{l}\text { Researcher: } \\
\text { Sample: } \\
\text { Setting: } \\
\text { Variable: } \\
\text { Instrument: } \\
\text { Findings: }\end{array}$ & $\begin{array}{l}\text { Retsas \& Wilson, } 1996 \\
\text { Registered Nurses }(\mathrm{N}=143) \\
\text { Classroom } \\
\text { Critical thinking } \\
\text { WGCTA } \\
\text { Bacc grads scored sig lower }\end{array}$ \\
\hline $\begin{array}{l}\text { Researcher: } \\
\text { Sample: } \\
\text { Setting: } \\
\text { Variable: } \\
\text { Instrument: } \\
\text { Findings: }\end{array}$ & $\begin{array}{l}\text { Pepa, Brown \& Alverson, } 1997 \\
\text { BSN students - traditional }(\mathrm{N}=45) \text {; accelerated }(\mathrm{N}=43) \\
\text { Classroom } \\
\text { Influence of program on } \mathrm{CT} \\
\text { WGCTA } \\
\text { Sig diff at beginning of program }\end{array}$ \\
\hline $\begin{array}{l}\text { Researcher: } \\
\text { Sample: } \\
\text { Setting: } \\
\text { Variable: } \\
\text { Instrument: } \\
\text { Findings: }\end{array}$ & $\begin{array}{l}\text { Bethune \& Jackling, } 1997 \\
\text { Postgraduate nursing students }(\mathrm{N}=44) \\
\text { Survey } \\
\text { Perceptions of CT skills } \\
\text { Questionnaire } \\
\text { Pos shift perceived by half. Others perceived lack of CT }\end{array}$ \\
\hline $\begin{array}{l}\text { Researcher: } \\
\text { Sample: } \\
\text { Setting: } \\
\text { Variable: } \\
\text { Instrument: } \\
\text { Findings: } \\
\end{array}$ & $\begin{array}{l}\text { Rossignol, } 1997 \\
\text { Senior nursing students }(\mathrm{N}=57) \\
\text { Clinical post-conferences } \\
\text { Selected discourse strategies \& CT } \\
\text { Bellack's Ling Analysis System; WGCTA } \\
\text { Less student talk \& student-to-student talk cor CT }\end{array}$ \\
\hline $\begin{array}{l}\text { Researcher: } \\
\text { Sample: } \\
\text { Setting: } \\
\text { Variable: } \\
\text { Instrument: } \\
\text { Findings: }\end{array}$ & $\begin{array}{l}\text { Vaughan-Wrobel, O'Sullivan \& Smith, } 1997 \\
\text { Baccalaureate nursing students }(\mathrm{N}=391) \\
\text { Academic health sciences centre } \\
\text { Critical thinking skills } \\
\text { WGCTA } \\
\text { No significant differences }\end{array}$ \\
\hline $\begin{array}{l}\text { Researcher: } \\
\text { Sample: } \\
\text { Setting: } \\
\text { Variable: } \\
\text { Instrument: } \\
\text { Findings: }\end{array}$ & $\begin{array}{l}\text { Shin, } 1998 \\
\text { Assoc degree \& bacc students }(\mathrm{N}=119) \\
\text { Classroom } \\
\text { CT \& CDM } \\
\text { WGCTA; Nursing Performance Simulation } \\
\text { Sig mean differences favouring baccalaureate students. Relationship } \\
\text { between CT \& CDM weak }\end{array}$ \\
\hline
\end{tabular}


Figure 1: Preceptorship \& Critical Thinking The Process

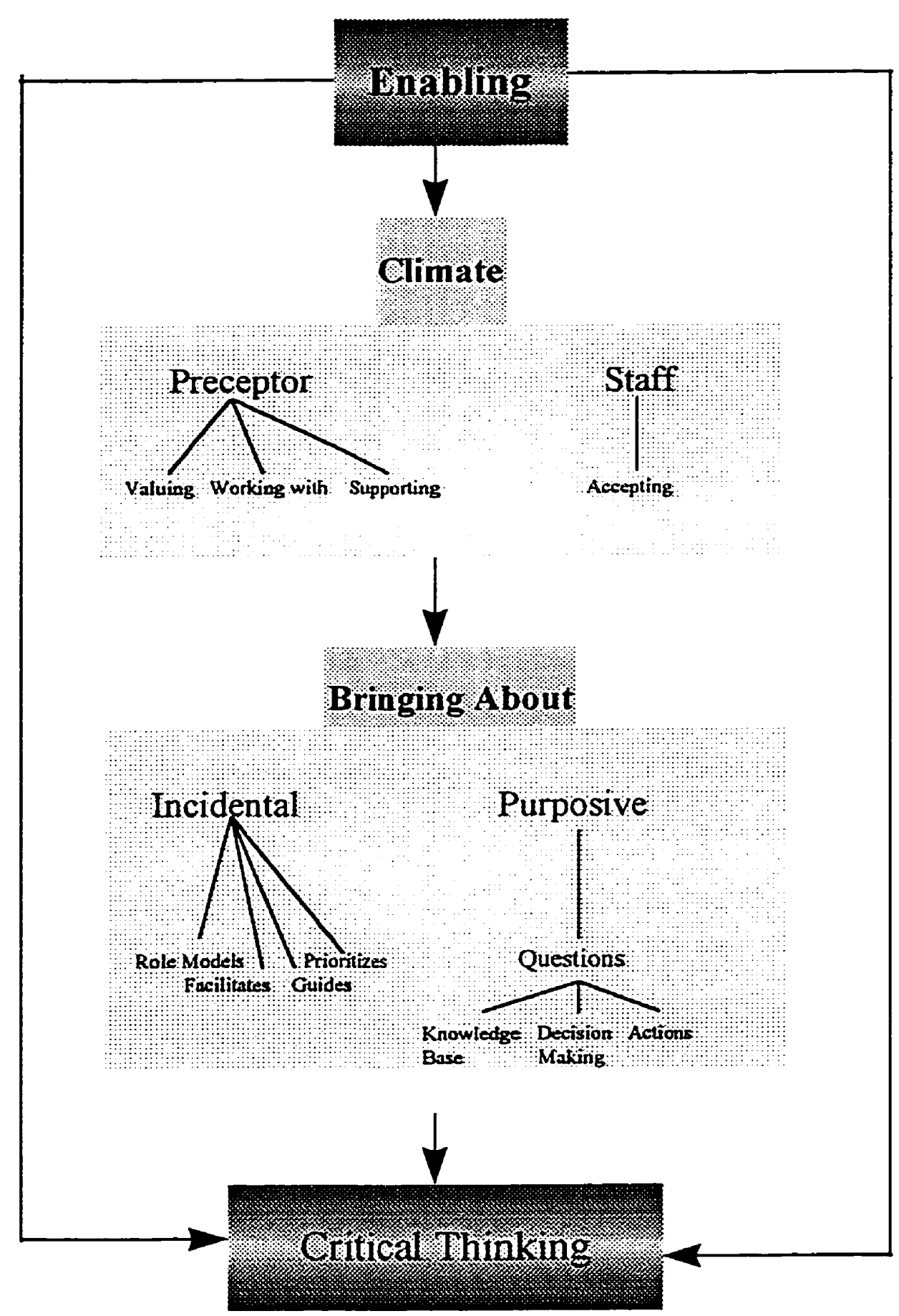




\section{Figure 2: Preceptorship \& Critical Thinking The Process}

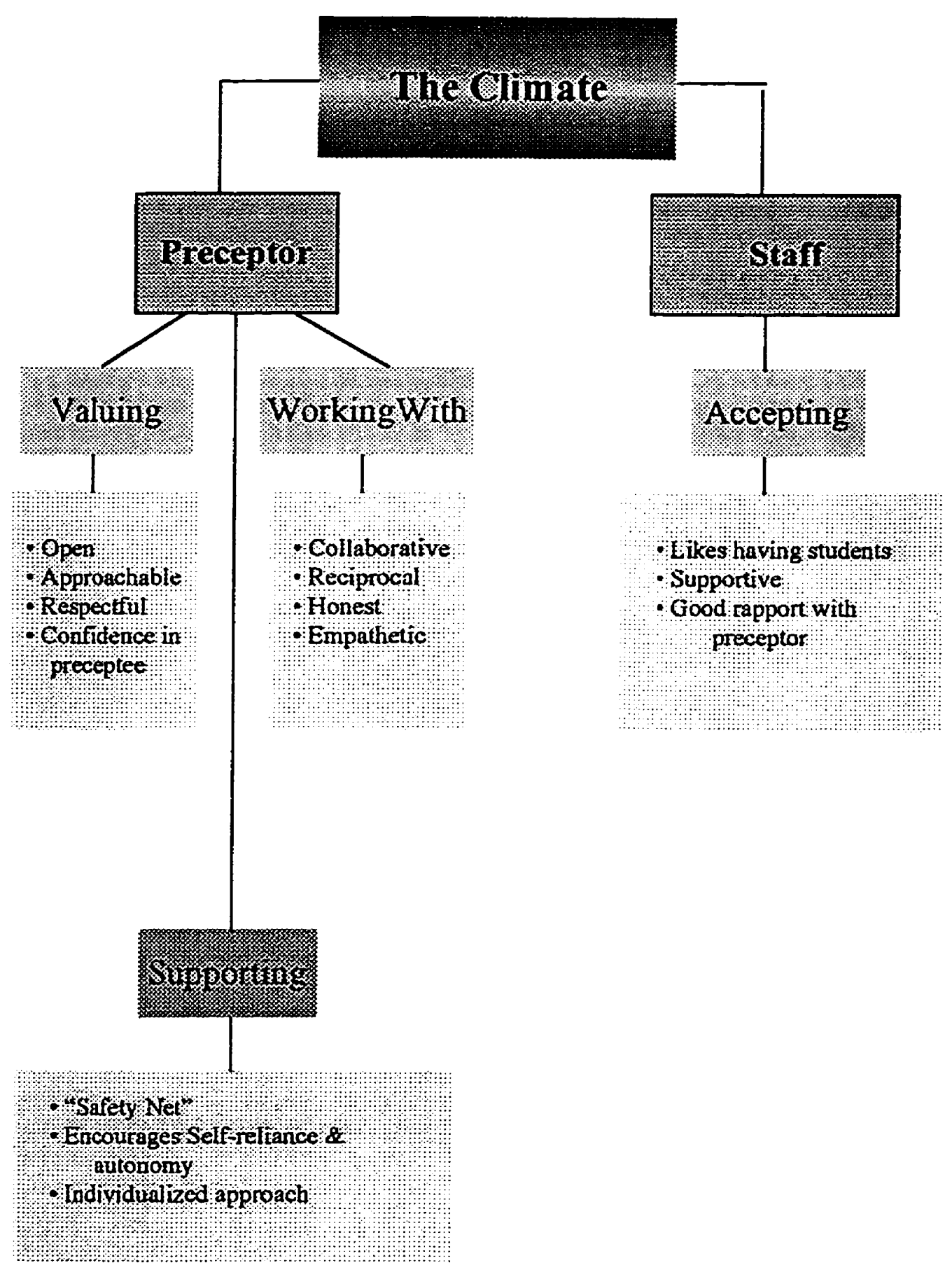


Figure 3: Preceptorship \& Critical Thnking The Process

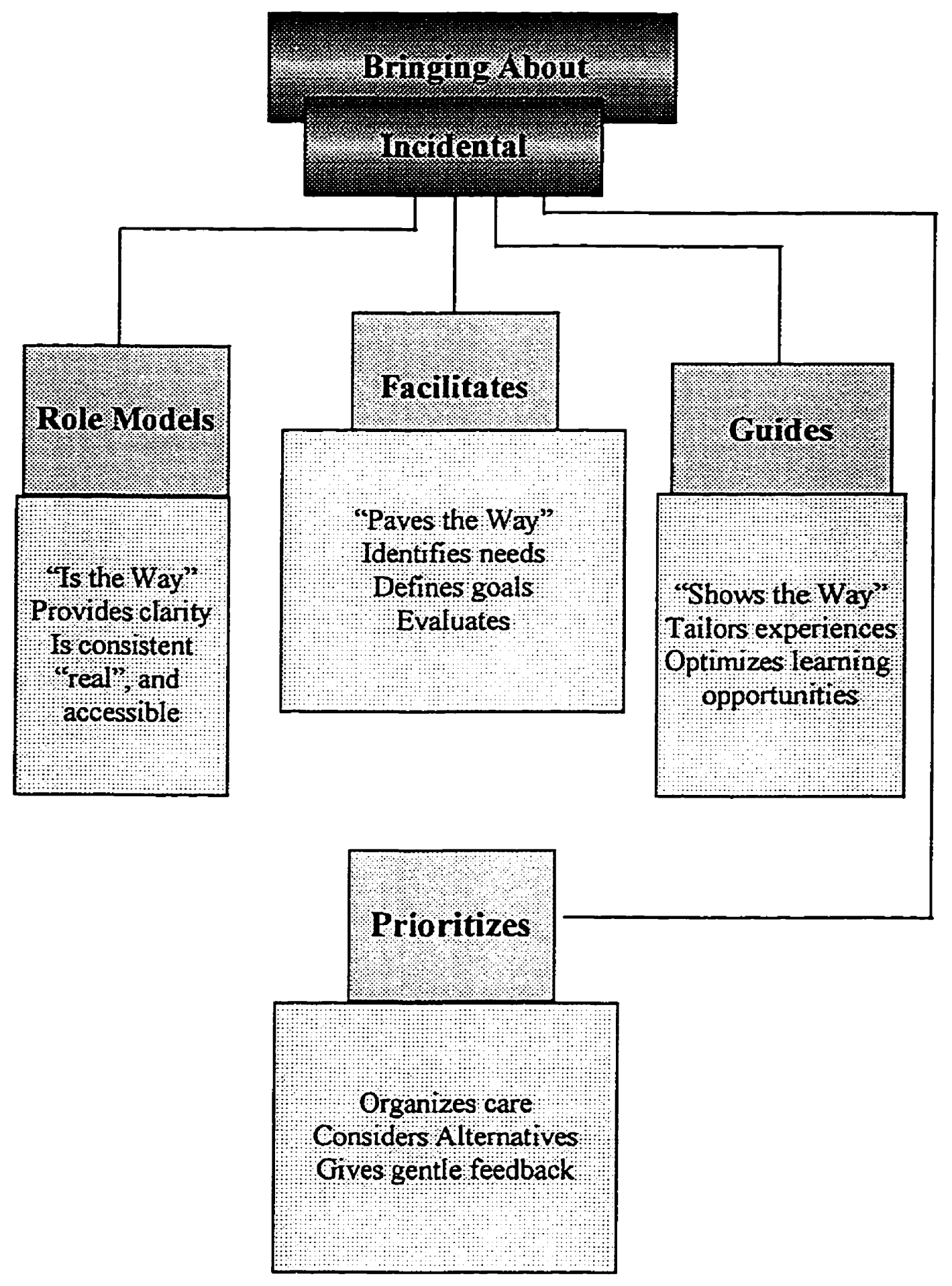


Figu re 4: Preceptorship \& Critical Thinking The Process




Figure 5: Schematic Representation of Emergent Framework

Sample

Emerging Data

Questions \& Hypotheses

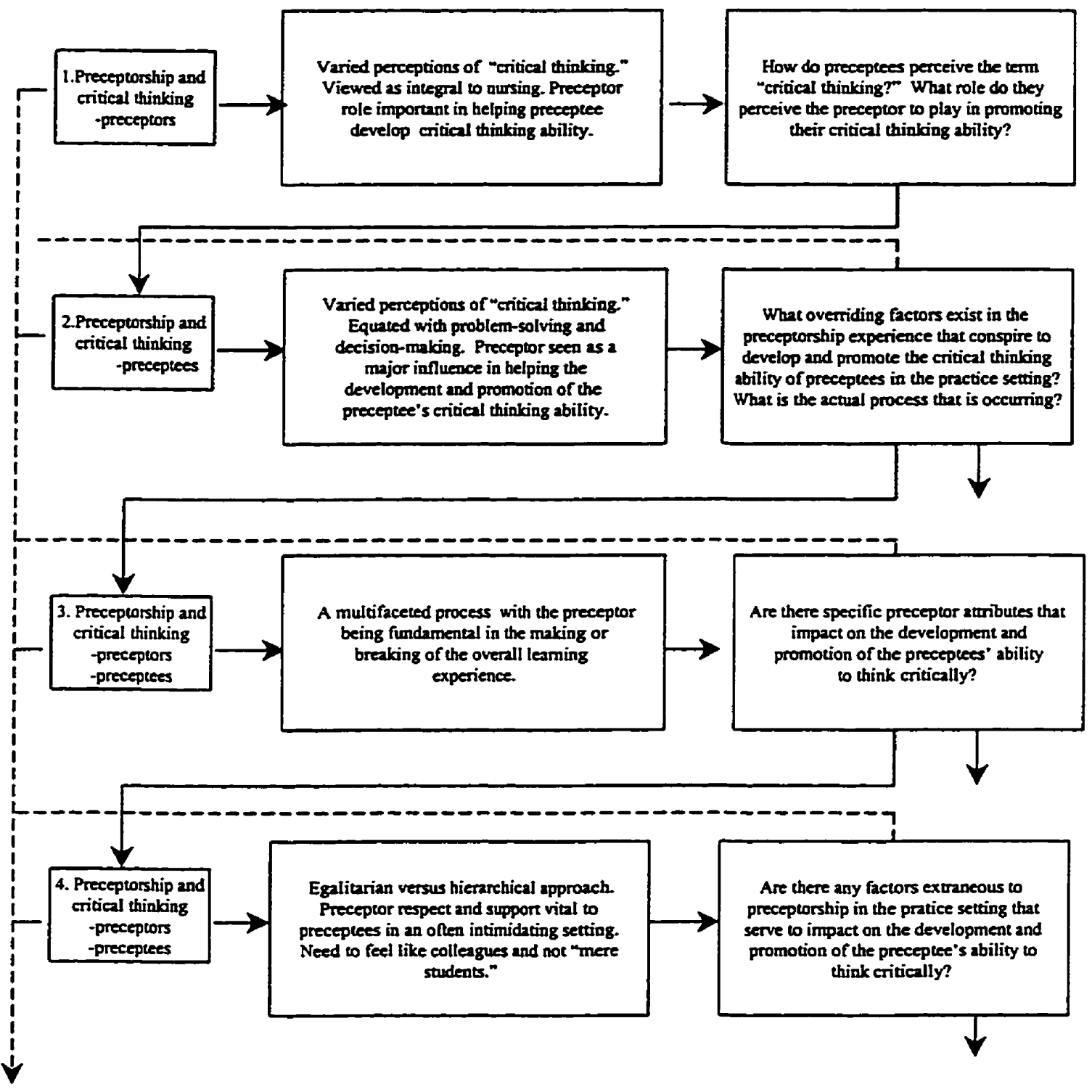




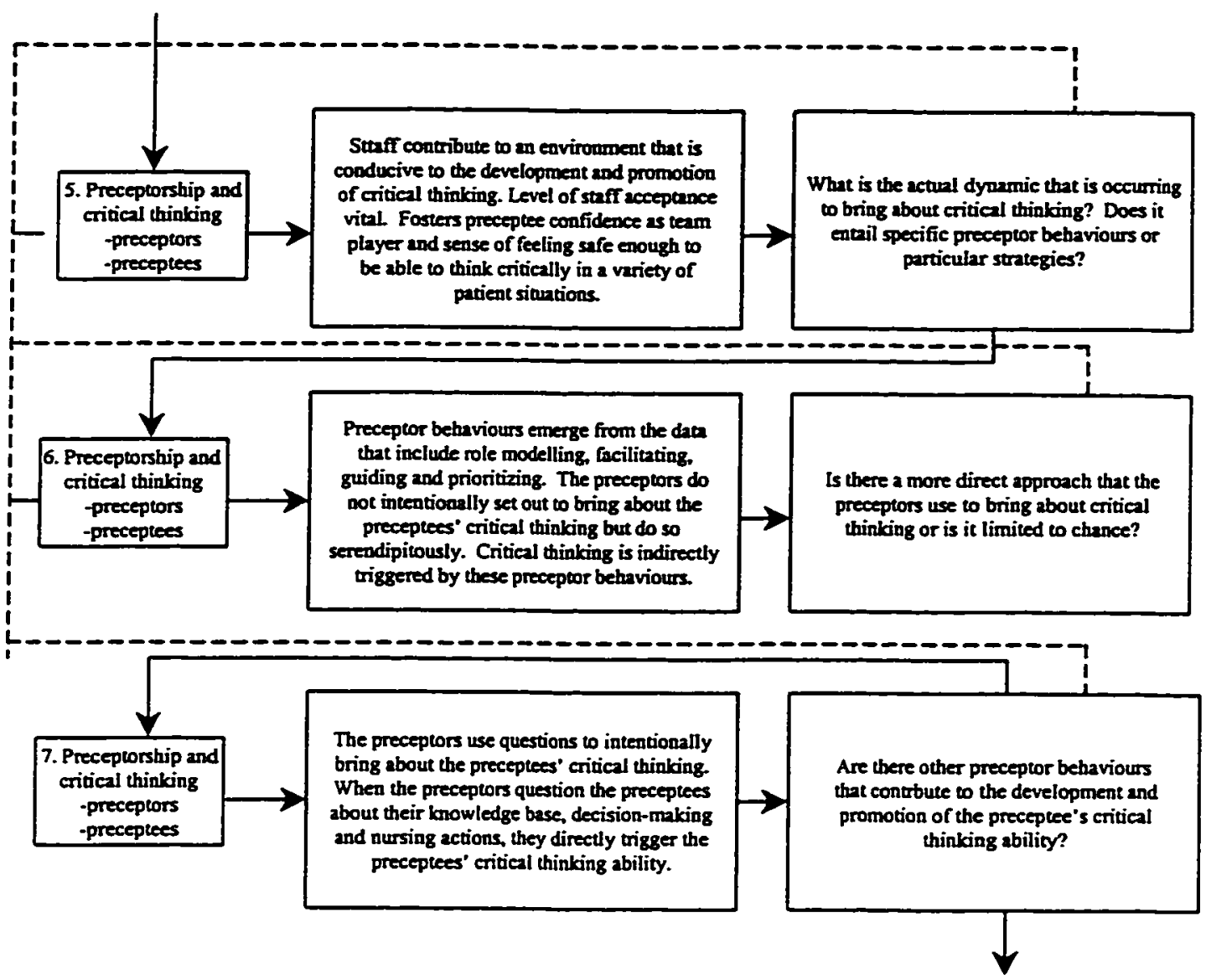

This schematic representation illustrates the pattern of questions as they emerge from the identification of emerging concepts and their interrelationships. New sources of data are discovered that are subsequently compared and contrasted (indieated by solid arrow) and the researcher is thus directed to previous collected data for further sources of comparison (indicated by broken arrow). 
